\title{
ESSAYS IN APPLIED MICROECONOMICS
}

\author{
by \\ VU NGUYEN DOAN
}

\begin{abstract}
A thesis
submitted to the Victoria University of Wellington in fulfilment of the requirements for the degree of Doctor of Philosophy in Economics.
\end{abstract}

Victoria University of Wellington 


\begin{abstract}
This dissertation explores topics in the field of applied microeconomics: labour supply, education, and health. The unifying theme across all three papers is the application of a modern econometric quasi-experimental methodological lens to rich datasets in order to estimate causal effects.

In the second chapter, I employ the twin birth instrument and census data to estimate the causal effects of fertility on female labour supply in more than 30 countries. I match the estimated motherhood employment penalties with gender wage gaps in each country and document a negative relationship between the motherhood employment penalty and gender wage gap, indicating that the effects of childbirth on employment are more negative in countries with larger gender wage gaps. The association is especially strong in within-country analysis and remains nearly the same when controlling for macroeconomic factors related to the labour market.

In the third chapter, I apply fixed effects models to a rich panel dataset of U.S. high schools merged with schools' annual varsity team football win-loss records. Motivated by a recent literature documenting negative effects of sports success on the wider student body, I leverage the within-school variation in team success to estimate the causal effects of football team's success on a variety of outcomes including measures of university aspirations, academic performance, and anti-social behaviour. I find that greater athletic success increases SAT/ACT test participation and AP course enrolment, implying positive effects on university aspirations. However, there are no effects of a team's success on actual academic performance or antisocial behaviour. The findings are particularly important given previous work that has documented negative impacts of sports on college campuses.
\end{abstract}


In the final chapter, I use synthetic control methods with macroeconomic and remotesensing nightlight data to estimate the causal effects of the 2003 SARS outbreak on China's provincial economies. I apply the algorithm to create a synthetic control for each of the most affected Chinese regions: Beijing, Guangdong, Hebei, and Shanxi. By comparing outcomes in a treated unit with its synthetic control, I find a long-term negative impact on night-time lights per capita in the affected Chinese region, Beijing. This suggests identifiable adverse impacts on economic activity from pandemic outbreaks prior to COVID-19. 
To my father and mother, who always picked me up on time.

To my wife for always understanding and standing by my side.

To my little sister. And to my sons, Cypress Doan and Maple Doan. 


\section{ACKNOWLEDGMENTS}

I would like to express my gratitude to Luke Chu and Harold Cuffe, who have guided and helped me in conducting research from the beginning of my $\mathrm{PhD}$ career. I would also like to thank Ilan Noy for his guidance throughout the second year of my graduate career and supporting me through Chair in Economics of Disasters Scholarship. 


\section{TABLE OF CONTENTS}

Page

CHAPTER 1. INTRODUCTION $\ldots \ldots \ldots \ldots \ldots \ldots \ldots$

CHAPTER 2. MOTHERHOOD EMPLOYMENT PENALTY AND GENDER WAGE GAP ACROSS COUNTRIES: $1990-2010 \ldots \ldots \ldots$. . . . . . . . . . . . . . 4

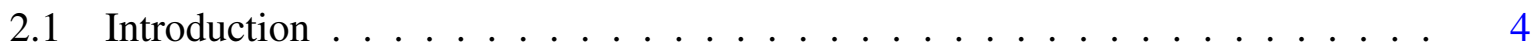

2.2 Data . . . . . . . . . . . . . . . . . 8

2.3 Model . . . . . . . . . . . . . . . . . . . . . . . . . 13

2.4 Results and Discussion . . . . . . . . . . . . . . . . . . . . . 17

2.4.1 The Association Between the Motherhood Employment Penalty and Gender Wage Gap . . . . . . . . . . . . . . . . . . . . . . . . 17

2.4 .2 Is there Sample Selection Issue? . . . . . . . . . . . . . . . . . 22

2.4.3 How much of the Relationship between the Motherhood Employment Penalty and Gender Wage Gap is Attributed to Macroeconomic Heterogeneity? . . . . . . . . . . . . . . . . . . . 24

2.4 .4 Robustness Checks . . . . . . . . . . . . . . . . . . . . 32

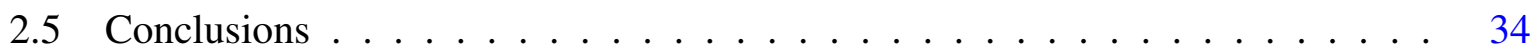

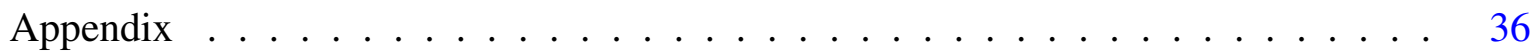

CHAPTER 3. ARE STUDENTS' GOALS, GRADES AND FIGHTS INFLUENCED BY FRIDAY NIGHT LIGHTS $? \ldots \ldots \ldots$. . . . . . . . . . . . . . . 51

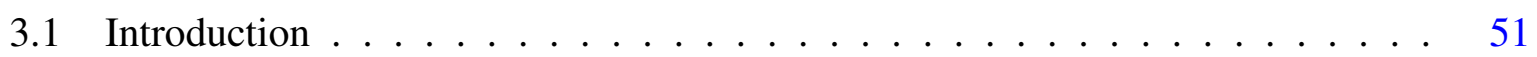

3.2 Related Literature . . . . . . . . . . . . . . . . . . . . . . . . 56

3.3 Data . . . . . . . . . . . . . . . . . . 58

3.4 Identification Strategy . . . . . . . . . . . . . . . . . . . . . . . 64

3.5 Results and Discussion . . . . . . . . . . . . . . . . . . 66

3.5.1 Effects of Athletic Success on University Aspiration, Academic Performance, and Antisocial Behaviour . . . . . . . . . . . . . 66

3.5.2 Are Effects of Success Driven by Athletes or Non-athletes? . . . . . . 69

3.5.3 Effects of Athletic Success on Boys Relative to Girls . . . . . . . . 72

3.5 .4 Robustness Checks . . . . . . . . . . . . . . . . . . . . . 74

3.5.5 Heterogenous Effects of Athletic Success . . . . . . . . . . . . . 79

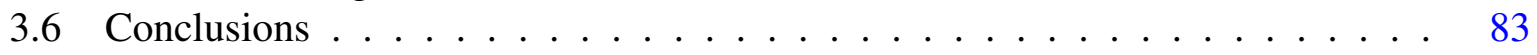

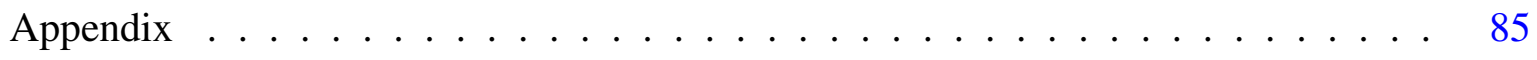


CHAPTER 4. THE ECONOMIC IMPACTS OF A PANDEMIC OUTBREAK. WHAT HAPPENED AFTER SARS IN $2003 ? \ldots \ldots$. . . . . . . . . . . . . . 98



4.2 Background on Economic Impacts of 2003 SARS . . . . . . . . . . . . . 101

4.3 Data and Methodology . . . . . . . . . . . . . . . . . . . 103

$4.3 .1 \quad$ Data . . . . . . . . . . . . . . . . . . . . . 103

4.3.2 Methodology . . . . . . . . . . . . . . . . . . . . . . 104

4.4 Results and Discussion . . . . . . . . . . . . . . . . . . . . . . . 105

4.5 Conclusions . . . . . . . . . . . . . . . . . . . . . . 110

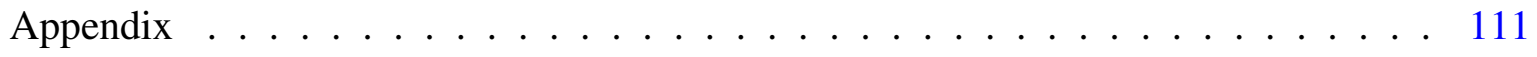

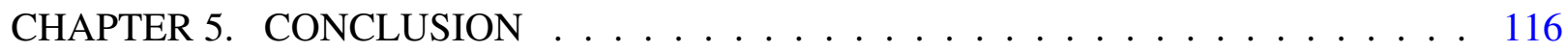

BIBLIOGRAPHY . . . . . . . . . . . . . . . . . . . . . . . . . . . . . 119 


\section{LIST OF FIGURES}

Page

Figure 2.1 Cross- and Within-Country Associations Between Second Twin Birth and Female Employment Rate . . . . . . . . . . . . . . . . . 15

Figure 2.2 Distributions of the Motherhood Employment Penalty Estimates . . . . . 18

Figure 2.3 Cross- and Within-Country Associations Between Gender Wage Gap and 2SLS Estimates of Motherhood Employment Penalty . . . . . . . . . 20

Figure 2.4 Cross- and Within-Country Associations Between Gender Wage Gap and OLS Estimates of Motherhood Employment Penalty . . . . . . . . . . . 21

Figure 2.5 Within-Country Changes in Motherhood and Gender Wage Gap . . . . . 23

Figure 2.6 Within-Country Changes in Mothers' Characteristics and Gender Wage Gap . . . . . . . . . . . . . . . . . . . .

Figure 2.7 Cross- and Within-Country Associations Between Gender Wage Gap and Motherhood Employment Penalty After Partialling Out Gender Education Gap . . . . . . . . . . . . . . . . . .

Figure 2.8 Cross- and Within-Country Associations Between Gender Wage Gap and Motherhood Employment Penalty After Partialling Out Log GDP Per

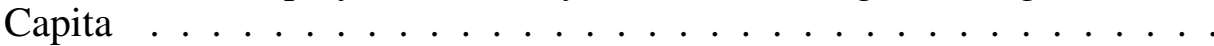

Figure 2.9 Cross- and Within-Country Associations Between Gender Wage Gap and Motherhood Employment Penalty After Partialling Out Gini Coefficient

Figure 2.10 Cross- and Within-Country Associations Between Gender Wage Gap and Motherhood Employment Penalty After Partialling Out GDP Per Capita, Gender Education Gap, and Gini Coeffficent . . . . . . . . . . . . .

Figure 2.11 Cross- and Within-Country Associations Between Gender Wage Gap and 2SLS Estimates of Percentage Motherhood Employment Penalty . . . .

Figure 2.12 Cross- and Within-Country Associations Between Gender Wage Gap and 2SLS Estimates of Percentage Motherhood Employment Penalty After Partialling Out GDP Per Capita, Gender Education Gap, and Gini Coeff-

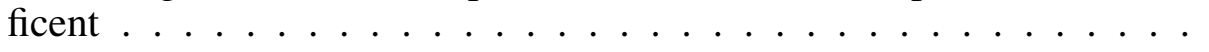


Figure A2.1 Sources of Gender Wage Gaps . . . . . . . . . . . . . . . . 36

Figure A2.2 Studies Estimating the Motherhood Employment Penalty by Twin Birth IV 37

Figure A2.3 Cross- and Within-Country Associations Between Second Twin Birth and Female Employment Rate for All 1990s-2010s Samples in IPUMS-I . . . . . . . . . . . . . . . . . . . . 38

Figure A2.4 First-stage Estimates by the Twin Birth and Sibling Sex IVs . . . . . . . 39

Figure A2.5 Distribution of Motherhood Employment Penalty Estimates for All 1990s-2010s Samples in IPUMS-I . . . . . . . . . . . . . . . . . 40

Figure A2.6 Cross-country Association Between Gender Employment ratio and Gender Tertiary Education Enrolment Ratio . . . . . . . . . . . . . . . . 41

Figure A2.7 Cross-country Association Between Motherhood Employment Penalty and Maternity Paid Leave . . . . . . . . . . . . . . . . . .

Figure 3.1 The Distribution of Football Team's Winning Percentage after Partialling School-level Fixed-Effects . . . . . . . . . . . . . . . . . . 65

Figure 3.2 The Association Between Effect and School Size . . . . . . . . . . 70

Figure 3.3 Effects of Athletic Success on the SAT/ACT Taking and AP Enrolment Rates of Male Students by State . . . . . . . . . . . . . . . . 71

Figure A3.1 The Timeline of 2015-16 CRDC and Football Season . . . . . . . . 85

Figure A3.2 The Distribution of Football Team's Winning Percentage . . . . . . . . 86

Figure A3.3 The Distribution of Male Enrolments . . . . . . . . . . . . . 86

Figure A3.4 Effects of Athletic Success on Male SAT/ACT Taking and AP Enrolment by Winning Percentile . . . . . . . . . . . . . . 87

Figure 4.1 Synthetic Analysis for Annual NTL Per Capita:

Beijing, Guangdong, Hebei, Shanxi . . . . . . . . . . . . . . . . 107

Figure 4.2 Placebo Tests of Synthetic Analysis for Annual NTL Per Capita:

Beijing, Guangdong, Hebei, Shanxi . . . . . . . . . . . . . . . 108

Figure A4.1 Synthetic Analysis for Annual GDP Per Capita:

Beijing, Guangdong, Hebei, Shanxi . . . . . . . . . . . . . . . 111

Figure A4.2 Placebo Tests of Synthetic Analysis for Annual GDP Per Capita:

Beijing, Guangdong, Hebei, Shanxi . . . . . . . . . . . . . . . . . 112

Figure A4.3 The Distribution of the 2003 SARS cases in China . . . . . . . . . . . 113 


\section{LIST OF TABLES}

Page

Table $2.1 \quad$ List of Samples $\ldots \ldots \ldots \ldots$

Table $2.2 \quad$ Summary Statistics $\ldots \ldots \ldots \ldots$

Table 2.3 The Association Between Motherhood Employment Penalty and Gender Wage Gap, Log GDP Per Capita, Gender Education Gap, Gini Coefficient 31

Table A2.1 Empirical Strategy to Identify the Motherhood Employment Penalty . . 43

Table A2.2 Motherhood Employment Penalty Estimates for All 1990s-2010s Samples in IPUMS-I . . . . . . . . . . . . . . . . . . . 45

Table $3.1 \quad$ Summary Statistics $\ldots \ldots \ldots$. . . . . . . . . . . 63

Table 3.2 Effects of Athletic Success on University Aspirations and Academic Performances . . . . . . . . . . . . . . . . . 67

Table 3.3 Effects of Athletic Success on Antisocial Behaviours . . . . . . . . . 68

Table 3.4 Relative Effects of Athletic Success on University Aspirations and Academic Performances . . . . . . . . . . . . . . . . . . 73

Table $3.5 \quad$ Relative Effects of Athletic Success on Antisocial Behaviours . . . . . 73

Table 3.6 Relative Effects of Athletic Success on University Aspirations, Academic Performances and Antisocial Behaviours: Lead-Lag Estimates . . . . . . 75

Table 3.7 Relative Effects of Athletic Success on University Aspirations, Academic Performances and Antisocial Behaviours: by Winning Percentile . . . 78

Table 3.8 Relative Effects of Athletic Success on University Aspirations, Academic Performances and Antisocial Behaviours: by SES . . . . . . . . 80

Table 3.9 Relative Effects of Athletic Success on University Aspirations, Academic Performances and Antisocial Behaviours: by Race . . . . . . . . . . 82

Table A3.1 Variable Definition . . . . . . . . . . . . . . . 88

Table A3.2 Summary Statistics by Race and Socioeconomic Status _ . . . . . . 90 
Table A3.3 The Association Between Team' Winning and School Characteristics . . 91

Table A3.4 Effects of Athletic Success on University Aspirations, Academic Performances and Antisocial Behaviours:

Lead-lag Estimates . . . . . . . . . . . . . . . . . . . 92

Table A3.5 Effects of Athletic Success on University Aspirations, Academic Performances and Antisocial Behaviours:

by Winning Percentile . . . . . . . . . . . . . . . . . . 93

Table A3.6 Effects of Athletic Success on University Aspirations, Academic Performances and Antisocial Behaviours:

by SES . . . . . . . . . . . . . . . . . . . . 94

Table A3.7 Effects of Athletic Success on University Aspirations, Academic Performances and Antisocial Behaviours:

by Race . . . . . . . . . . . . . . . . . . . . . . . . . . . . 95

Table A3.8 Multiple Hypotheses Testing for University Aspirations, Academic Performances and Antisocial Behaviours . . . . . . . . . . . . 96

Table A3.9 The Importance of Selection on Unobservables . . . . . . . . . . . . 97

Table $4.1 \quad$ List of the Treated and Control Provinces of China . . . . . . . . . . . 104

Table 4.2 Synthetic Control Estimates for the Effects of SARS on Normalized Annual NTL per capita: Beijing, Guangdong, Hebei, Shanxi . . . . . . . . 109

Table A4.2 Synthetic Control Estimates for the Effects of SARS on Log Annual GDP per capita: Beijing, Guangdong, Hebei, Shanxi . . . . . . . . . . . . . . 114

Table A4.4 Predictors of Synthetic Analysis for Beijing, Guangdong, Hebei, Shanxi 115 


\section{CHAPTER 1. INTRODUCTION}

This dissertation explores topics in the field of applied microeconomics: labour supply, education, and health. The unifying theme across all three papers is the application of a modern econometric quasi-experimental methodological lens to rich datasets in order to estimate causal effects. The current chapter gives a brief introduction to all three.

The second chapter considers the hypothesis that gender disparities in labour market pay underly the magnitude of the employment effects of childbirth. I am the primary author of this study, which is co-authored with my supervisors, Dr. Luke Chu and Dr. Harold Cuffe. First, we employ twin birth as an instrument to estimate the causal effects of fertility on female employment using 72 censuses from 37 countries in 1990-2010. Then, among potential mechanisms that underlie motherhood employment penalty across countries and time, we posit that where the returns to formal labour market work are low for women, relative to men, the negative impact of childbearing on women's labour supply will be large (emphasizing the substitution effect on the extensive margin in the standard neoclassical labour supply model). We employ the gender wage gap to explain the heterogeneity in the motherhood employment penalty. We document a strong linear association between the gender wage gap and the estimated motherhood employment penalty both across countries and within countries, over time. Reductions in the gender wage gap are associated with decreases in motherhood employment penalty. Our estimates for cross-country analysis suggest that a reduction of one percentage-point in the gender wage gap is associated with a decrease of 0.40 percentage-points in the estimated motherhood employ-

ment penalty. The within-country relationship is particularly strong, and a one-percentage-point reduction in the gender wage gap is associated with a 0.46 -percentage-point decline in the estimated motherhood employment penalty. These associations remain nearly the same when 
partialling out other macroeconomic factors related to the labour market. Our finding supports the notion that women's job prospects in the labour market play a direct role in a mother's labour supply response to childbirth.

The third chapter turns the quasi-experimental toolkit to bear on the effects of athletic success on a variety of secondary school outcomes, including students' university aspirations, academic performance, and antisocial behaviour. Motivated by the literature presenting adverse effects of greater athletic success on college campuses, I expand what is known by examining the effects in high schools. I leverage within-school variation to estimate the effects of football team performance using a panel of U.S. public high schools in the 2009-2017 academic years. In contrast with the consequences on college campuses, I find no negative effects of athletic success on the academic performance and antisocial behaviour of high school students. Moreover, I find that greater athletic success increases university aspirations of high school students. The estimates show that a one-standard-deviation increase in a team's winning percentage increases SAT/ACT test taking and AP course enrolment by 0.18 and 0.14 percentage-points respectively, consistent with a positive effect on university aspiration. Ancillary analysis shows a specific negative association between the magnitude of effects and school size which would arise when the effects of success are mainly driven by athletes. Moreover, the effects of athletic success are not likely biased because of endogeneity from measurement errors or confounding trends.

The final chapter quantifies the economic impacts of SARS on the most affected Chinese regions (Beijing, Guangdong, Hebei, Shanxi). I am the primary author of this study, which is co-authored with my supervisor, Dr. Ilan Noy. Motivated by the COVID-19 crisis, we revisit the economic impacts of SARS 2003 due to the similarities between the two coronaviruses themselves in order to gain suggestive evidence on the long-term consequences of a pandemic outbreak. In this study, focusing particularly on China, we use the synthetic control method with macroeconomic and remote-sensing night-light data. We detect a persistent decrease in per-capita night-time lights of 20 percent in Beijing, one of the most affected Chinese regions. 
This downturn appears to be robust to placebo tests. Overall, the finding suggests that the benign picture that emerges from the $\mathrm{V}$-shaped recovery of economies must be taken with additional nuance, because while national economies have indeed bounced back quickly, local economies have taken longer to recover. 


\section{CHAPTER 2. MOTHERHOOD EMPLOYMENT PENALTY AND GENDER WAGE GAP ACROSS COUNTRIES: 1990-2010}

\subsection{Introduction}

Around the world, women provide direct childcare in disproportionate amounts relative to men. Despite substantial progress in gender equality, motherhood is still strongly associated with negative labour market outcomes (Goldin, 2014; Goldin and Mitchell, 2017). The so-called motherhood penalty remains ubiquitous. Women with young children are less likely to work, they work fewer hour and earn a lower wage than their male counterparts (Anderson et al., 2003; Blau and Kahn, 2013, 2017; Blundell and MaCurdy, 1999; Cools et al., 2017; Gangl and Ziefle, 2009; Grimshaw and Rubery, 2015; Kleven and Landais, 2017; Kleven et al., 2019; Marianne, 2011; Morrissey, 2017; Olivetti and Petrongolo, 2016). In contrast, the presence of children has little effect or even slightly positive effects on men's labour supply and earnings (Addati et al., 2018; Angrist and Evans, 1998; Grimshaw and Rubery, 2015; Kleven et al., 2019).

Among different dimensions of the motherhood penalty, the employment penalty is perhaps the most important since labour supply responses, especially along the extensive margin, can explain a large part of the diminished labour market outcomes of mothers. The economics literature has provided strong evidence that the negative association between childbirth and labour supply is largely causal. The seminal work by Bronars and Grogger (1994) and Angrist and Evans (1998) utilizes twin birth and sibling sex as instrumental variables (IVs) for the number of children. These two well-known IVs have been applied to data all over the world 
to estimate the motherhood employment penalty (Ajefu, 2019; Cools et al., 2017; Cruces and Galiani, 2007; Fontaine, 2017; Guo et al., 2018; He and Zhu, 2016; Jacobsen et al., 1999; Vere, 2011; Zhang, 2017). These papers find substantial cross-country differences in the motherhood employment penalty. However, very few studies aim to formally examine the factors that underly the employment effects of childbirth across countries and time.

In this paper, we document cross- and within-country relationships between the motherhood employment penalty and gender wage gap. Since both the motherhood penalty and gender wage gap express different dimensions of gender equality, the results are correlational. Nevertheless, gender wage gaps reflect not only gender inequality but also the actual labour market prospects for women and the returns to specialization within families. Gender wage gaps influence the opportunity cost of not working and likely play a direct role in determining the size of the motherhood employment penalty. To investigate the motherhood penalty across countries, first, we estimate the effect of having an additional child on a mother's labour force participation in each country using harmonized international censuses from the Integrated Public Use Microdata Series, International (IPUMS-I). To find plausibly exogenous variations available across all the countries, we utilize the second twin birth as an IV for having an additional child. We focus on the period of 1990-2010 and separately estimate the motherhood employment penalty in each available census from the IPUMS-I. Second, we collect information on the (unconditional) gender wage gap from several sources. (See Appendix Figure A2.1.) We have gender wage gap data in the period of 1990-2010 from 72 censuses of 37 countries. Finally, we plot estimates for the employment penalty against gender wage gaps across countries and time. Since we have more than one census in 27 of the 37 countries, we also plot within-country differences in employment penalties against within-country differences in gender wage gaps in these countries.

We find a strong cross-country correlation indicating that the effects of childbirth on employment are more negative in countries with larger gender wage gaps. Since a larger gender wage gap implies higher gender inequality and lower returns from participating in the labour 
market (relative to men), it is intuitive that the motherhood employment penalty is greater in these countries. On average, a one-percentage-point reduction of the gender wage gap corresponds with a 0.40 -percentage-point decrease in the estimated motherhood employment penalty. Importantly, the association is not driven by country heterogeneity. The pattern becomes stronger when we restrict attention to within-country changes in gender wage gaps and fertility effects. The estimated motherhood penalty decreases by 0.46 percentage-points when the gender wage gap shrinks by one percentage point. We show that gender differences in human capital accumulation do not appear to explain the relationship between wage gaps and work that we document. Our results also stay largely unchanged after we partial out two macroeconomic variables associated with the labour market: per-capita GDP and the Gini coefficient. While we cannot claim causality due to the nature of our exercise, our findings are consistent with the notion that improvements in the labour market position of women (relative to men) raise the opportunity cost of labour force inactivity for mothers, thereby reducing the apparent child penalty on employment.

Our paper contributes to the literature that utilizes plausible randomness in twin birth and sibling sex as IVs to estimate motherhood employment penalty. One advantage of twin birth and sibling sex is that the required information can be obtained in many household level datasets, including census data that are available in most countries. The motherhood employment penalty has been estimated by the two IVs in numerous countries, including the U.S. (Angrist and Evans, 1998; Bronars and Grogger, 1994; Jacobsen et al., 1999; Vere, 2011), Argentina and Mexico (Cruces and Galiani, 2007), China (Guo et al., 2018; He and Zhu, 2016), Nigeria (Ajefu, 2019), Taiwan (Zhang, 2017), and several European countries (Cools et al., 2017; Fontaine, 2017). ${ }^{1}$ Although there is a large amount of international research, very few studies in this literature investigate cross-country differences in the motherhood penalty on employment. Aaronson et al. (2017) pool censuses in IPUMS-I by per-capita gross domestic product (GDP)

\footnotetext{
${ }^{1}$ Appendix Figure A2.2 summarizes the point estimates and the 95 percent confidence intervals of selected studies identifying the motherhood employment penalty using the twin birth IV.
} 
and find that the motherhood employment penalty appears to increase with GDP. BaranowskaRataj and Matysiak (2016) pool a number of European countries by region and find that the motherhood employment penalty in European countries is greater in places with little public support for working parents such as Anglo-Saxon and southern European countries. CáceresDelpiano (2012) pools data from 40 developing countries and shows the size of the employment penalty can depend on birth order and types of jobs. ${ }^{2}$ Like these above cross-county studies, our paper cannot claim causality. However, we do not pool data across countries and therefore are able to investigate both cross-country and within-country variation in the gender wage gap and the motherhood penalty on employment. ${ }^{3}$

Our paper is also related to the broader literature on the impacts of childbirth on female labour supply. In addition to the literature cited above, another strand of literature employs arguably exogenous variation in fertility as a research design. Cristia (2008) and Lundborg et al. (2017) use access to fertility service as an IV for childbirth that can identify the causal effect of the first child on labour participation. Similarly, Agüero and Marks (2011) use infertility shocks as an IV for family size. Exogenous variation generated by legal changes related to fertility are also employed to investigate the effects of fertility on labour market outcomes. These examples include access to birth control pills (Bailey, 2006; Bentancor and Clarke, 2017; Edlund and Machado, 2015), legalization of abortion (Bloom et al., 2009; Oreffice, 2007), and family planning policies (Schultz, 2009; Wang, 2014). Relatedly, policy reforms to child benefit receipt (González, 2013; Sandner, 2019) and paid paternity leave (Ginja et al., 2020) are used as natural experiments as well. Lastly, some studies address the endogeneity problem relying on traditional techniques such as event-study design (Kleven et al., 2019; Lundberg and Rose, 2000) and simultaneous equation models (Chevalier and Viitanen, 2003). (In Appendix Table A2.1,

\footnotetext{
${ }^{2}$ Cáceres-Delpiano (2012) and Baranowska-Rataj and Matysiak (2016) document that having an additional child relates to a 2-percentage-point and 10-percentage-point motherhood employment penalty in developing countries and in European countries respectively.

${ }^{3}$ Bisbee et al. (2017) and Dehejia et al. (2019) estimate the motherhood employment penalty using individual censuses from the IPUMS-I. These papers focus on the external validity of IV and do not investigate factors which determine cross-country differences in the motherhood penalty.
} 
we summarize locations, time periods, data types, and labour market outcomes of studies in this literature.)

The paper proceeds as follows: Section 2.2 describes the IPUMS-I data, and Section 2.3 discusses the IVs and the estimation models. Section 2.4 presents the results showing the association between the motherhood employment penalty and gender wage gap and provides discussion drawing on empirical findings. Section 2.5 summarizes our conclusions.

\subsection{Data}

We aim to explain variation in the motherhood employment penalty across countries with differences in gender wage gaps. To estimate the motherhood employment penalty, we use data from the IPUMS-I where the source data are provided by the statistical offices of each country. In total, IPUMS-I harmonizes 319 censuses and surveys in 89 countries between 1960 through the 2010s. ${ }^{4}$ To focus on a relatively recent period in which data on gender wage gaps are widely available, we use only censuses and surveys from 1989 to 2012 and exclude 127 datasets outside this period. ${ }^{5}$ To implement the twin-birth IV, we must further discard 31 censuses and surveys where: a) persons are not organized into households, so we cannot match mothers with their children (11 datasets $)^{6}$; b) ages are coded in categories, so we cannot identify birth orders and twin births $(11 \text { datasets })^{7}$; c) the first-stage F-statistics using the twin-birth IV are lower than 10 , implying that the twin birth is a weak instrument $\left.(8 \text { datasets })^{8} ; \mathrm{d}\right)$ the information regarding

\footnotetext{
${ }^{4}$ The IPUMS-I also includes 46 historical datasets before 1960: The U.S. 1850-1910; Canada 1852-1911; UK 1851-1911; Germany 1819; Norway 1801-1910; Sweden 1880-1910; Iceland 1703-1910; and Denmark 1787-1801.

${ }^{5}$ We keep at most one census or survey per decade for each country and exclude these additional datasets in the middle of a decade: France 2006, India 1999, Indonesia 1995 and 2005, Mexico 1995 and 2005, Philippines 1995, South Africa 2007, United States 2005.

${ }^{6}$ Persons are not organized into households: Argentina 2010, Austria 2011, Canada 1971, 1981, 1991, and 2001, Netherlands 2001 and 2011, Poland 2011, Trinidad and Tobago 1990, and Ukraine 2001.

${ }^{7}$ Ages are coded in categories: Ireland 1991, 1996, 2002, and 2006, Israel 1995, Italy 2001 and 2011, Palestine 1997 and 2007, Slovenia 2002, United Kingdom 2001.

${ }^{8}$ Twin birth may be a weak instrument: Nigeria 2007, 2008, and 2009, Puerto Rico 2005 and 2010, Rwanda 1991, Saint Lucia 1991, and Zambia 1990.
} 
employment status is not available (1 dataset $)^{9}$. Consequently, we have 161 censuses and surveys in IPUMS-I in the period of 1989-2012 that we can use to estimate the motherhood penalty on employment via the twin-birth IV.

Nearly all of the datasets in the IPUMS-I do not provide information on earnings or wage rates. Therefore, we collect data on gender wage gaps from several sources including: the International Labour Organization, the Organization for Economic Co-operation and Development, United Nations Economic Commission for Europe, and International Trade Union Confederation. (In the Appendix, Figure A2.1 shows the data sources.) Unfortunately, international data on gender wage gaps are often limited, especially in developing countries. The available information only allows us to match the gender wage gaps to 72 censuses in 37 countries. (We exclude the largest gender wage gap of 54 percent; the outlier is from Armenia 2001. The estimated slopes of the relationship between motherhood employment penalty and gender wage gap is still statistically significant when we include Armenia in the regression.) We match each census to the gender wage gap of the closest year, though they are not necessarily from exactly the same years. Table 2.1 shows the list of country-year censuses used for analysis in this paper. (All datasets in Table 2.1 are censuses except for 2006 Uruguay data which has a sample size of 8 percent population and is comparable to a census.)

\footnotetext{
${ }^{9}$ Employment status information is not available: Pakistan 1998.
} 
Table 2.1: List of Samples

\begin{tabular}{|c|c|c|c|c|c|c|c|}
\hline Country & Year & GWG & Year $_{\text {GWG }}$ & Country & Year & GWG & Year $_{\text {GWG }}$ \\
\hline Argentina & 1991 & $8 \%$ & 1992 & Ireland & 2011 & $10 \%$ & 2011 \\
\hline Argentina & 2001 & $12 \%$ & 2002 & Jamaica & 1991 & $28 \%$ & 1990 \\
\hline Armenia & 2011 & $35 \%$ & 2011 & Jamaica & 2001 & $7 \%$ & 2001 \\
\hline Austria & 1991 & $16 \%$ & 1991 & Mexico & 1990 & $21 \%$ & 1990 \\
\hline Austria & 2001 & $23 \%$ & 2001 & Mexico & 2000 & $13 \%$ & 2002 \\
\hline Belarus & 1999 & $19 \%$ & 2000 & Mexico & 2010 & $14 \%$ & 2012 \\
\hline Belarus & 2009 & $25 \%$ & 2009 & Nicaragua & 1995 & $7 \%$ & 1993 \\
\hline Bolivia & 1992 & $21 \%$ & 1992 & Nicaragua & 2005 & $3 \%$ & 2001 \\
\hline Bolivia & 2001 & $20 \%$ & 2001 & Panama & 1990 & $18 \%$ & 1990 \\
\hline Botswana & 1991 & $3 \%$ & 1995 & Panama & 2000 & $4 \%$ & 2000 \\
\hline Botswana & 2001 & $18 \%$ & 2005 & Paraguay & 1992 & $34 \%$ & 1992 \\
\hline Brazil & 1991 & $15 \%$ & 1992 & Paraguay & 2002 & $28 \%$ & 2002 \\
\hline Brazil & 2000 & $17 \%$ & 2001 & Peru & 1993 & $20 \%$ & 1997 \\
\hline Brazil & 2010 & $16 \%$ & 2012 & Peru & 2007 & $22 \%$ & 2011 \\
\hline Canada & 2011 & $19 \%$ & 2011 & Philippines & 2010 & $17 \%$ & 2008 \\
\hline Chile & 1992 & $14 \%$ & 1998 & Poland & 2002 & $11 \%$ & 2002 \\
\hline Chile & 2002 & $2 \%$ & 2003 & Portugal & 2001 & $10 \%$ & 2001 \\
\hline China & 1990 & $11 \%$ & 1992 & Portugal & 2011 & $13 \%$ & 2011 \\
\hline China & 2000 & $9 \%$ & 2002 & Romania & 1992 & $21 \%$ & 1995 \\
\hline Colombia & 2005 & $1 \%$ & 2007 & Romania & 2002 & $16 \%$ & 2002 \\
\hline Costa Rica & 2000 & $9 \%$ & 2001 & Romania & 2011 & $10 \%$ & 2011 \\
\hline Costa Rica & 2011 & $15 \%$ & 2008 & Spain & 2001 & $17 \%$ & 2001 \\
\hline Dominican & 2002 & $5 \%$ & 2005 & Spain & 2011 & $18 \%$ & 2011 \\
\hline Dominican & 2010 & $8 \%$ & 2012 & Swiss & 2000 & $22 \%$ & 2000 \\
\hline Egypt & 1996 & $19 \%$ & 1996 & United States & 1990 & $28 \%$ & 1990 \\
\hline Egypt & 2006 & $12 \%$ & 2006 & United States & 2000 & $23 \%$ & 2000 \\
\hline France & 1990 & $15 \%$ & 1995 & United States & 2010 & $19 \%$ & 2010 \\
\hline France & 1999 & $14 \%$ & 1999 & United Kingdom & 1991 & $31 \%$ & 1991 \\
\hline France & 2011 & $14 \%$ & 2010 & Uruguay & 1996 & $15 \%$ & 1996 \\
\hline Greece & 2001 & $14 \%$ & 2004 & Uruguay & 2006 & $12 \%$ & 2006 \\
\hline Greece & 2011 & $11 \%$ & 2011 & Uruguay & 2011 & $13 \%$ & 2010 \\
\hline Honduras & 2001 & $5 \%$ & 2001 & Venezuela & 1990 & $12 \%$ & 1989 \\
\hline Hungary & 1990 & $22 \%$ & 1990 & Venezuela & 2001 & $2 \%$ & 2001 \\
\hline Hungary & 2001 & $20 \%$ & 2001 & Vietnam & 1989 & $23 \%$ & 1989 \\
\hline Hungary & 2012 & $20 \%$ & 2012 & Vietnam & 1999 & $19 \%$ & 1998 \\
\hline Indonesia & 2010 & $14 \%$ & 2008 & Vietnam & 2009 & $15 \%$ & 2008 \\
\hline
\end{tabular}

Notes: The table includes countries with available gender wage gap data. Gender wage gap (GWG) is the difference between male and female earnings divided by male wages. Year ${ }_{\mathrm{GWG}}$ is the year available of gender wage gap. 
To be consistent across countries, we follow Angrist and Evans (1998) and create samples of mothers aged 21-35 with at least two children under 18 years old in each of the countryyear censuses. We exclude a small number of mothers whose first child is older than 18 and second child is younger than one year old. As in Angrist and Evans (1998), we want to focus on biological children, but information on number of children ever born to a woman is not available in many datasets. To link a birth to its biological mother, we use the direct information that indicates whether or not the mother of a person lives in the same household. This information does not distinguish different social relationships such as stepmother and adopted mother. Thus, to identify biological birth, we also use indirect information including identified non-biological relationships (stepchild, adopted child, child of unmarried partner, or child-in-law), mother or child reported not present in the household, mother having no children born or surviving, mother reported deceased, and the number of children larger than known fertility of mother. Besides, we drop any observations with the age gap between a mother and a child is less than 12 or greater than 54 years old. The information that can identify whether a mother is employed also varies across censuses. We identify a mother as working for pay if there is a record of labour force status (employed/unemployed/not in the labour force), a record of occupation or industry, or a record of worker types such as self-employed and paid/unpaid family workers. (Only paid family workers are counted as employed.) Note that we can only identify employment status but not labour force participation consistently across datasets because information on unemployment is not always available in census data. We are able to construct a number of variables across datasets, including age, age at first birth, sex of the first birth, and educational attainment. Table 2.2 presents sample means and standard deviations averaged across 72 censuses by decade. 
Table 2.2: Summary Statistics

\begin{tabular}{|c|c|c|c|c|}
\hline & All Decades & 1990s & $2000 \mathrm{~s}$ & 2010s \\
\hline \multirow[t]{2}{*}{ Gender wage gap } & 0.16 & 0.18 & 0.13 & 0.16 \\
\hline & $(0.07)$ & $(0.07)$ & $(0.08)$ & $(0.06)$ \\
\hline \multirow{2}{*}{ Employment rate } & 0.48 & 0.48 & 0.47 & 0.50 \\
\hline & $(0.19)$ & $(0.23)$ & $(0.18)$ & $(0.14)$ \\
\hline \multirow[t]{2}{*}{ Second birth is a twin } & 0.01 & 0.01 & 0.01 & 0.01 \\
\hline & $(0.00)$ & $(0.00)$ & $(0.00)$ & $(0.00)$ \\
\hline \multirow[t]{2}{*}{ Have more than two children } & 0.48 & 0.54 & 0.47 & 0.40 \\
\hline & $(0.16)$ & $(0.17)$ & $(0.16)$ & $(0.12)$ \\
\hline \multirow[t]{2}{*}{ First birth is a boy } & 0.51 & 0.51 & 0.51 & 0.51 \\
\hline & $(0.01)$ & $(0.01)$ & $(0.02)$ & $(0.01)$ \\
\hline \multirow[t]{2}{*}{ Age } & 29.16 & 28.89 & 29.06 & 29.73 \\
\hline & $(0.91)$ & $(0.75)$ & $(0.84)$ & $(1.02)$ \\
\hline \multirow[t]{2}{*}{ Age at first birth } & 21.91 & 21.55 & 21.66 & 22.87 \\
\hline & $(1.46)$ & $(1.06)$ & $(1.33)$ & $(1.82)$ \\
\hline \multirow[t]{2}{*}{ Lower primary education } & 0.23 & 0.31 & 0.24 & 0.11 \\
\hline & $(0.21)$ & $(0.23)$ & $(0.20)$ & $(0.10)$ \\
\hline \multirow{2}{*}{ Primary education only } & 0.37 & 0.39 & 0.39 & 0.31 \\
\hline & $(0.19)$ & $(0.19)$ & $(0.18)$ & $(0.21)$ \\
\hline \multirow[t]{2}{*}{ Secondary education only } & 0.35 & 0.30 & 0.36 & 0.42 \\
\hline & $(0.21)$ & $(0.22)$ & $(0.21)$ & $(0.16)$ \\
\hline \multirow[t]{2}{*}{ Tertiary education or above } & 0.09 & 0.05 & 0.07 & 0.18 \\
\hline & $(0.09)$ & $(0.06)$ & $(0.06)$ & $(0.10)$ \\
\hline \multirow[t]{2}{*}{ Gender education gap } & -0.03 & 0.06 & -0.05 & -0.10 \\
\hline & $(0.19)$ & $(0.23)$ & $(0.16)$ & $(0.12)$ \\
\hline \multirow[t]{2}{*}{ Gini Coefficient } & 42.68 & 42.20 & 45.05 & 39.19 \\
\hline & $(10.14)$ & $(11.16)$ & $(10.36)$ & $(7.14)$ \\
\hline \multirow[t]{2}{*}{ Log GDP per capita } & 8.88 & 8.53 & 8.84 & 9.49 \\
\hline & $(1.18)$ & $(1.29)$ & $(1.06)$ & $(1.01)$ \\
\hline Observations & 72 & 25 & 30 & 17 \\
\hline
\end{tabular}

Notes: The standard deviations are in parentheses. The samples consist of women aged 21-35 with at least two children from the 72 censuses shown in Table 2.1. Gender education gap is the difference between male and female secondary education (and above) completion rate divided by male secondary education (and above) completion rate. 


\subsection{Model}

To investigate the relationship between motherhood and employment, we estimate the following linear model by both ordinary least squares (OLS) and two-stage least squares (2SLS):

$$
\text { Work }_{i}=\alpha+\beta . \text { More } 2 \text { Children } i+X_{i} \cdot \Gamma+\varepsilon_{i}
$$

where Work $_{i}$ is an indicator denoting mother $i$ is working; More2Children M $_{i}$ is an indicator that equals one if mother $\mathrm{i}$ has more than two biological children and zero otherwise; $X_{i}$ is a vector of control variables including: mother's age, mother's age at first childbirth, the sex of the first child, and indicators for three education levels: primary, secondary, and university and above (less than primary is the omitted group). Because our sample is restricted to mothers with at least two biological children, $\beta$ represents the causal effect of having more than two children on employment relative to having just two children. We use $\widehat{\beta}$ as our measure of the motherhood employment penalty. The standard errors are made robust to heteroskedasticity.

Since the fertility decision is likely endogenous, to estimate Equation 2.1 by 2SLS, we estimate the following first stage regression where More 2 Children $_{i}$ is instrumented by SecondTwinbirth : $^{2}$

$$
\text { More } 2 \text { Children }_{i}=\delta+\theta . \text { SecondTwinbirth }_{i}+X_{i} \cdot \lambda+\epsilon_{i}
$$

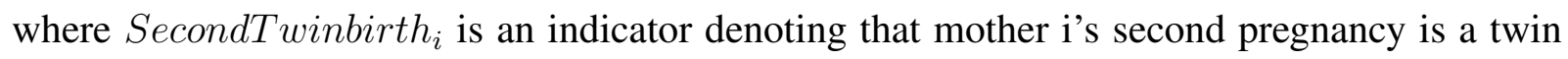
birth. ${ }^{10}$ Angrist and Evans (1998) utilize the birth quarter to more precisely identify twins, but similar information is not available in a majority of the datasets. For consistency, we identify

\footnotetext{
${ }^{10}$ Though using the first twin birth as an instrument is possible, few studies employ this instrument (Bronars and Grogger, 1994; Guo et al., 2018; Jacobsen et al., 1999). The skepticism of using the first twin birth is that women are more likely to have dizygotic twins if they undergo fertility treatments such as intrauterine insemination (IUI) or in vitro fertilization (IVF). However, women are less likely to seek fertility treatments for the second birth.
} 
children born in the same calendar year as twins in all datasets. Therefore, a tiny proportion of the "twins" could possibly be siblings born in the same calendar year. Aaronson et al. (2017) suggest that such potential measurement error has little impact on the estimates of motherhood penalty. ${ }^{11}$ Another concern is that the twin-birth IV may not be necessarily excludable. For example, it appears to be more common for older and wealthier women to have twin births. Bhalotra and Clarke (2019) suggest that having twin births is positively associated with a mother's health and a better prenatal environment. While we do not have information on health conditions of mothers, controlling for age and education can alleviate some potential violations of the excludability of twin birth. More importantly, unless the non-excludability of twin-birth is considerably different across countries or changes over time within a country, it has little impact on our cross- and within-country comparison of motherhood penalty estimates. In Figure 2.1, we show that there is virtually no cross- or within-country correlation between the proportions of mothers with a second twin birth and female employment rates. (Appendix Figure A2.3 shows a similar null relationship for all available samples in the IPUMS-I.)

\footnotetext{
${ }^{11}$ Aaronson et al. (2017) suggest that estimating motherhood penalty by same year twins is credible compared to same month or same quarter-of-birth twins. Also, we believe defining a twin as two children born in the same year makes the sample consistent across countries and help to alleviate measurement errors coming from the data of month or quarter of birth.
} 
Figure 2.1: Cross- and Within-Country Associations Between Second Twin Birth and Female Employment Rate
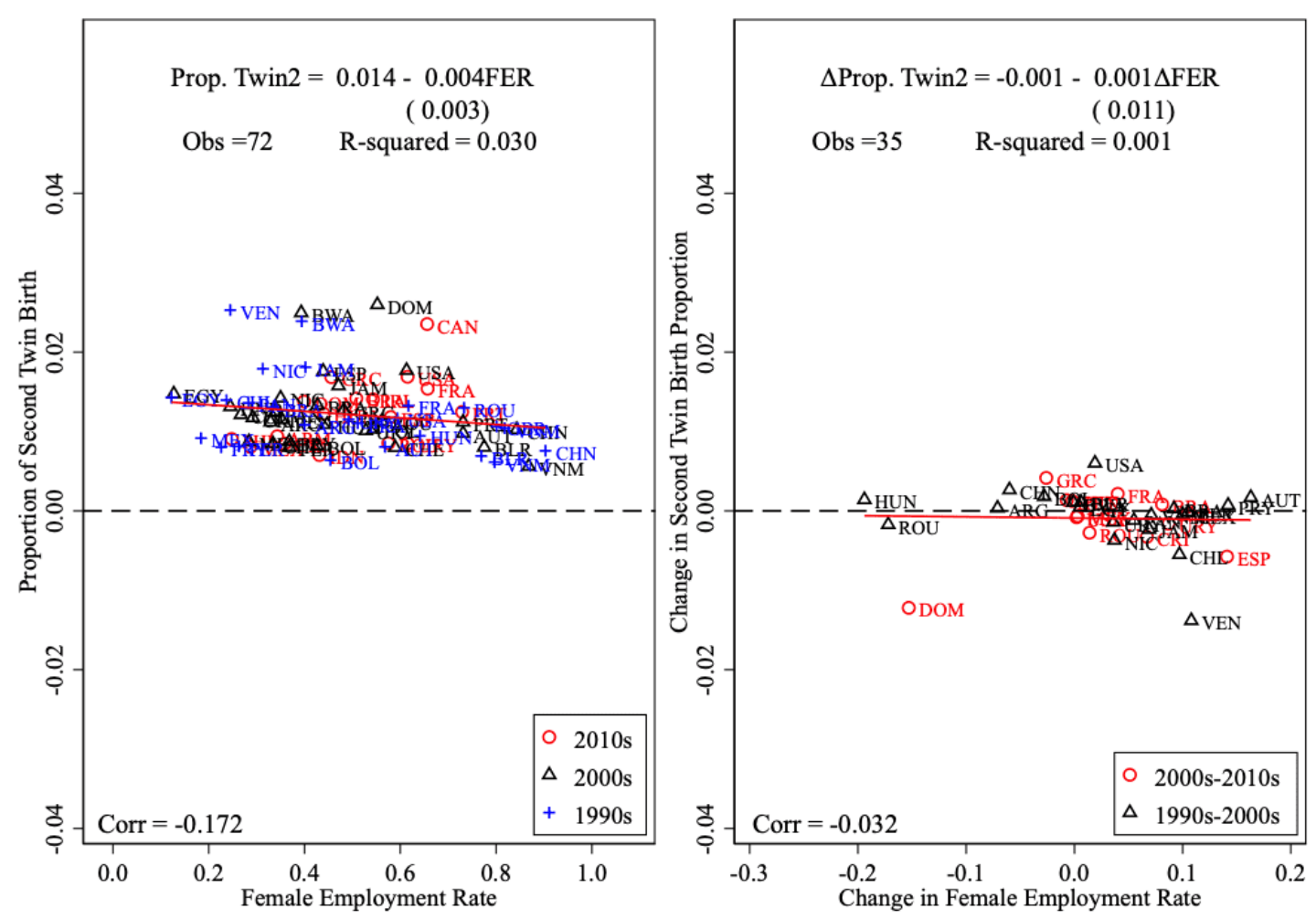

Notes: The standard errors are clustered at the country-level and are in parentheses.

As mentioned in the literature, the sibling sex is the other IV that can be used to explore the variation in the employment effects of childbirth across countries with census data. Angrist and Evans (1998) first employ the sibling sex IV to identify the motherhood employment penalty using the U.S. census of 1980 and 1990. However, the assumption about the mixed sex preference of parents may not be guaranteed for many countries in our sample (e.g. countries where the son preference is still prevalent). Angrist et al. (2010) suggest that the twin birth IV fits the whole population, while the sibling sex IV fits a certain sub-population only. Parents who want to have a third birth in developed countries are probably very different from parents in developing countries (e.g. families having two children may be from the middle class in high-income 
countries, but the high class in low-income countries). Thus, it is less persuasive to explain the variation in motherhood employment penalty across countries by employing the sibling sex IV. ${ }^{12}$

In this paper, gender wage gap $(\mathrm{GWG})$ is defined as the difference between average male earnings and average female earnings over average male earnings in percentage terms:

$$
G W G=\frac{\text { male earnings }- \text { female earnings }}{\text { male earnings }} \times 100
$$

$G W G$ represents an unconditional gender gap and is strictly positive in the data. One potential comparability issue is that the measures for earnings vary by country even for data from the same source. The reported gender wage gaps could be calculated based on annual earnings, monthly earnings, or hourly wage. Fortunately, because the earnings measures are constant within a country, the comparability is less of an issue when we compare within-country changes in gender wage gaps.

To investigate the relationship between the gender wage gap and motherhood employment penalty, we calculate the correlation coefficient between $\widehat{\beta}$ and $G W G$ as well as fitting the data with the following linear regression:

$$
\widehat{\beta}_{j c}=\gamma_{0}+\gamma_{1} \cdot G W G_{j c}+\mu_{j c}
$$

where $\widehat{\beta}_{j c}$ is the OLS or 2SLS estimates of the motherhood employment penalty from Equation 2.1 in country $j$ and decade $c, G W G_{j c}$ is the gender wage gap from country $j$ in decade $c$ defined in Equation 2.3, and $\gamma_{1}$ is the regression slope. To remove country heterogeneity that remains stable over time, we take the first difference of Equation 2.4 and estimate the following regression:

\footnotetext{
${ }^{12}$ The $F$-statistics analysis demonstrates a stronger first stage of the twin birth IV compared to the sibling sex IV. In the appendix, Figure A2.4 shows that the point estimates of the effect of twin birth on childbirth are much greater than the sibling sex.
} 


$$
\Delta \widehat{\beta}_{j c}=\kappa_{0}+\gamma_{1} \cdot \Delta G W G_{j c}+\Delta \mu_{j c}
$$

where $G W G_{j c}$ is the within-country difference in motherhood employment penalty in country $j, \Delta G W G_{j c}$ is the within-country difference in gender wage gap in country $j$, and $\gamma_{1}$ is the regression slope. Since each country $j$ has two or three censuses, the standard errors are clustered at the country level and therefore are robust to serial correlation and heteroskedasticity.

\subsection{Results and Discussion}

\subsubsection{The Association Between the Motherhood Employment Penalty and Gender Wage Gap}

Figure 2.2 plots the distributions of OLS and 2SLS estimates from 72 censuses, of the effects of having more than two children on mothers' employment. The OLS estimates are larger (more negative), on average, than the 2SLS estimates. The sample mean for the 2SLS estimates is -0.04 while the sample mean for the OLS estimates is -0.11 . The OLS estimates appear to be downward biased and overstate the size of the motherhood employment penalty. Note that the 2SLS estimates represent the local average treatment effect (LATE). Therefore, some of the difference in Figure 2.2 might owe to 2SLS and OLS estimating different effects. ${ }^{13}$

\footnotetext{
${ }^{13}$ In the appendix, Table A2.2 and Figure A2.5 show the OLS and 2SLS estimates from all 161 available censuses and surveys. Figure A2.5 exhibits a pattern similar to Figure 2.2 that the OLS estimates are larger in magnitudes than the 2SLS estimates. The sample mean for all 161 2SLS estimates is -0.03 while the sample mean for all 161 OLS estimates is -0.06 .
} 
Figure 2.2: Distributions of the Motherhood Employment Penalty Estimates

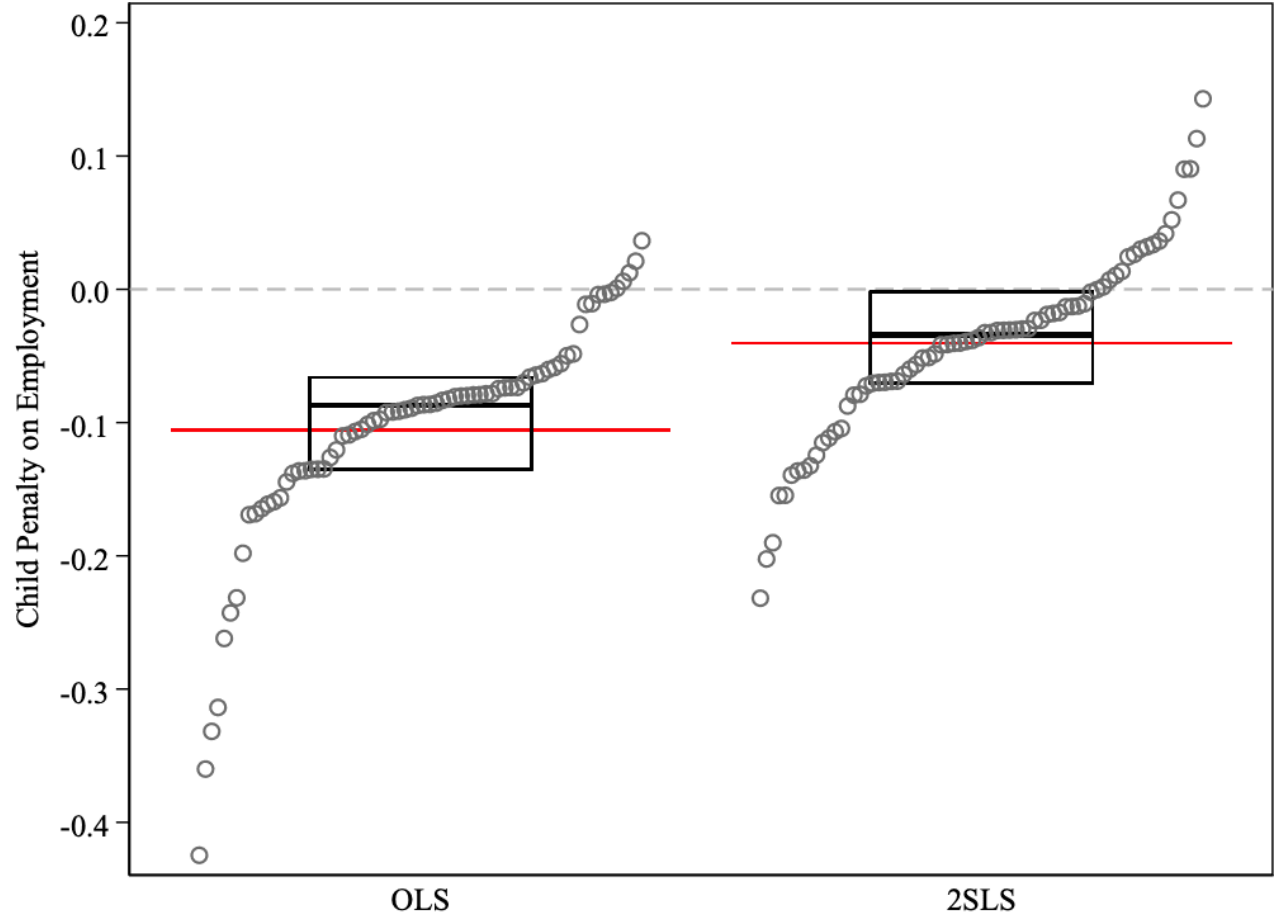

Notes: The red lines indicate the sample means of estimates.

In the left panel of Figure 2.3, we plot the 2SLS estimates of the motherhood employment penalty $\left(\widehat{\beta}_{2 S L S}\right)$ against the gender wage gap $(G W G)$ in each country. There is a strong negative association between the gender wage gap and the motherhood employment penalty. The slope of the fitted regression line is -0.40 and statistically significant at less than the 1 percent level. Therefore, on average, a one-percentage-point reduction of the gender wage gap is associated with a 0.40-percentage-point decrease in the estimated motherhood employment penalty. The correlation coefficient is -0.43 and indicates a strong negative correlation between the motherhood penalty and gender wage gap. Nevertheless, some of the cross-country association between motherhood penalty and gender wage gap could be driven by country heterogeneity. For example, both the motherhood penalty and gender wage gaps tend to be large in countries with strong religious and traditional values. In the right panel of Figure 2.3, we control for time-invariant country heterogeneity by plotting within-country changes in the estimates for motherhood penalty $\left(\Delta \widehat{\beta}_{2 S L S}\right)$ against within-country changes in gender wage gap $(\Delta G W G)$ 
(Countries with only one census are excluded). The association becomes even stronger when we control for country heterogeneity. In the within-country regression, not only is the estimated slope larger in magnitude but the estimated standard error is also smaller. The slope of the fitted regression line is statistically significant below the 1 percent level and implies that a onepercentage-point reduction in the gender wage gap is associated with a 0.46-percentage-point decrease in the estimated motherhood employment penalty. The $R$ - squared becomes larger and suggests that more than 30 percent of the within-country variation in motherhood employment penalty can be explained by variation in the gender wage gap. The correlation coefficient also indicates a stronger correlation and is equal to -0.56. Because a smaller gender wage gap implies a higher opportunity cost for domestic work and childcare, the observed linear association in Figure 2.3 is consistent with a substitution effect on the extensive margin in the standard neoclassical labour supply model: mothers are more likely to work for pay when the return to market work is high relative to domestic work. 
Figure 2.3: Cross- and Within-Country Associations Between Gender Wage Gap and 2SLS Estimates of Motherhood Employment Penalty
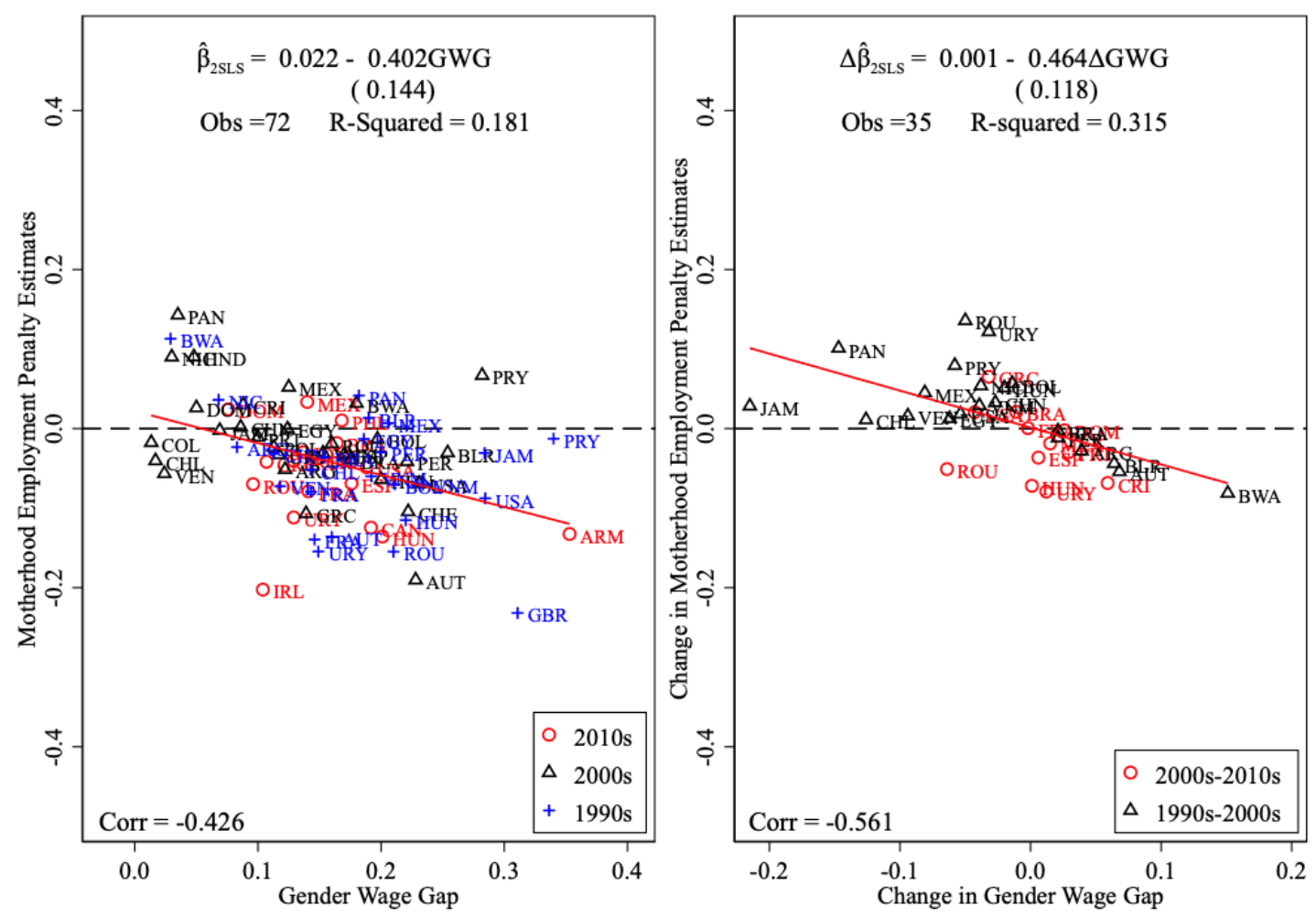

Notes: The standard errors are clustered at the country-level and are in parentheses.

Notice that the relationship gap shown in Figure 2.3 is quite linear. Although a 2SLS estimate is only able to identify the LATE, Bisbee et al. (2017) and Dehejia et al. (2019) show that extrapolation of LATE based on observable covariates works reasonably well. Moreover, at least in the fertility context, macro covariates seem to dominate over micro covariates for reducing errors in extrapolation. The linearity between the motherhood employment penalty and gender wage gap therefore is consistent with the findings in Bisbee et al. (2017) and Dehejia et al. (2019). In Figure 2.4, for comparison, we plot the OLS estimates of the motherhood employment penalty against gender wage gaps. While the OLS estimates tend to overestimate the size of the motherhood penalty on employment, there is no strong relationship between the OLS estimates and gender wage gaps. Both the cross- and within-country estimates are not significantly different from zero at any conventional level, although the slope estimates are still 
negative. In contrast to the strong relationship in Figure 2.3 based on the 2SLS estimates, the non-relationship in Figure 2.4 is likely a result of endogeneity bias in the OLS estimates. In fact, Bisbee et al. (2017) show that even extrapolated LATE estimates often work better than OLS estimates because the extrapolation error tends to be smaller than the endogeneity bias. Since actual 2SLS estimates remove endogeneity bias but without any extrapolation error, it is not surprising that they perform much better than the OLS estimates in revealing the association between the motherhood employment penalty and gender wage gap.

Figure 2.4: Cross- and Within-Country Associations Between Gender Wage Gap and OLS Estimates of Motherhood Employment Penalty
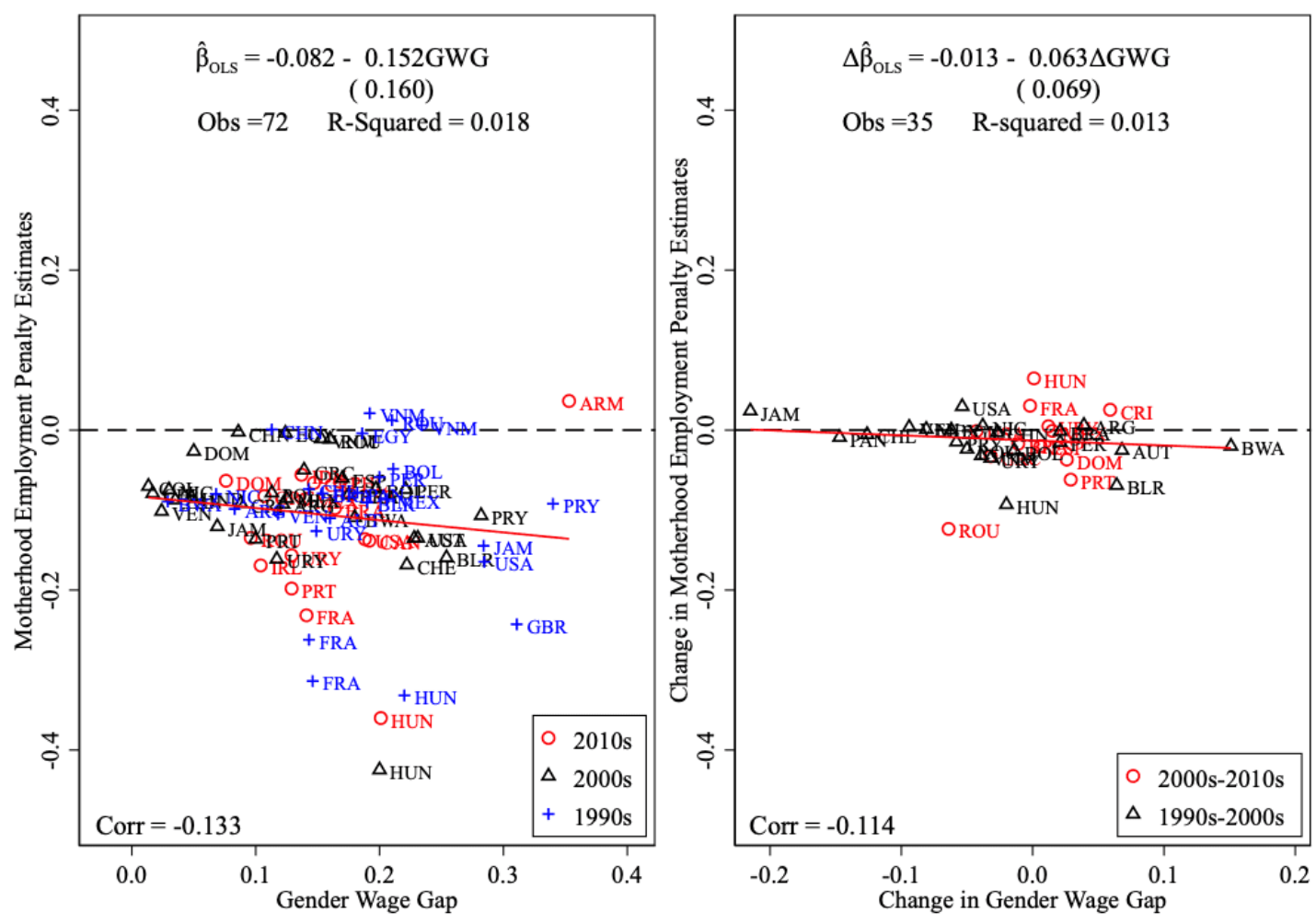

Notes: The standard errors are clustered at the country-level and are in parentheses. 


\subsubsection{Is there Sample Selection Issue?}

The strong within-country association in Figure 2.3 suggests that the relationship between the motherhood penalty and gender wage gap is not likely driven by country heterogeneity. However, changes in gender wage gaps could lead to different compositions of mothers and compliers, which could lead to different LATE estimates and potentially generate the withincountry association observed in Figure 2.3. For example, a reduction in the gender wage gap may attract more women to stay in employment longer and delay fertility, which could lead to a pool of older women who are more likely to give twin births. Also, better labour market prospects may lead to adverse selection into motherhood, and the pool of mothers might become even more family oriented and with stronger preference towards more children. To address the concern of potential sample selection, in Figure 2.5 we plot changes in gender wage gaps against changes in the proportion of second twin births (left panel) and changes in the proportion of mothers with three or more children (right panel). The small and insignificant slope estimates suggest that changes in gender wage gaps have no influence on the propensity of having twin birth or having more than two children. 
Figure 2.5: Within-Country Changes in Motherhood and Gender Wage Gap


Notes: The standard errors are clustered at the country-level and are in parentheses.

In Figure 2.6, we plot changes in gender wage gaps against changes in mothers' age at first birth and changes in the proportion of high school graduates (and above). ${ }^{14}$ Again, the slope estimates are small and insignificant, suggesting that changes in gender wage gaps do not change mothers' characteristics. Figures 2.5 and 2.6 find no evidence of compositional changes in the pool of mothers and compliers. Therefore, sample selection cannot be the explanation of the strong linear association between gender wage gap and motherhood employment penalty in Figure 2.3.

\footnotetext{
${ }^{14}$ The right panel of Figure 2.6 shows a negative slope that is entirely driven by one outlier, Jamaica (top left corner of the figure). The slope estimate is not statistically significant at any conventional level.
} 
Figure 2.6: Within-Country Changes in Mothers' Characteristics and Gender Wage Gap
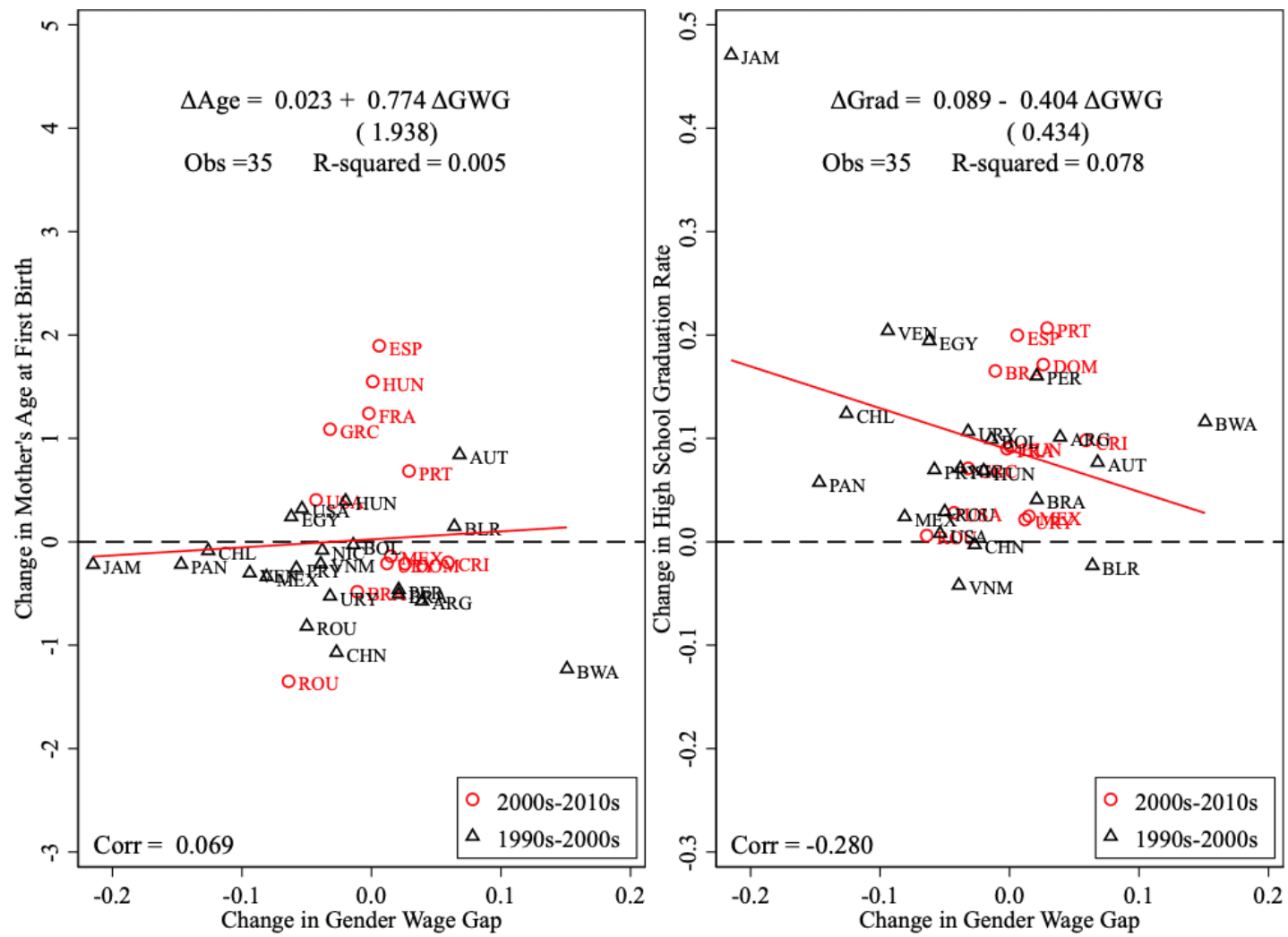

Notes: The standard errors are clustered at the country-level and are in parentheses.

\subsubsection{How much of the Relationship between the Motherhood Employment Penalty and Gender Wage Gap is Attributed to Macroeconomic Heterogeneity?}

The result in Figure 2.3 presents a stylized fact and is correlational in its nature because both motherhood penalty and gender wage gap reflect not only labour market prospects but also overarching gender equality. In this part of the paper, we investigate some macroeconomic channels that are correlated with gender equality and may influence both the gender wage gap and a mother's decision to return to the labour force. Here, our goal is to quantify the contribution of these broad economic forces to the observed association between gender wage gap and motherhood employment penalty. 
How much of the relationship between the gender wage gap and motherhood penalty can be explained by disparities in earlier human capital investments? In Figure 2.7, we plot the residuals of the motherhood penalty against the residuals of the gender wage gap after partialling out gender education gaps. (Notice that the univariate residual regression shown in Figure 2.7 is numerically identical to a multivariate regression of motherhood employment penalty on the gender wage gap and gender education gap. The intercept of a residual regression is zero by construction.) We define the gender education gap as the gender difference in the proportion of high school (and above) graduates among the population 21-35 years old. ${ }^{15}$ In the left panel, the cross-country slope estimate of the fitted residual regression equals -0.36 and remains statistically significant at the 5 percent level. (The 1991 U.K. census was excluded due to lack of information on educational attainment.) In the right panel, the within-country slope estimate is 0.43 and statistically significant below the 1 percent level. Thus, it does not appear that variation in relative human capital investments at a macro-level explains our documented co-movement of gender wage gaps and the motherhood penalty. It may seem surprising that our estimate remains substantively unchanged after partialling out education gaps-a variable which measures one aspect of gender disparity and involves education which is directly tied to productivity and wage determination. However, the relationship between gaps in the labour market and gaps in education is not as strong as might be expected. In fact, particularly in rich countries, women have surpassed men in terms of educational attainment while their labour market outcomes still lag behind men's. ${ }^{16}$

Kleven and Landais (2017) show that economic development is associated with improved gender equality. It is also possible that economic development drives the correlation

\footnotetext{
${ }^{15}$ We calculate gender education gap $(G E G)$ directly from IPUMS-I datasets. $G E G$ is defined as the difference between average male high school graduation rate and average female high school graduation rate over average male high school graduation rate in percentage terms.

${ }^{16}$ For example, in Appendix Figure A2.6, OECD data for 40 countries in 2018 shows a correlation of only 0.20 between the female-male tertiary education enrolment ratio and the female-male employment ratio of the 25-34year-olds. The correlation drops to 0.06 when a single outlier (Turkey) is excluded. Notably, the female-male employment ratio is less than one, while the female-male tertiary education enrolment ratio is greater than one in almost all countries.
} 
Figure 2.7: Cross- and Within-Country Associations Between Gender Wage Gap and Motherhood Employment Penalty After Partialling Out Gender Education Gap
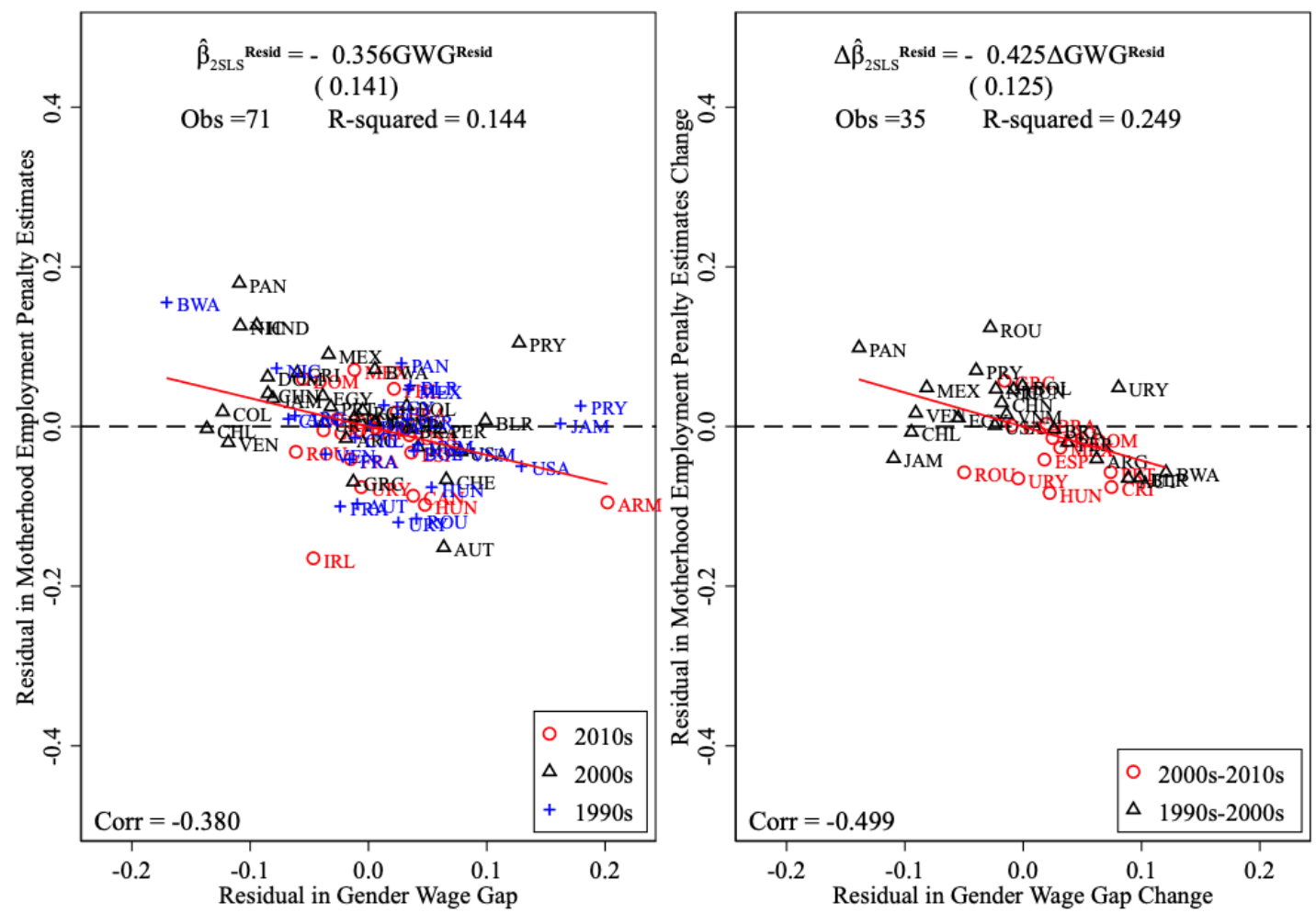

Notes: The 1991 U.K. census was excluded due to lack of information on educational attainment. The standard errors are clustered at the country-level and are in parentheses.

in the motherhood penalty and the gender wage gap. For example, secular GDP growth could tighten the labour market for women and reduce the gender wage gap, consequently pulling more mothers into formal work. On the other hand, Aaronson et al. (2017) document larger motherhood employment penalties at higher levels of development. In Figure 2.8, we partial out GDP per capita (in logarithm form) from the gender wage gap and motherhood employment penalty and then plot the residuals. The slope estimates of the fitted residual regression remain statistically significant at the 1 percent level and equal to -0.37 and -0.46 in the left and right panels, respectively. Both of the estimate magnitudes in Figure 2.8 are nearly identical to those in Figure 2.3. This suggests that our correlation between the gender wage gap and motherhood penalty is not merely reflective of changes instituted by raw economic growth. 
Figure 2.8: Cross- and Within-Country Associations Between Gender Wage Gap and Motherhood Employment Penalty After Partialling Out Log GDP Per Capita
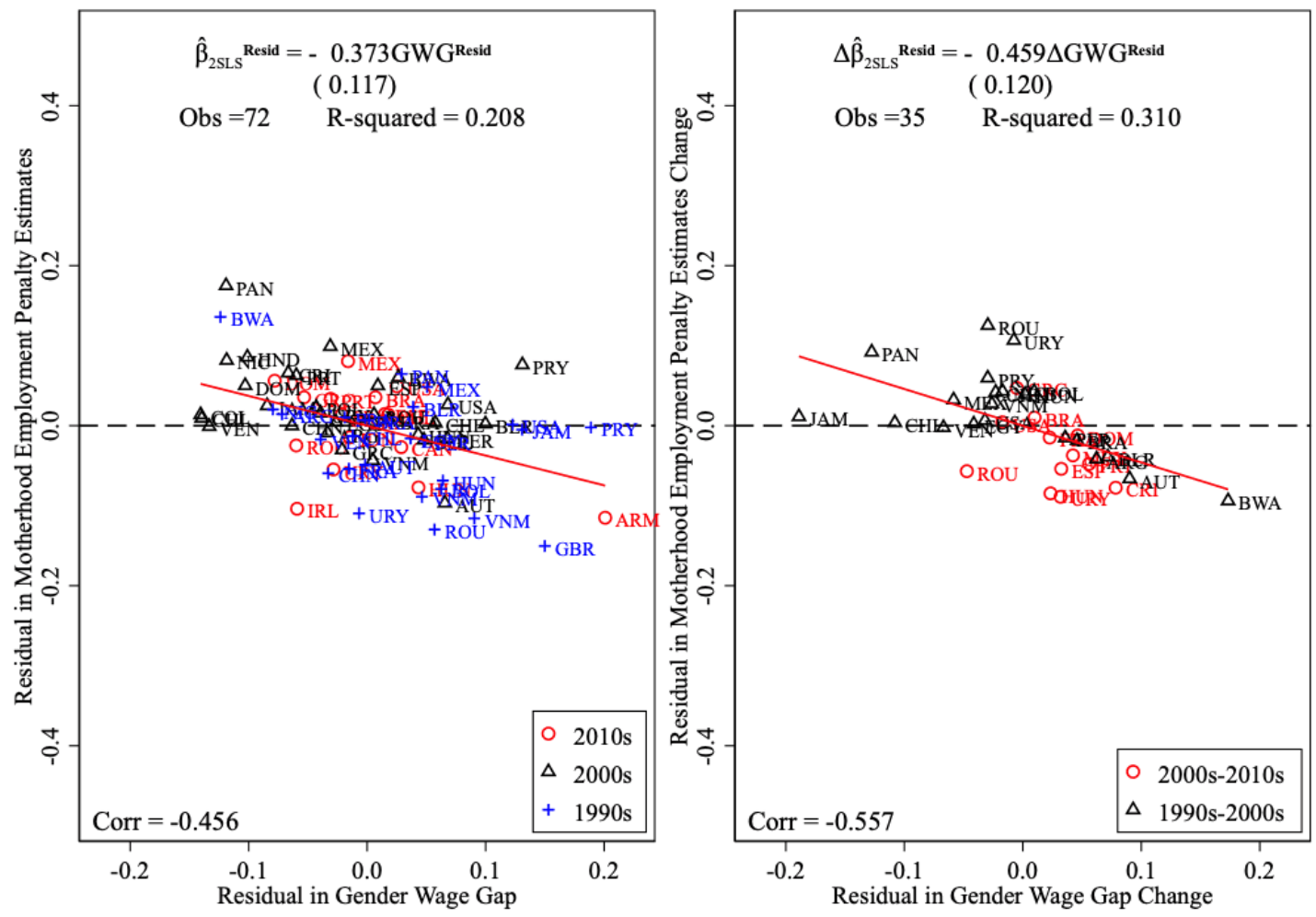

Notes: The standard errors are clustered at the country-level and are in parentheses.

Gender inequality could also be associated with cross-sectional income inequality. Income inequality is heightened in labour markets with job polarization and more "extreme jobs" that offer high salaries but demand long working hours (Autor, 2010, 2014; Gascoigne et al., 2015; Mishel et al., 2013). In such settings, the gender wage gap and motherhood penalty both would be large because women are known to be less likely to be employed in these extreme jobs, and the need for a household division of labour is high, especially with a child present (Gascoigne et al., 2015; Raley et al., 2012). In Figure 2.9, we partial out the Gini coefficient from the motherhood employment penalty and the gender wage gap and plot the residuals. The Gini coefficient and gender wage gap appear to be somewhat correlated across countries but not within countries. In Figure 2.9, the cross-country correlation in the left panel declines relative to Figure 2.3. The cross-country slope estimate in the left panel is -0.23 and only statistically 
significant at the 10 percent level. Gini coefficients appear to explain a substantial proportion of the cross-country correlation between the motherhood penalty and gender wage gap. In contrast, the within-country correlation in the right panel remains quantitatively similar to Figure 2.3. The within-country slope estimate in the right panel equals -0.42 and remains statistically significant below the 1 percent level.

Figure 2.9: Cross- and Within-Country Associations Between Gender Wage Gap and Motherhood Employment Penalty After Partialling Out Gini Coefficient
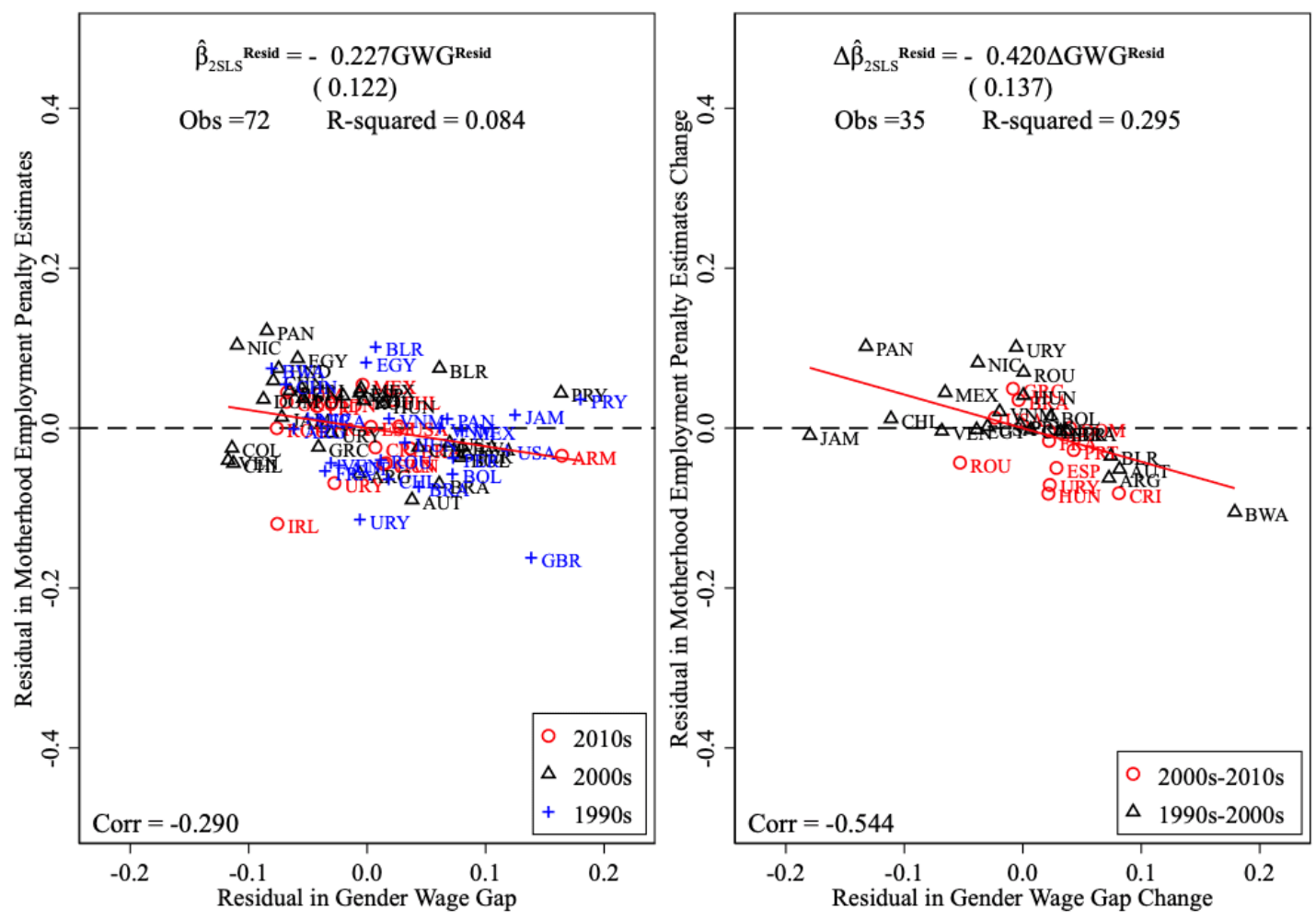

Notes: The standard errors are clustered at the country-level and are in parentheses. 
As an additional robustness check, in Figure 2.10, we partial out all three variables: log GDP per capita, gender education gap, and the Gini coefficient. In the left panel, the slope estimate from the cross-country correlation drops even further to -0.20 and is only statistically significant at the 5 percent level. However, in the right panel, the within-country correlation between the motherhood employment penalty and gender wage gap remains strong and very linear. The slope estimate is equal to -0.39 and statistically significant at the 1 percent level. The partial R-squared in the right panel of Figure 2.10 is equal to 0.24 , which is only a one-quarter drop from an R-squared of 0.32 in the right panel of Figure 2.3. Therefore, after controlling for economic development, gender gaps in human capital, and cross-sectional inequality, withincountry variation in the gender wage gap can still explain 24 percent of the within-country variation in the motherhood employment penalty. In Table 2.3, we estimate multivariate regressions of the motherhood employment penalty on gender wage gap controlling for all three variables as well as country fixed effects, and the results are quantitatively similar to Figure 2.10. 
Figure 2.10: Cross- and Within-Country Associations Between Gender Wage Gap and Motherhood Employment Penalty After Partialling Out GDP Per Capita, Gender Education Gap, and Gini Coeffficent
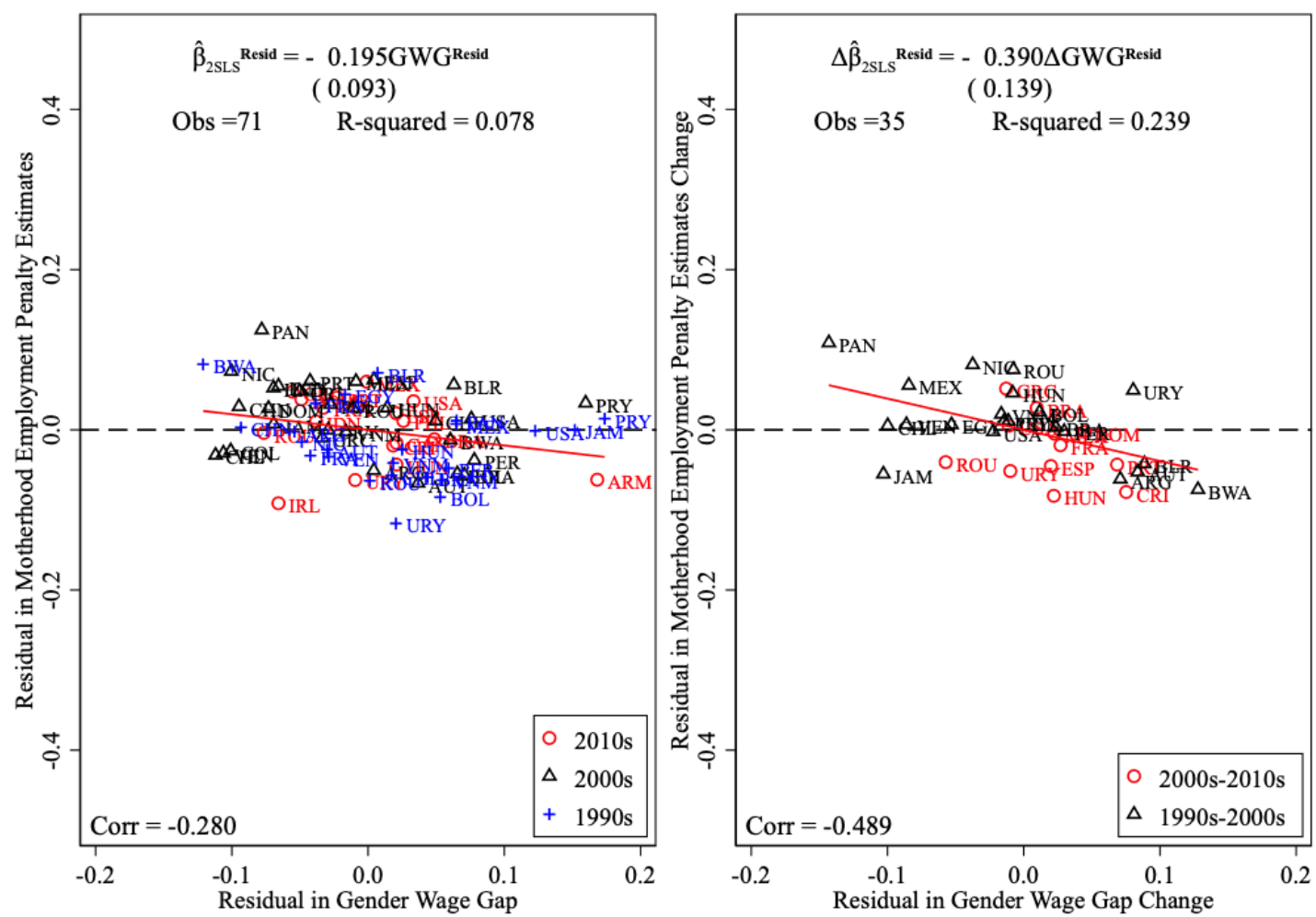

Notes: The 1991 U.K. census was excluded due to lack of information on educational attainment. The standard errors are clustered at the country-level and are in parentheses. 
Table 2.3: The Association Between Motherhood Employment Penalty and Gender Wage Gap, Log GDP Per Capita, Gender Education Gap, Gini Coefficient

\begin{tabular}{|c|c|c|c|}
\hline & $\begin{array}{c}(1) \\
\widehat{\beta}_{2 S L S}\end{array}$ & $\begin{array}{c}(2) \\
\widehat{\beta}_{2 S L S}\end{array}$ & $\begin{array}{c}(3) \\
\Delta \widehat{\beta}_{2 S L S}\end{array}$ \\
\hline$G W G$ & $\begin{array}{c}-0.195 * * \\
(0.096)\end{array}$ & $\begin{array}{c}-0.421 * * \\
(0.170)\end{array}$ & \\
\hline $\ln (G D P)$ & $\begin{array}{c}-0.020 * * * \\
(0.006)\end{array}$ & $\begin{array}{c}0.004 \\
(0.027)\end{array}$ & \\
\hline$G E G$ & $\begin{array}{c}0.002 \\
(0.039)\end{array}$ & $\begin{array}{c}0.002 \\
(0.123)\end{array}$ & \\
\hline Gini & $\begin{array}{c}0.003 * * * \\
(0.001)\end{array}$ & $\begin{array}{c}0.002 \\
(0.002)\end{array}$ & \\
\hline$\Delta G W G$ & & & $\begin{array}{c}-0.390 * * \\
(0.146)\end{array}$ \\
\hline$\Delta \ln (G D P)$ & & & $\begin{array}{c}-0.003 \\
(0.016)\end{array}$ \\
\hline$\triangle G E G$ & & & $\begin{array}{c}0.037 \\
(0.109)\end{array}$ \\
\hline$\Delta G i n i$ & & & $\begin{array}{c}0.003 \\
(0.002)\end{array}$ \\
\hline Constant & $\begin{array}{c}0.039 \\
(0.069)\end{array}$ & $\begin{array}{l}-0.152 \\
(0.271)\end{array}$ & $\begin{array}{c}0.004 \\
(0.012)\end{array}$ \\
\hline Observations & 71 & 71 & 35 \\
\hline$R^{2}$ & 0.547 & 0.915 & 0.412 \\
\hline Partial $R^{2}$ for $G W G$ or $\Delta G W G$ & 0.078 & 0.327 & 0.239 \\
\hline Country FEs & No & Yes & No \\
\hline
\end{tabular}

Notes: The 1991 U.K. census was excluded due to lack of information on educational attainment. Standard errors are clustered at the country-level and are in parentheses. ${ }^{* * *} p<0.01, * * p<0.05,{ }^{*} p<0.10$. 


\subsubsection{Robustness Checks}

In this section, we consider the difference in female employment rate across countries as it can correlate with changes in gender wage gap and possibly with changes in motherhood employment penalty. Also, the definition of labour force participation possibly varies from countries to countries. Controlling for overall base female labour force participation rate alleviates this concern. ${ }^{17}$ In Figure 2.11, we plot the percentage of estimated motherhood employment penalty against the gender wage gap. In the left graph of Figure 2.11, the slope of the fitted regression line is larger to the on in Figure 2.3 and statistically significant at the 5 percent level. On average, a one-percentage-point decline in the gender wage gap is associated to a 0.89-percent decrease in the motherhood employment penalty. Controlling for the time-invariant unobservable country heterogeneity, the slope estimate is -1.16 and statistically significant at the 1 percent level in the right graph of Figure 2.11. This suggests that a one-percentage-point reduction of the gender wage gap is correlated to a 1.16-percent decrease in the estimated motherhood employment penalty.

In Figure 2.12, applying the same exercise of Figure 2.10, we further partial out log GDP per capita, gender education gap, and the Gini coefficient from the percentage of motherhood employment penalty and the gender wage gap. The relationship between the percentage of motherhood employment penalty and gender wage gap remains persistent. The slopes of the fitted regression line in the left and right graph are equal to -0.52 and -1.09 respectively, and still statistically significant at below the 5 percent level.

\footnotetext{
${ }^{17}$ The percentage of motherhood employment penalty is calculated by the point estimates of motherhood employment penalty divided by the female employment rate.
} 
Figure 2.11: Cross- and Within-Country Associations Between Gender Wage Gap and 2SLS Estimates of Percentage Motherhood Employment Penalty
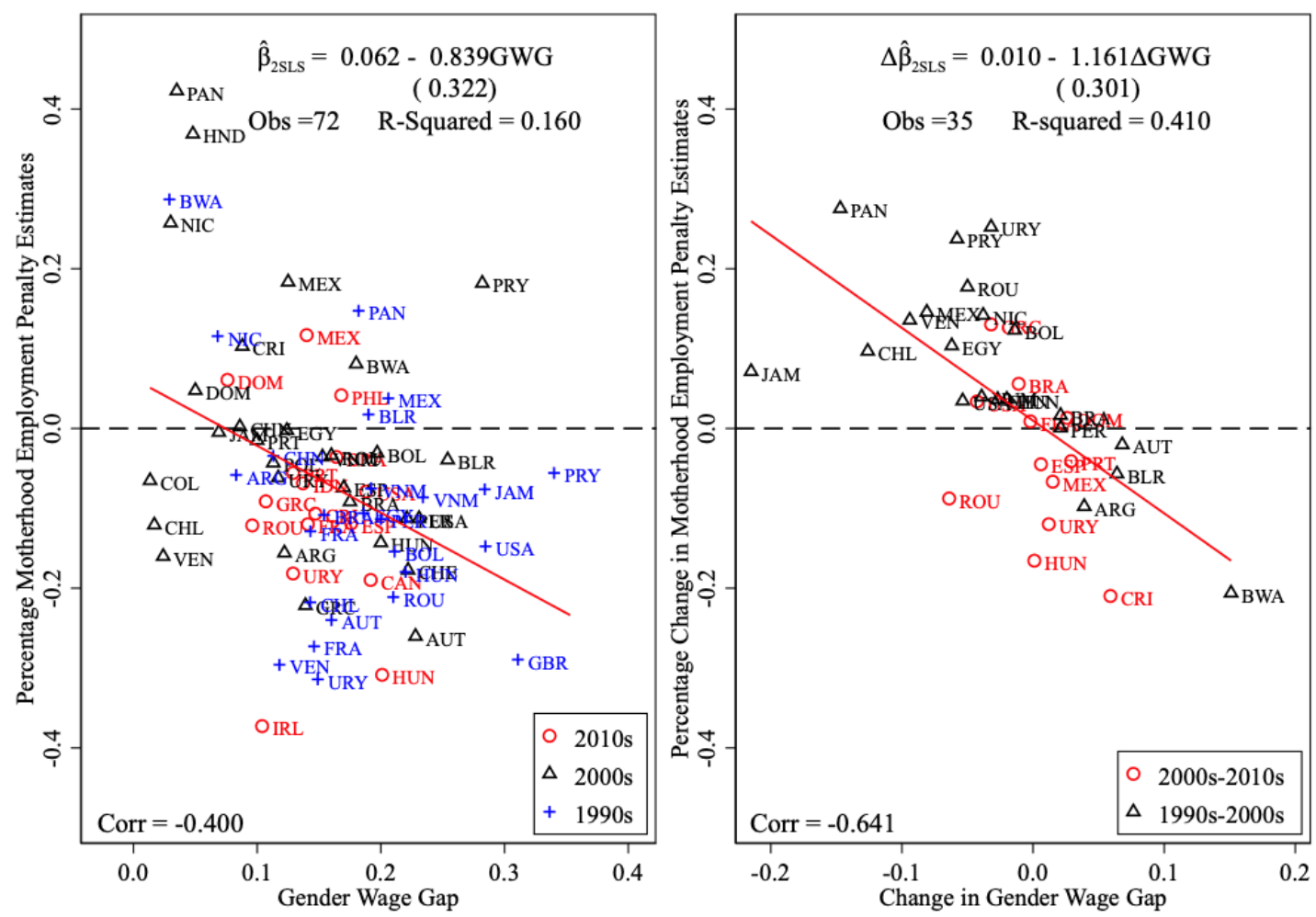

Notes: The percentage motherhood employment penalty is calculated by the point estimates of motherhood employment penalty divided by the female employment rate $\left(\widehat{\beta}_{2 S L S} / F E R\right)$. The standard errors are clustered at the country-level and are in parentheses.

Overall, while roughly half of the cross-country correlation between motherhood penalty and gender wage gap can be explained by these macroeconomic channels, especially income inequality, the within-country correlation is largely orthogonal to them and more directly associated with labour market opportunity. (In Appendix Figure A2.7, for 41 censuses in 2000s-2010s that we have data on paid maternity leave, we show that motherhood employment penalties tend to be larger in size in countries with longer months of paid maternity leave. Therefore, the opportunity cost of labour market inactivity seems to play a direct role in determining motherhood penalty on employment.) 
Figure 2.12: Cross- and Within-Country Associations Between Gender Wage Gap and 2SLS Estimates of Percentage Motherhood Employment Penalty After Partialling Out GDP Per

Capita, Gender Education Gap, and Gini Coeffficent
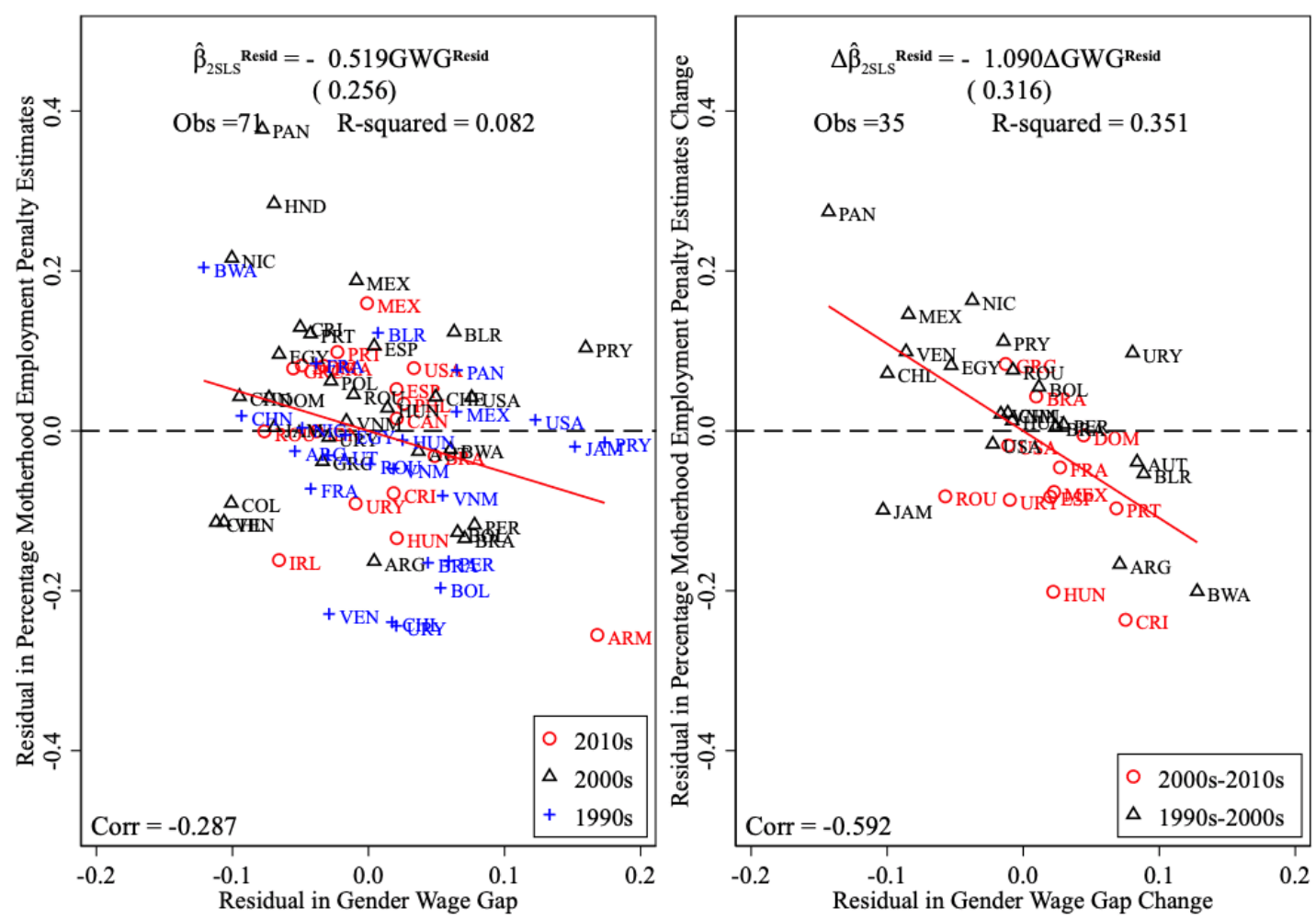

Notes: The 1991 U.K. census was excluded due to lack of information on educational attainment. The percentage motherhood employment penalty is calculated by the point estimates of motherhood employment penalty divided by the female employment rate $\left(\widehat{\beta}_{2 S L S} / F E R\right)$. The standard errors are clustered at the country-level and are in parentheses.

\subsection{Conclusions}

In this paper, we employ twin birth as an IV to estimate the causal effects of an additional child on mother's employment using censuses from all over the world between 1990-2010. On average, fertility leads to a reduction in a mother's labour supply on the extensive margin, but there are substantial differences in both the signs and sizes of the fertility effects across countries. To investigate factors associated with the differences across countries, we plot gender wage gaps against estimates of the motherhood employment penalty. To control for country heterogeneity, we take differences within a country and plot within-country changes in the estimates of 
the motherhood employment penalty against within-country changes in gender wage gaps. We find a strong linear association between the motherhood employment penalty and gender wage gap both across and within countries. The linear relationship remains largely unchanged after we partial out other macroeconomic forces including economic development, cross-sectional income inequality and gender equality in education. This implies that the association between the motherhood employment penalty and gender wage gap is not merely a by-product of secular trends in development, nor just a feature of economically equal-versus-unequal societies, and is not explained by differential access to education by sex.

While our findings are only correlational, they are consistent with a substitution effect on the extensive margin in the standard neoclassical labour supply model. The gender wage gap captures not only the real labour market prospects for women but also the opportunity cost of staying out of the labour force, and the returns to specialization within family units. Since the substitution effect implies that mothers are more likely to seek employment when the returns to market work become relatively high while the returns to domestic work become relatively low, it is intuitive that larger gender wage gaps are associated with stronger negative labour supply responses of mothers. In the analysis, we rule out some plausible macroeconomic forces, which could explain our findings even in a context with static gender norms. Nevertheless, because of the correlational nature of this study, we do not attempt to explain all the forces which guide societies to produce more or less equal labour outcomes. Exogenous movements in the deep parameters governing gender inequality (e.g. levels of taste-based discrimination) could result in shifts in the gender wage gap and societies' expectations of women and work. Future research on the motherhood penalty's causes and correlates may necessitate a narrower focus to evaluate the extent that changes to these deep parameters moderate or mediate our findings. 


\section{Appendix}

Figure A2.1: Sources of Gender Wage Gaps

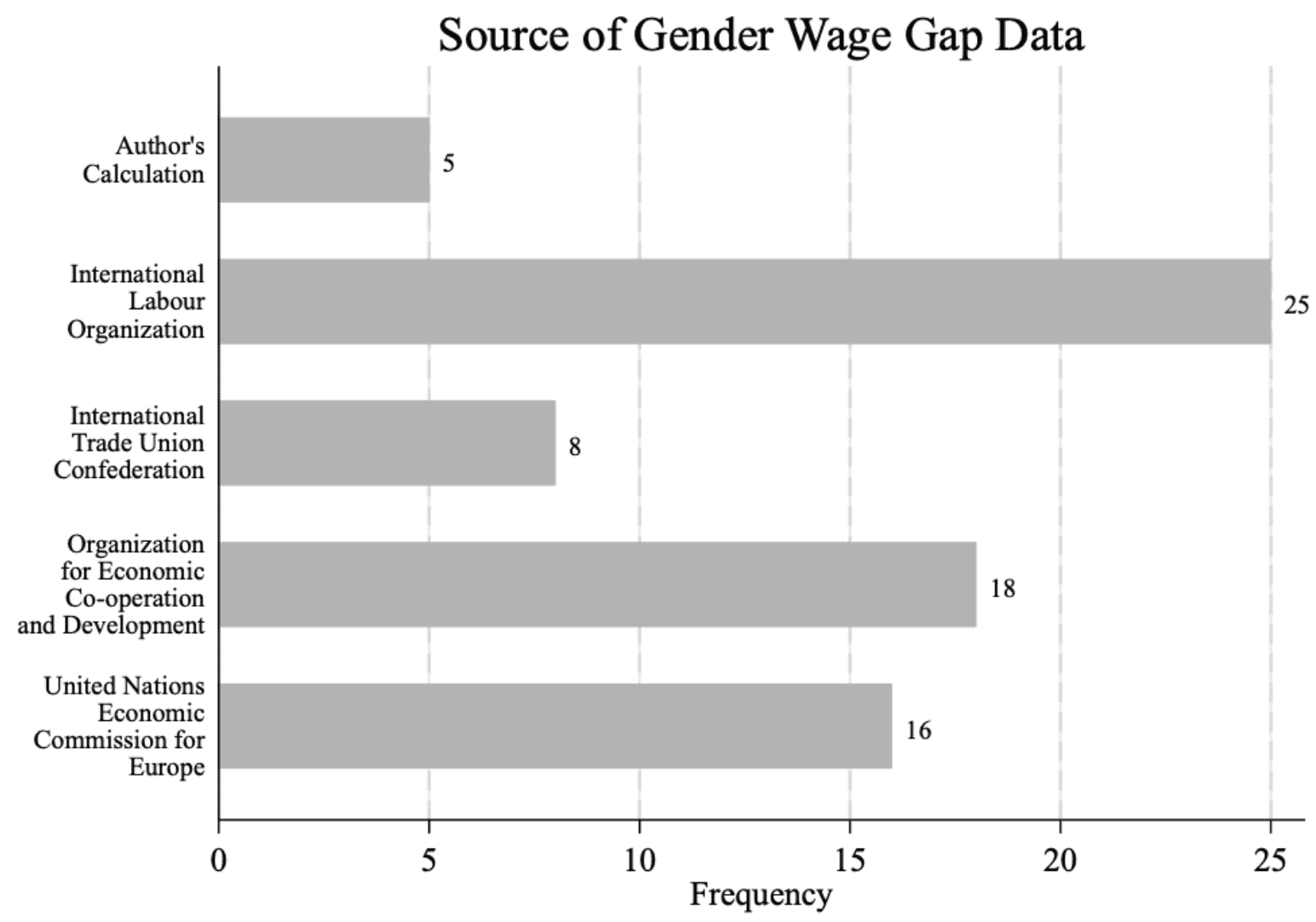

Notes: The authors calculate gender wage gaps in Vietnam and China from the Vietnam Household Living Standard Survey (VHLSS) and the China Health and Nutrition Survey (CHNS). 
Figure A2.2: Studies Estimating the Motherhood Employment Penalty by Twin Birth IV

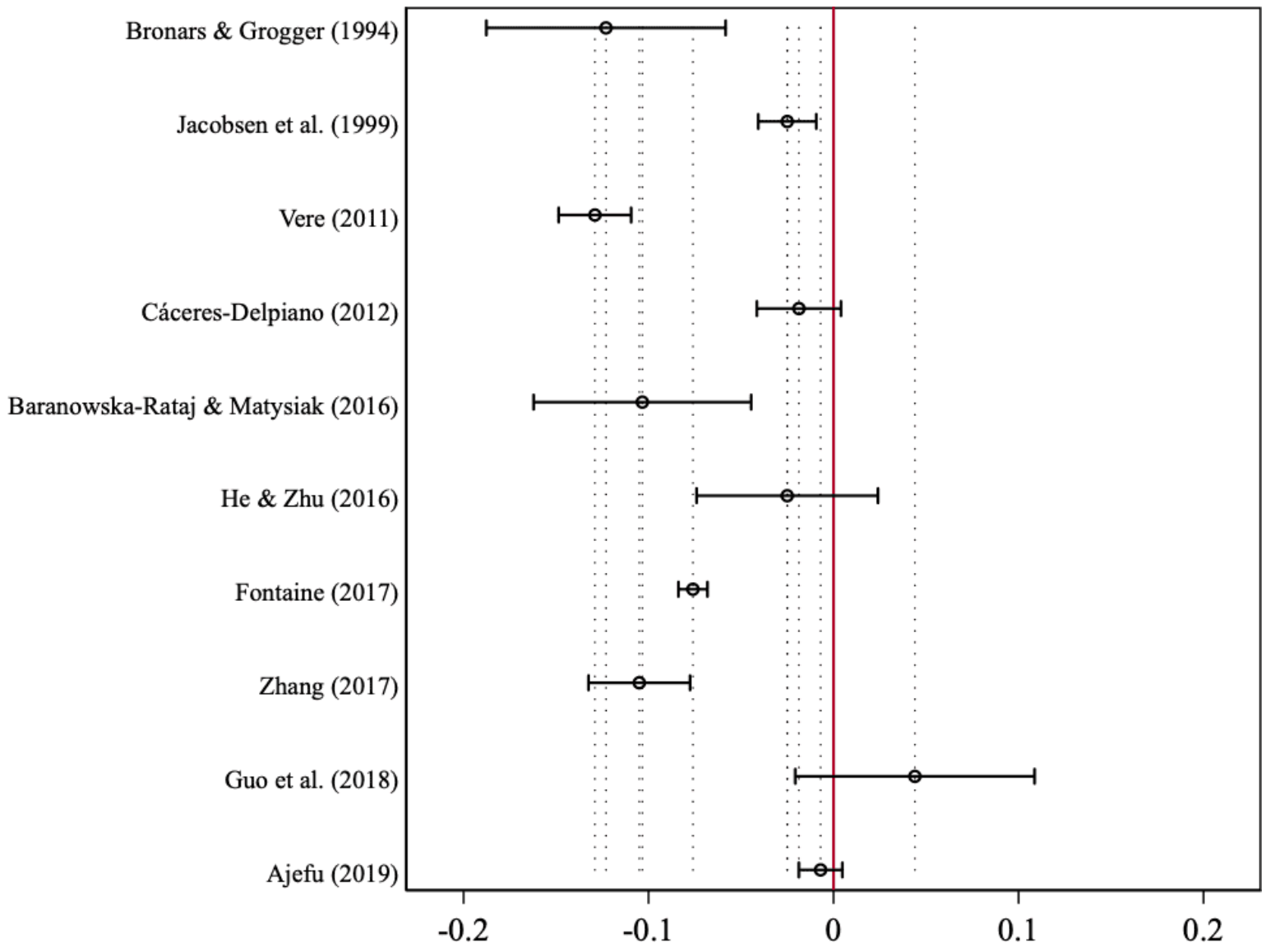

Notes: Figure reports point estimates and the 95 percent confidence intervals of each estimate using the twin birth IV. Estimates are ordered by date of publication. If there is more than one estimates for different samples in one study, we report the 2SLS estimates by the twin birth for the sample of all women in the most recent year. For Baranowska-Rataj and Matysiak (2016), we take the average effects for a group of European countries. The estimates of Jacobsen et al. (1999), Baranowska-Rataj and Matysiak (2016), He and Zhu (2016) and Guo et al. (2018) use the first twin birth IV, and the other estimates use the second twin birth IV. 
Figure A2.3: Cross- and Within-Country Associations Between Second Twin Birth and Female Employment Rate for All 1990s-2010s Samples in IPUMS-I
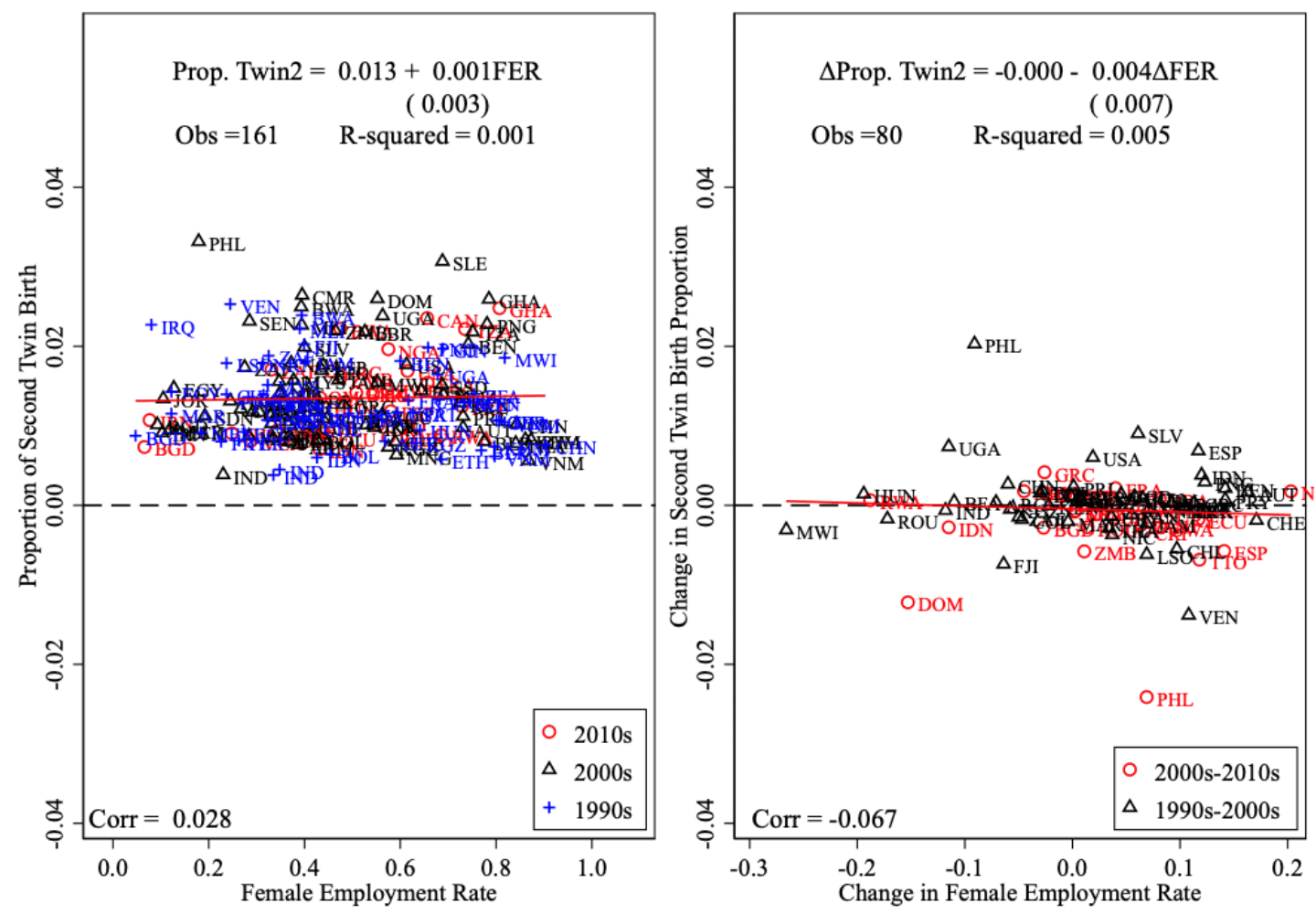

Notes: The standard errors are clustered at the country-level and are in parentheses. 
Figure A2.4: First-stage Estimates by the Twin Birth and Sibling Sex IVs



Notes: Figure gives the point estimates and standard errors in the first-stage estimates of the effects of twin births and same-sex siblings on having more children. We estimate the specification in Equation (2) by OLS. We regress the number of children on the twin birth IV and the sibling sex IV separately. The standard errors are made robust to heteroskedasticity. Figure shows that the sibling sex has smaller effect on motherhood compared to the second twin birth. The first-stage estimates by the sibling sex IV are not statistically significant in most censuses. 
Figure A2.5: Distribution of Motherhood Employment Penalty Estimates for All 1990s-2010s Samples in IPUMS-I

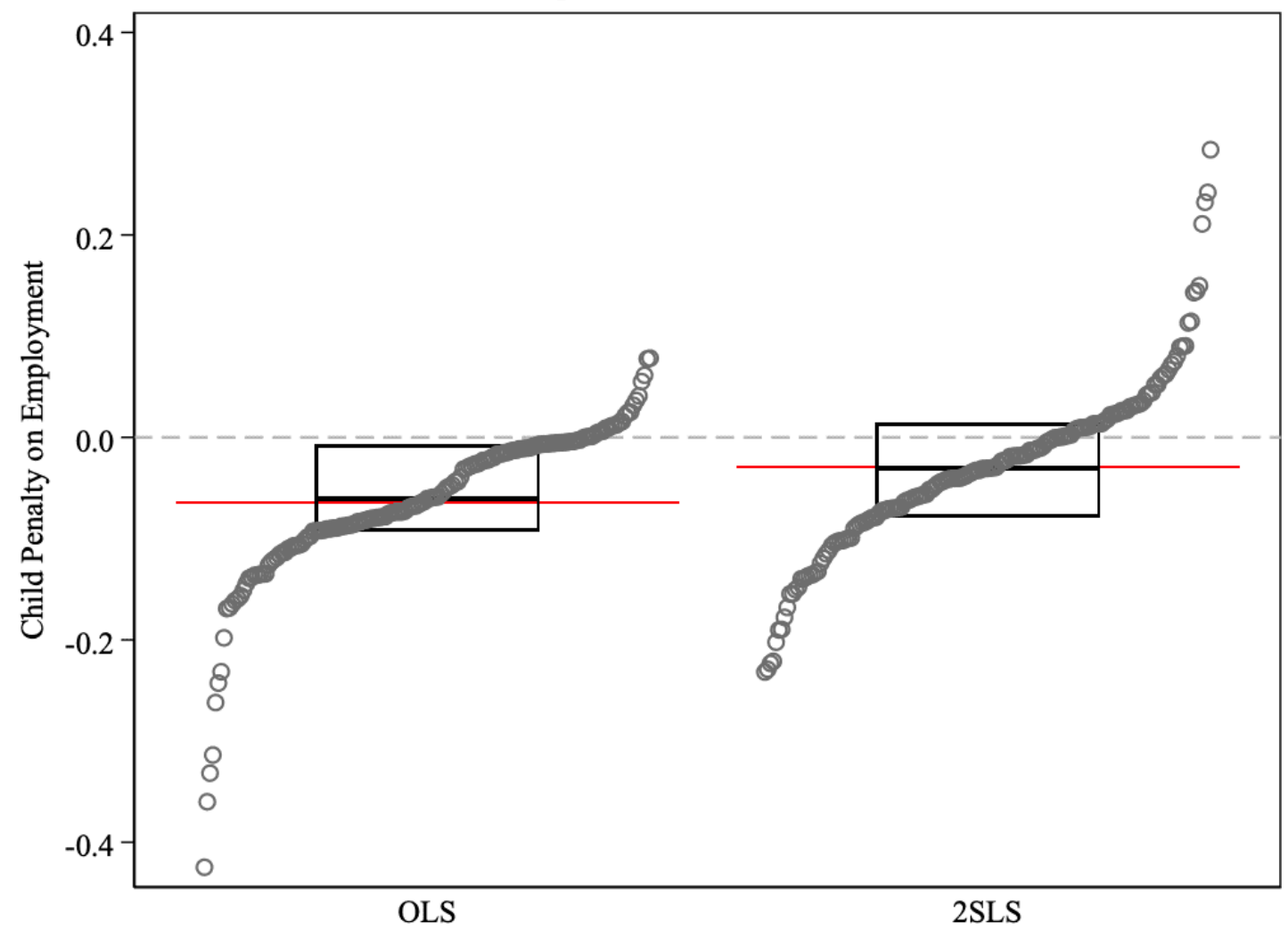

Notes: The red lines indicate the sample means of estimates. 
Figure A2.6: Cross-country Association Between Gender Employment ratio and Gender Tertiary Education Enrolment Ratio



Notes: Authors' calculations using data from: https://stats.oecd.org. 
Figure A2.7: Cross-country Association Between Motherhood Employment Penalty and Maternity Paid Leave

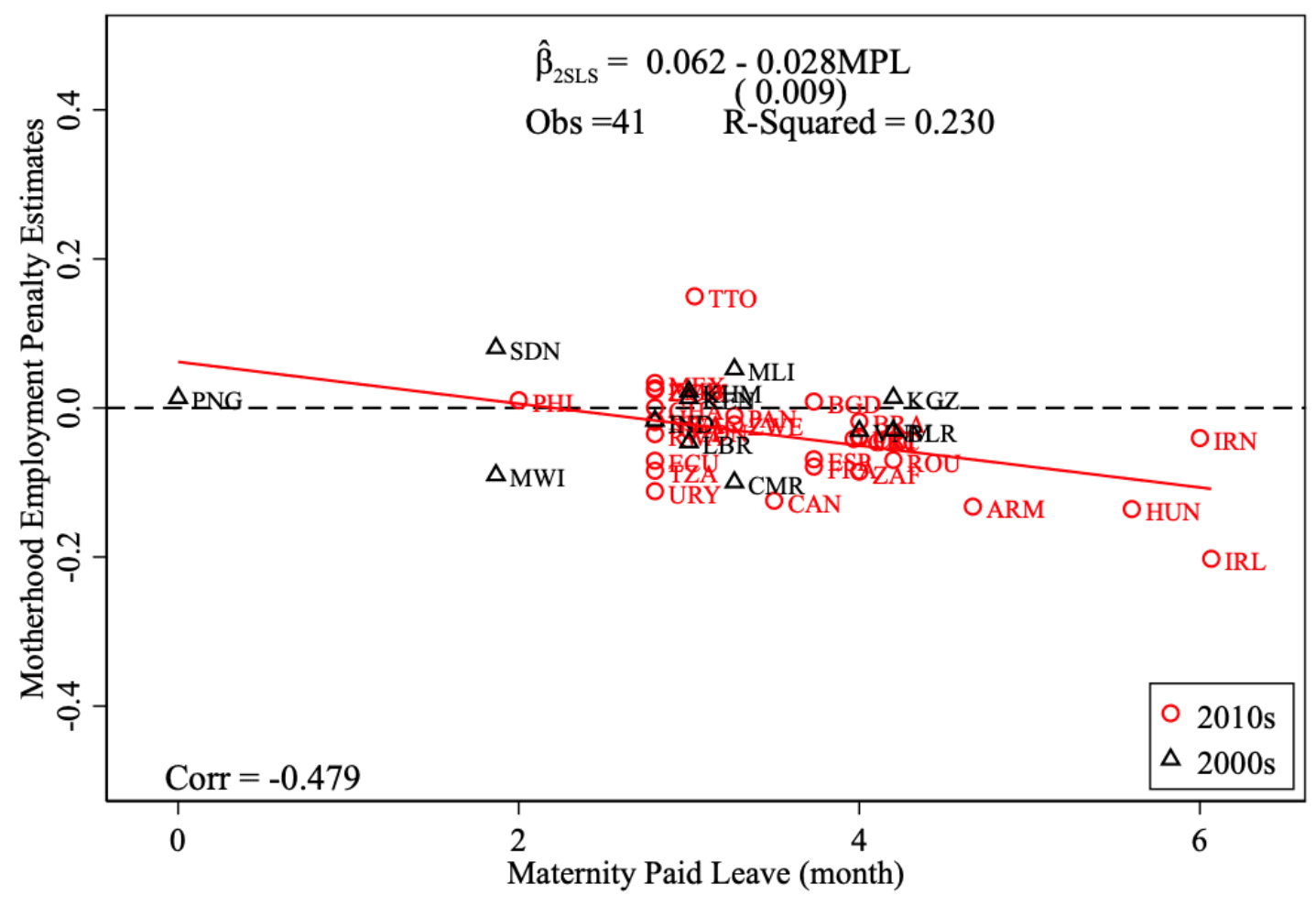

Notes: The standard errors are clustered at the country-level and are in parentheses. 


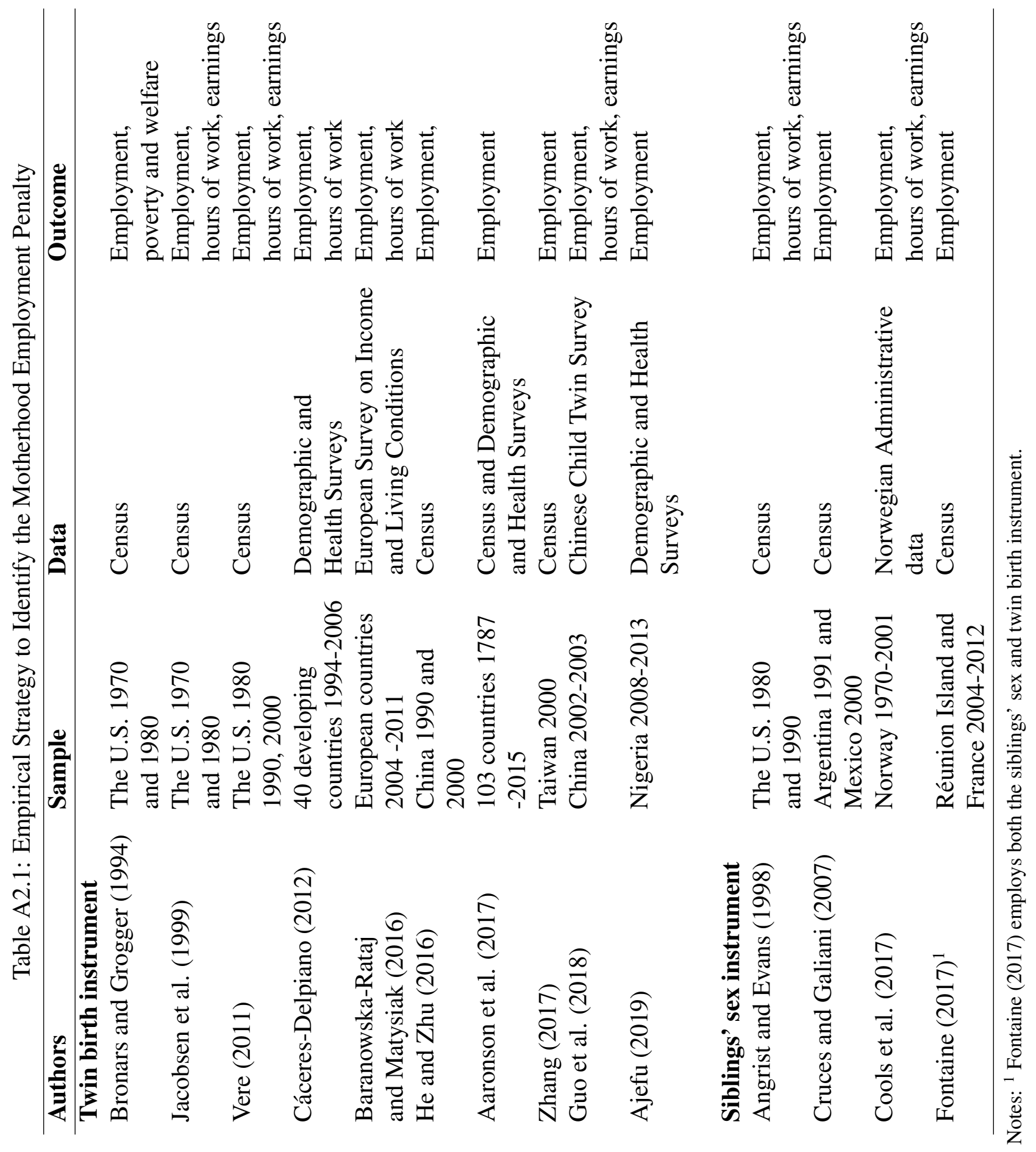




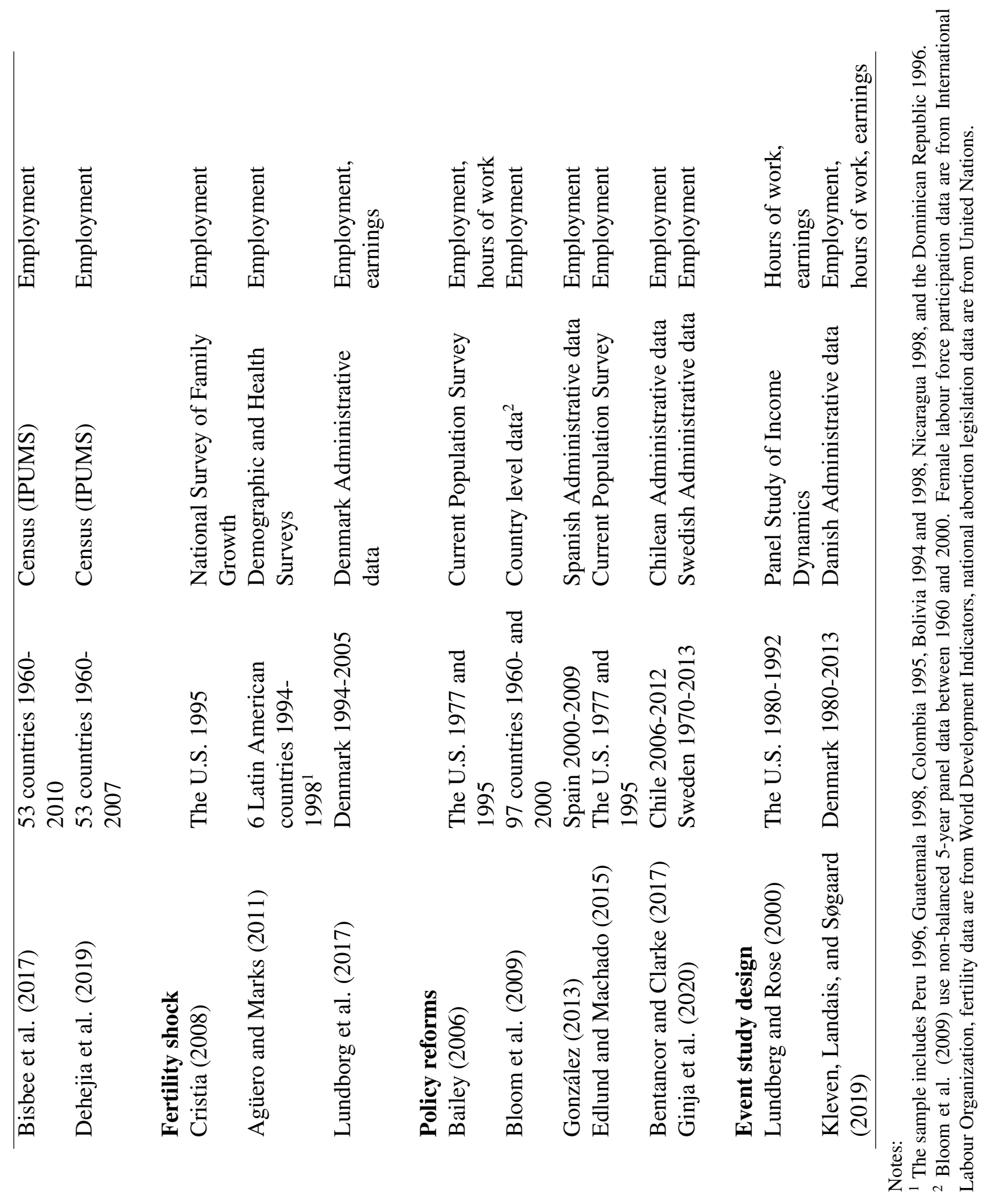




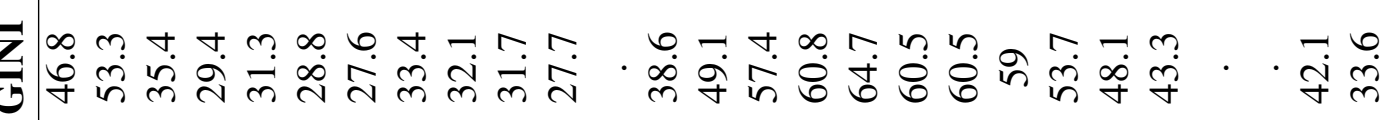

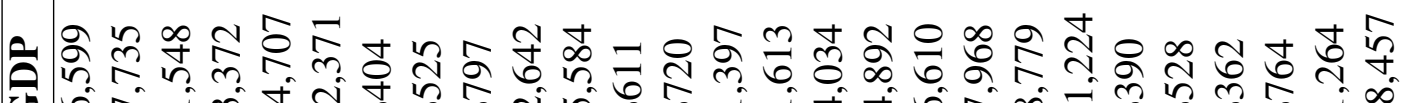

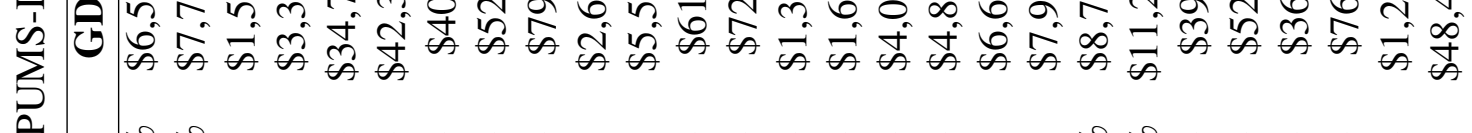

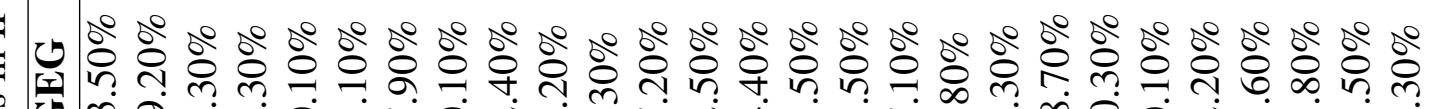

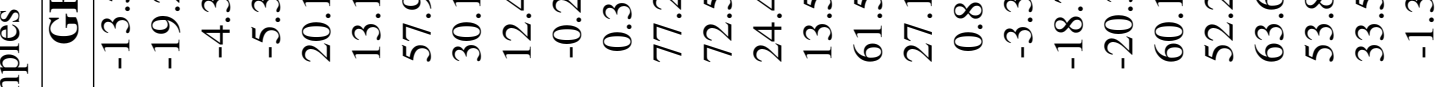

至

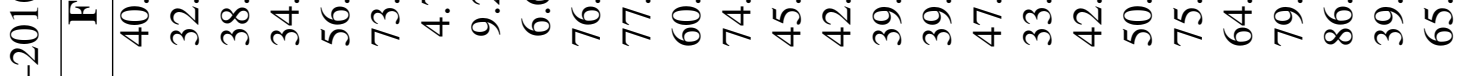

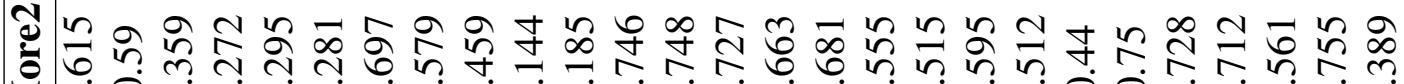
$\bar{\tau}$

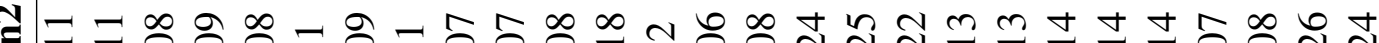

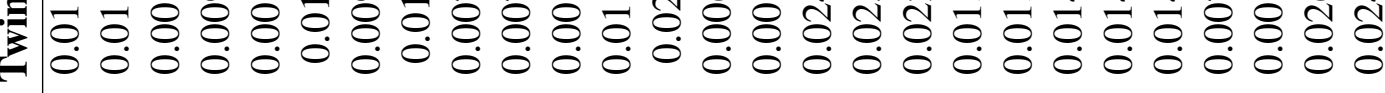

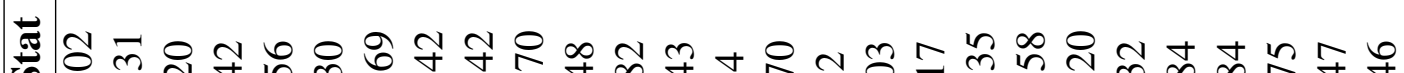

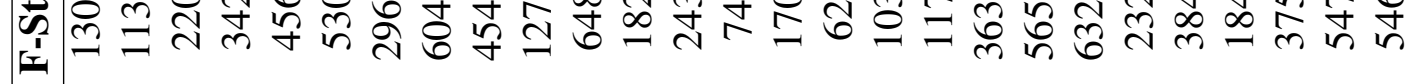

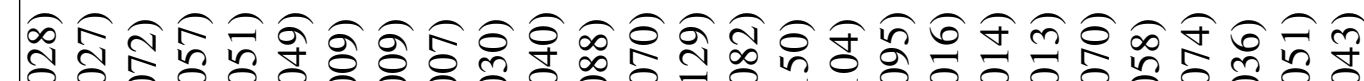

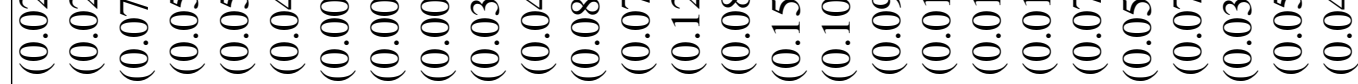

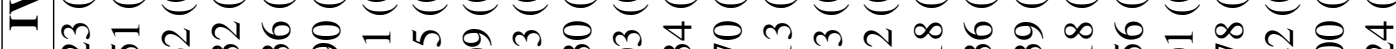
d.

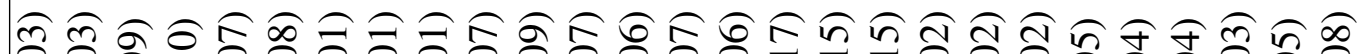

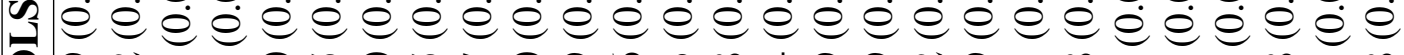

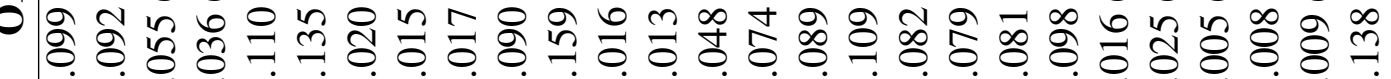

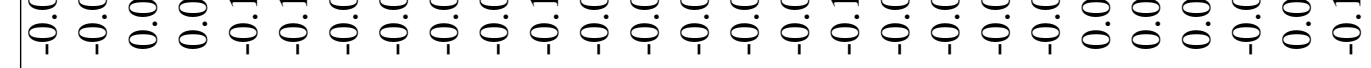

ن

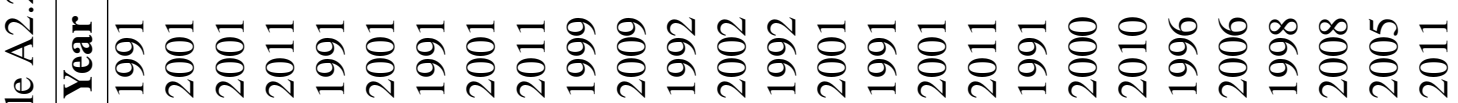
产

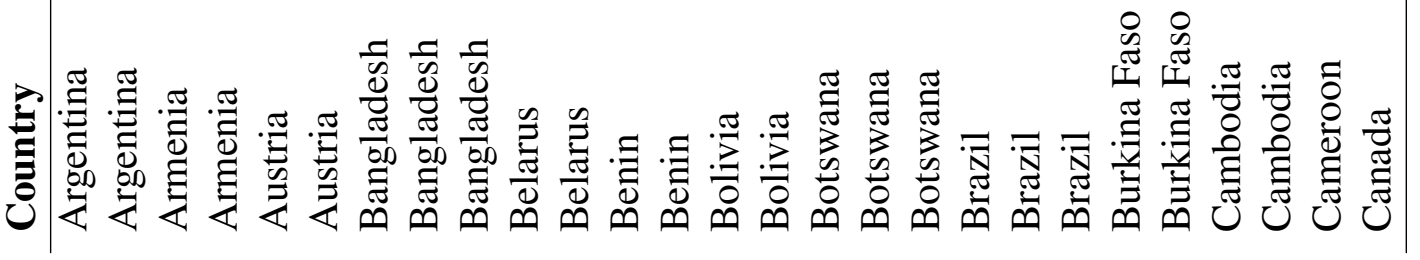




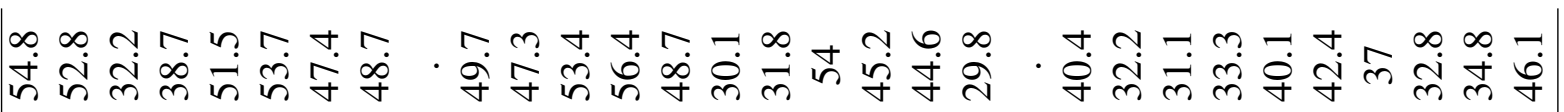

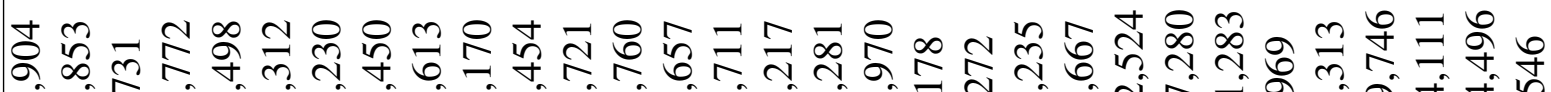

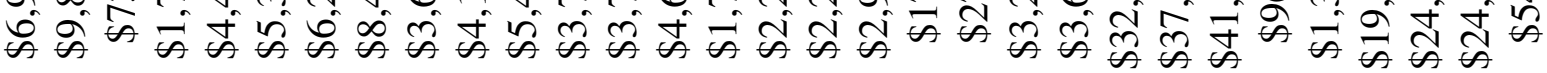

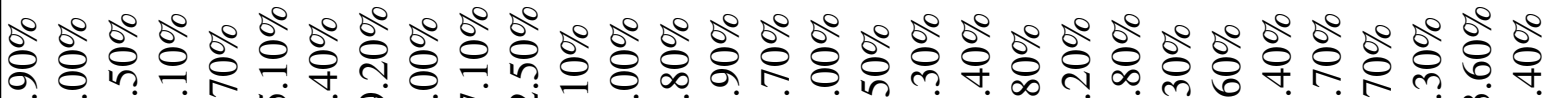

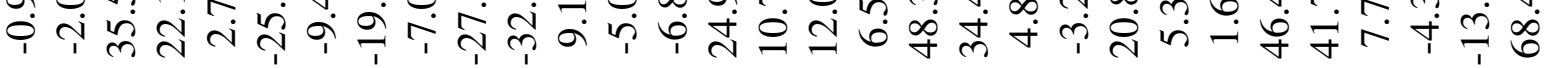



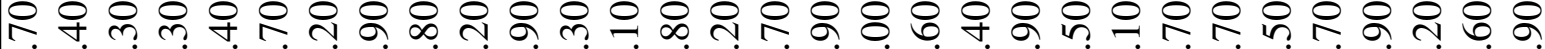
लंलू

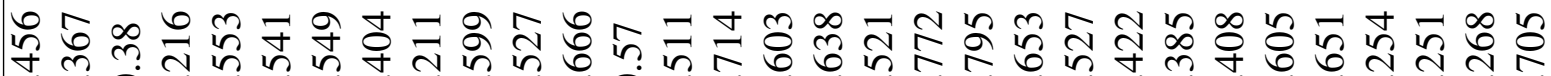



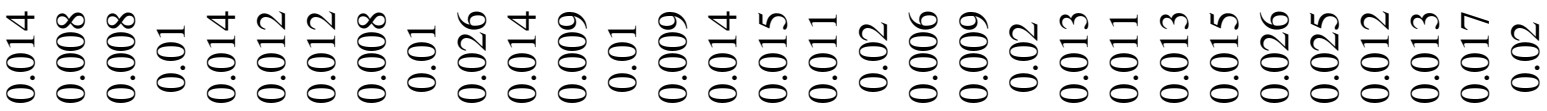

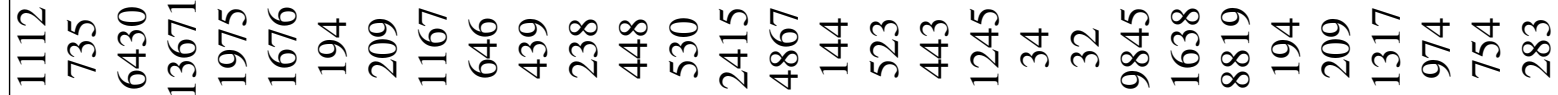
तิ

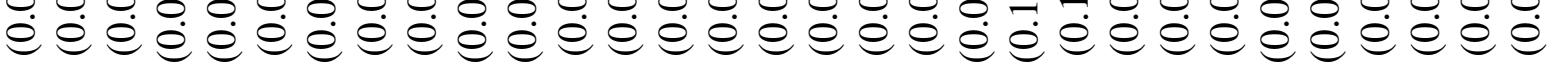

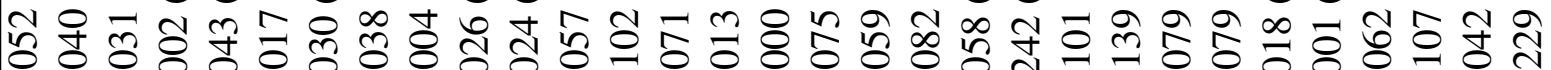

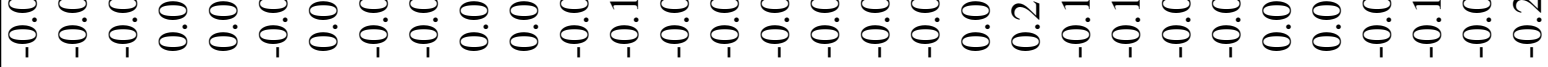

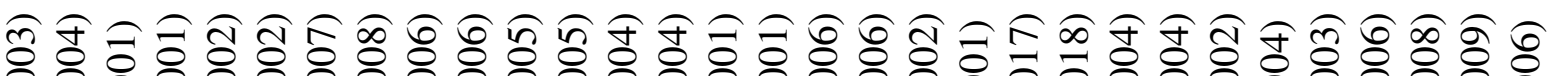
-

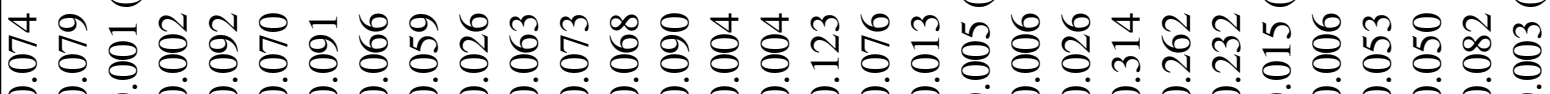

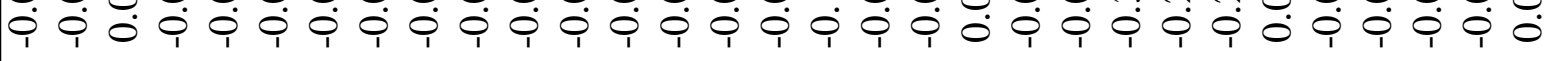

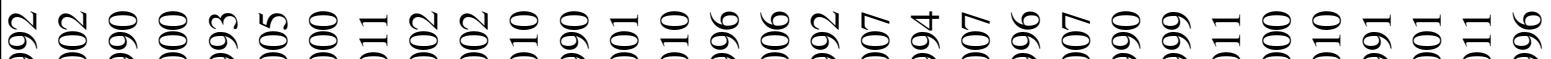

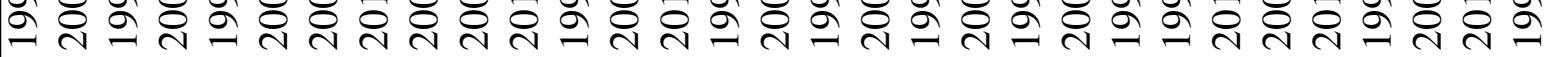

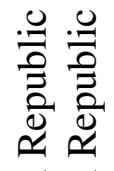

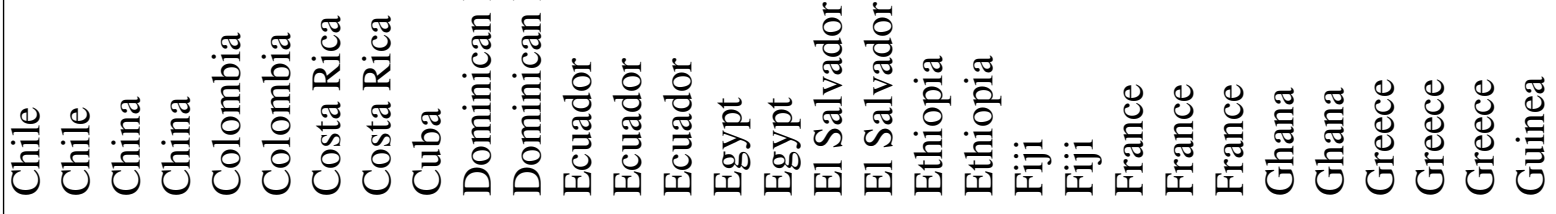




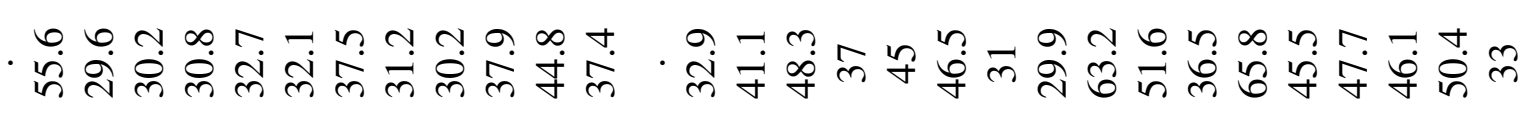
ฟ



先 तิ

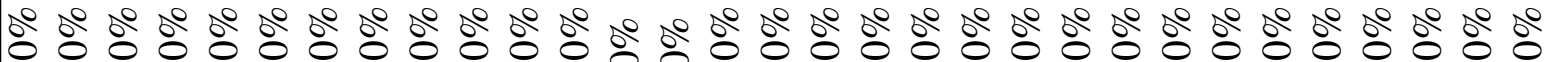

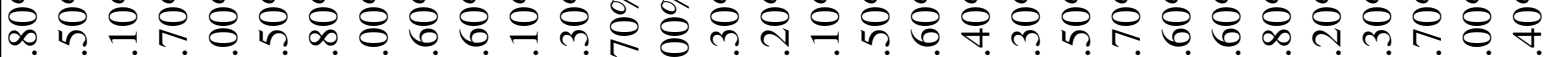
mं் ํํㅇํํำ

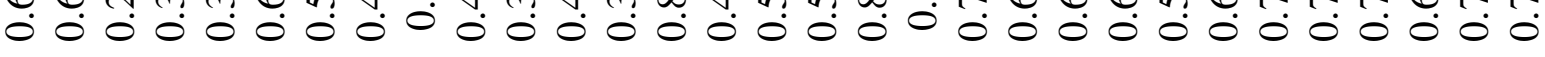

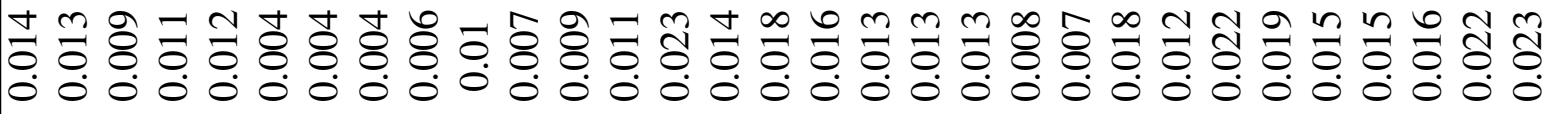
유

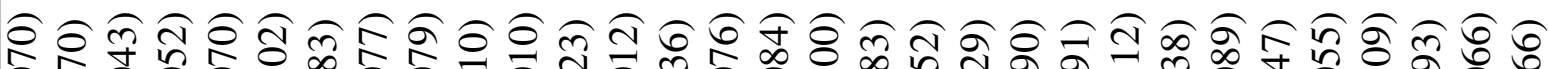

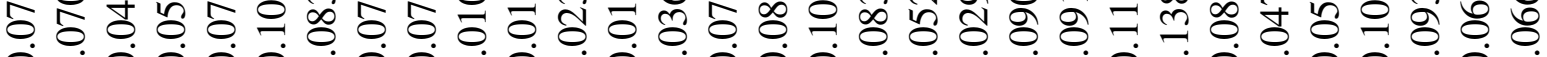

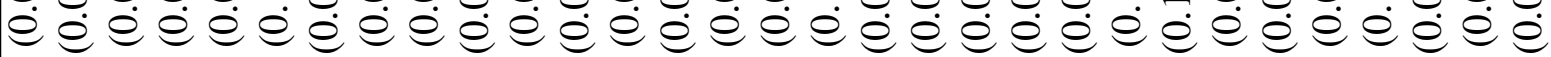

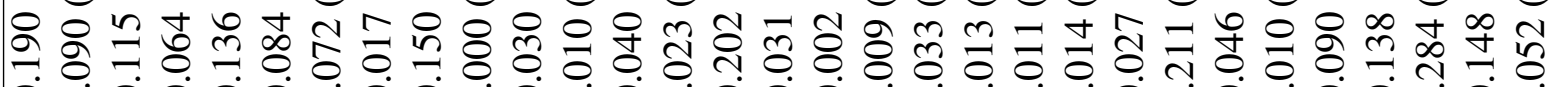
官

ธิช)

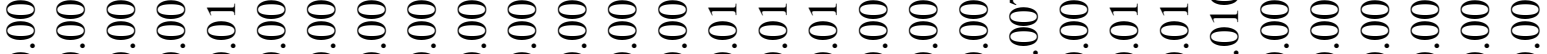
ée ée ée ๙ิ

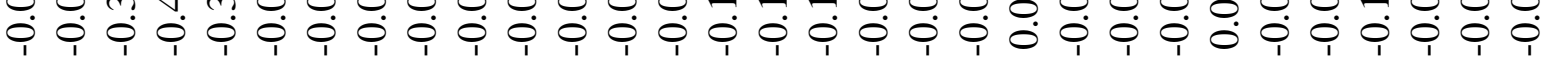
๙ 워

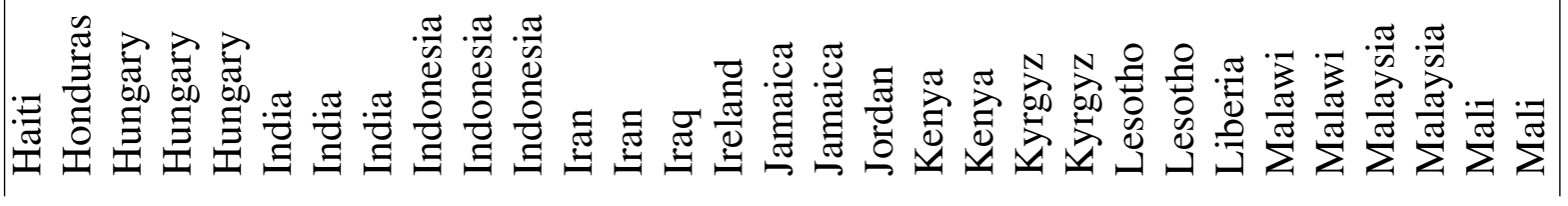




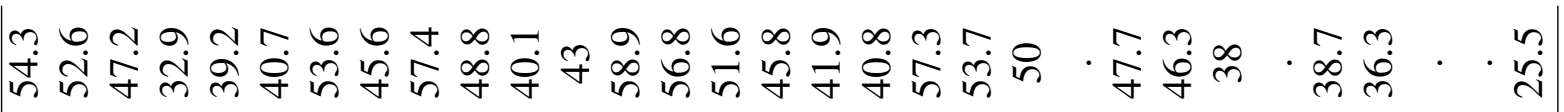

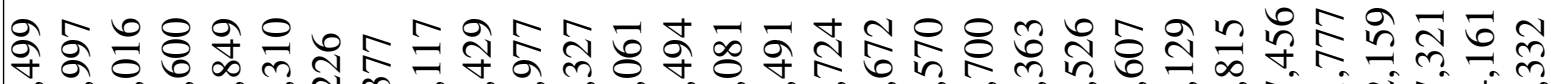

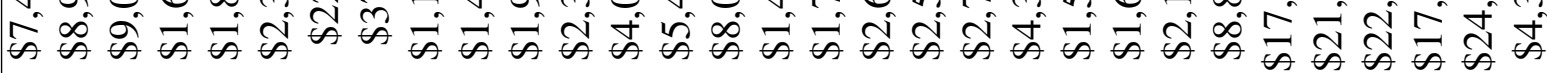

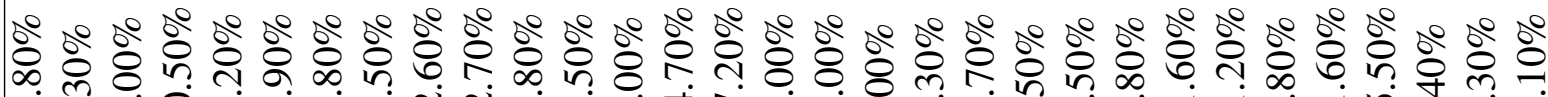
ते

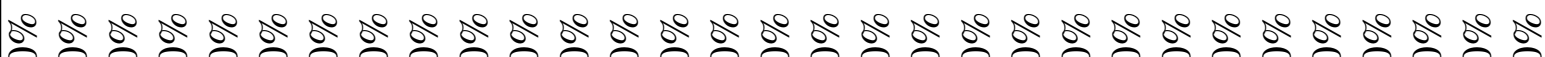

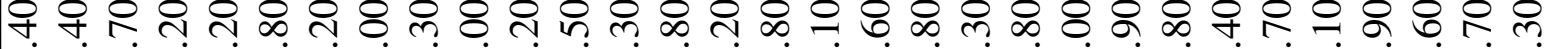
㐫 N

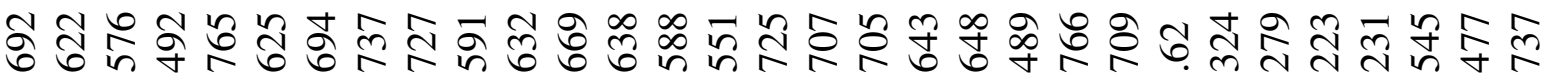

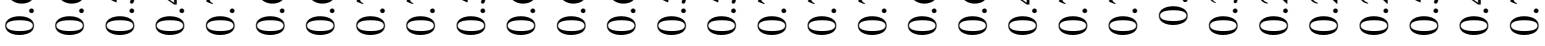
ริ \&

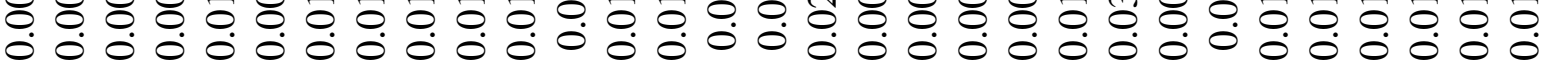

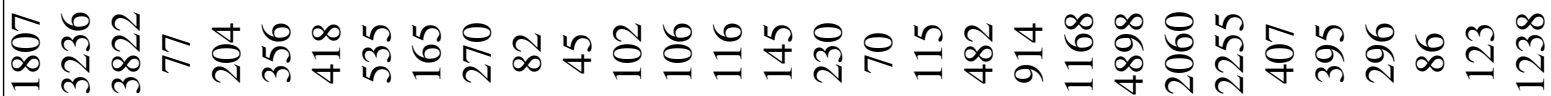

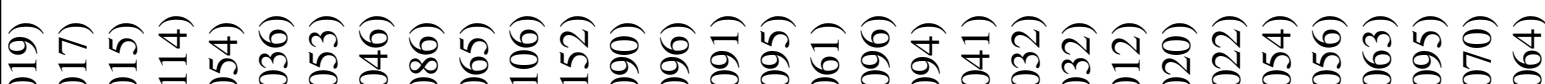

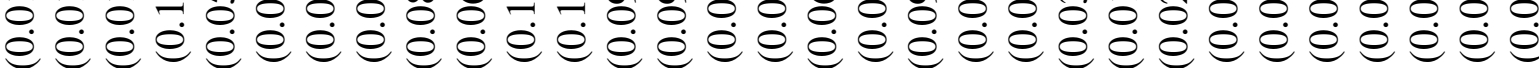
츙

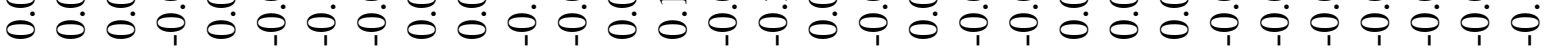

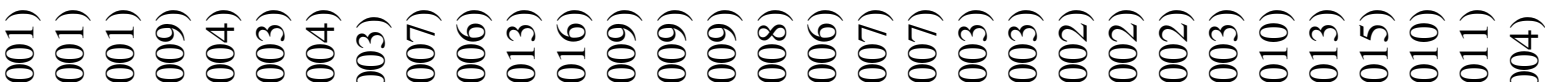

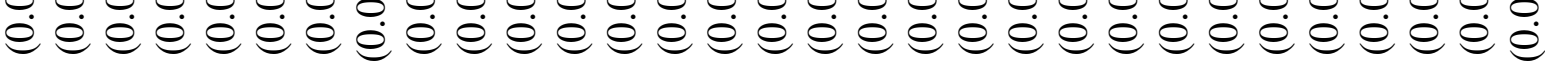

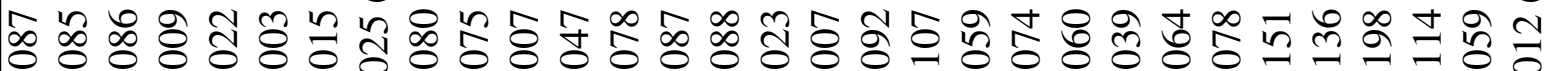

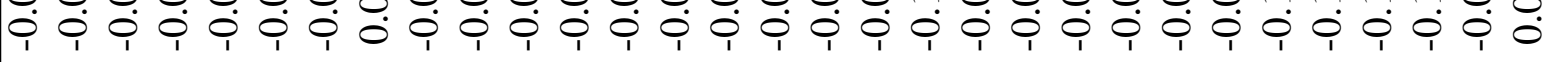

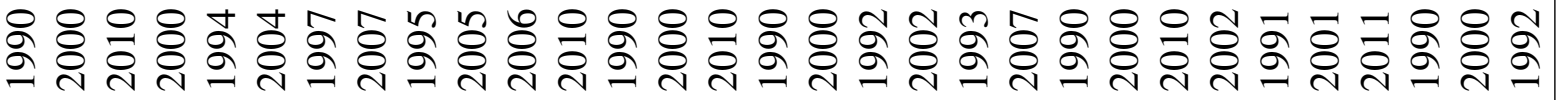

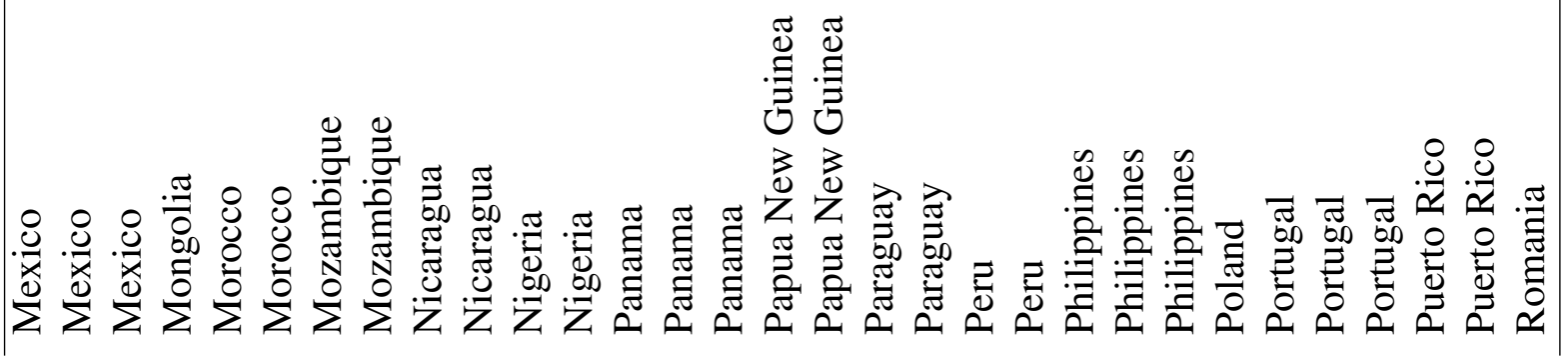


药

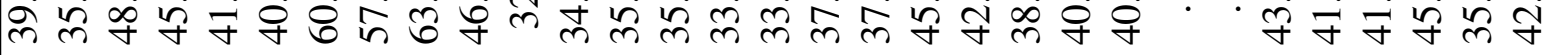

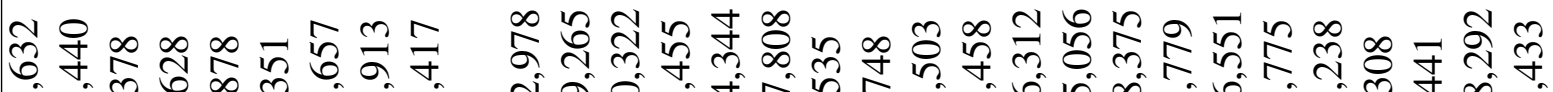

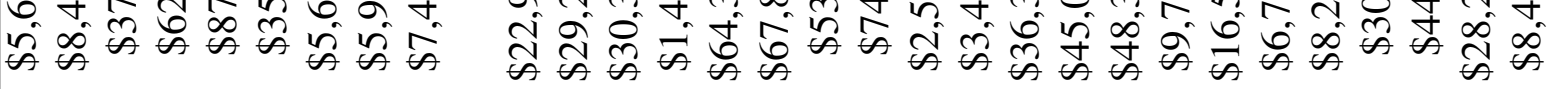

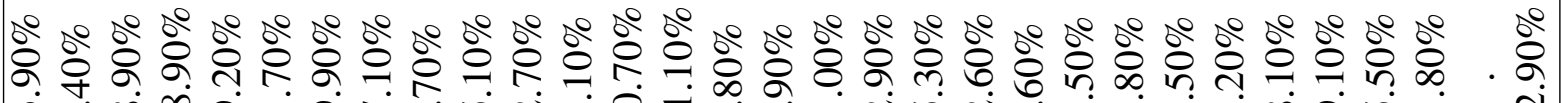

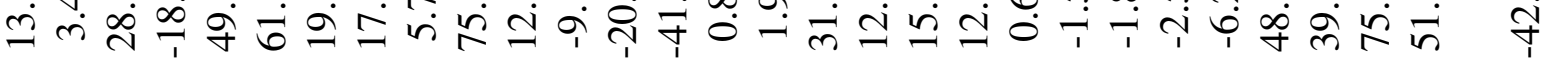



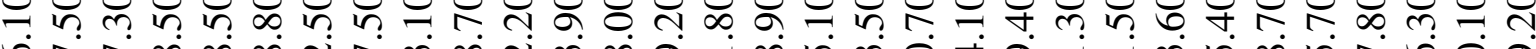

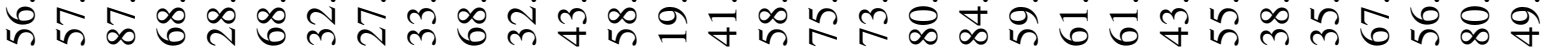

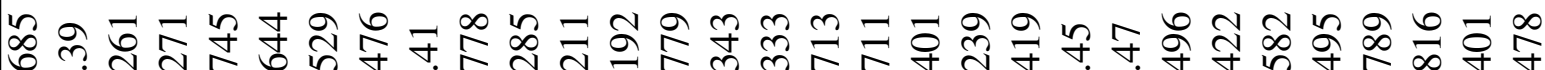

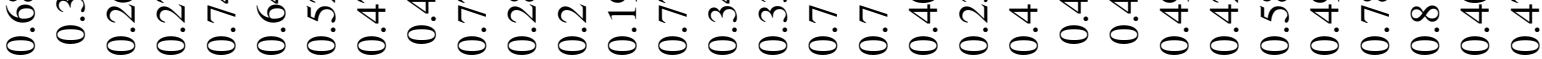
ㅎㅇㅇㅇㅇㅇㅎㅇ

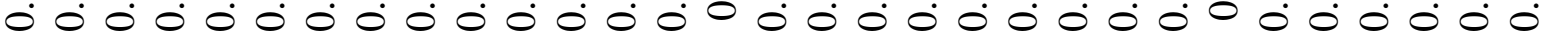

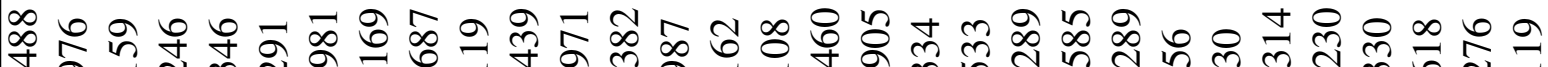
立

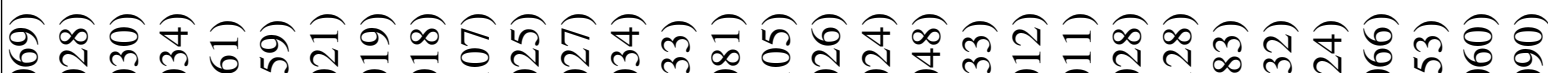
○ 궁


0ิ

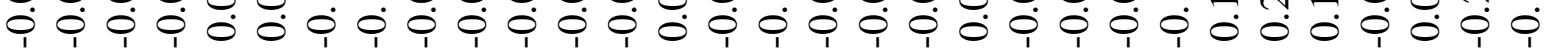

สิศิ์

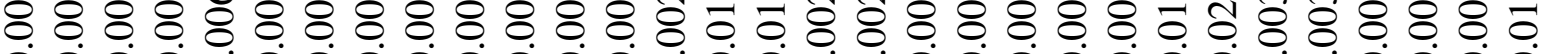

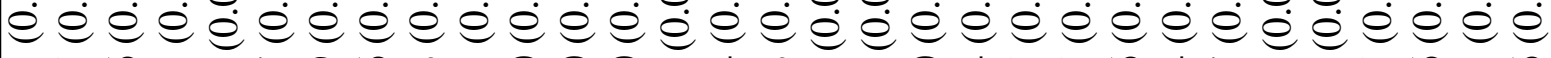
그의 ب

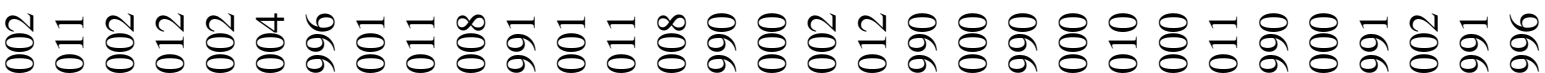

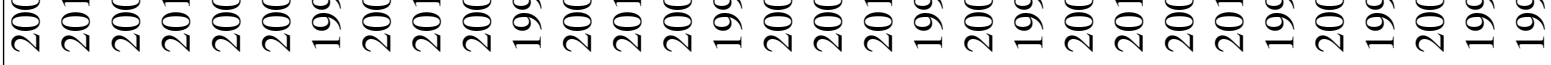

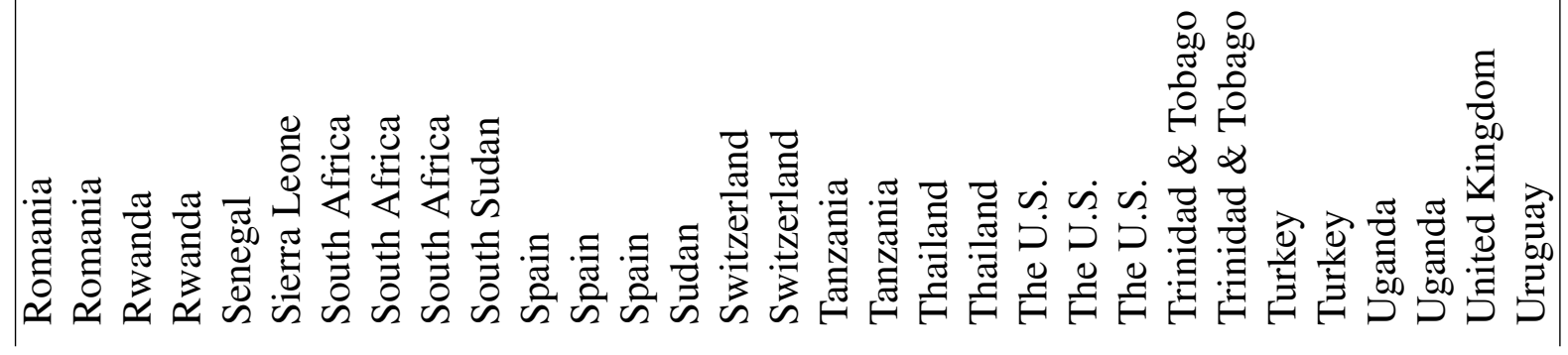




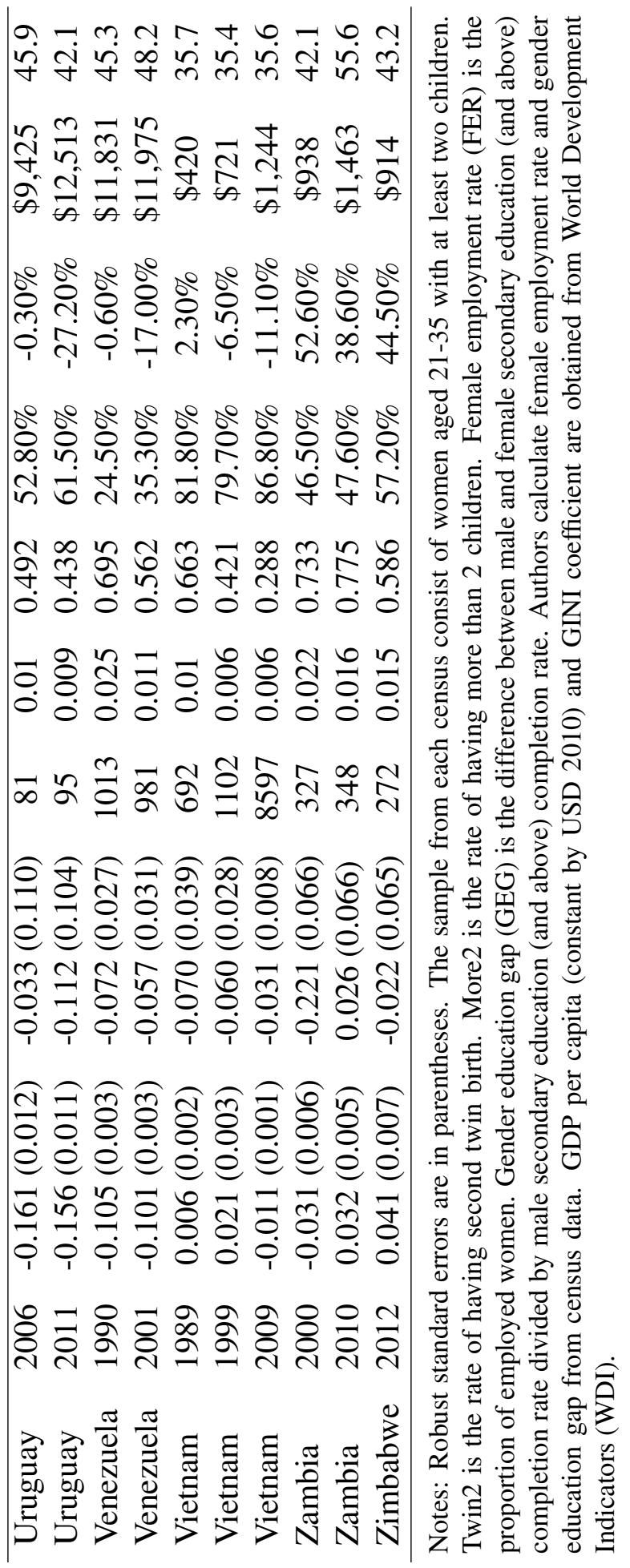




\section{CHAPTER 3. ARE STUDENTS' GOALS, GRADES AND FIGHTS INFLUENCED BY FRIDAY NIGHT LIGHTS?}

\subsection{Introduction}

Sports may benefit athletes' cognitive function and improve their noncognitive skills such as self-discipline, teamwork, and leadership. A mature literature has demonstrated the beneficial effects that participation of organized sports has on young athletes (Barron et al., 2000; Cuffe et al., 2017; Eide and Ronan, 2001; Lipscomb, 2007; Persico et al., 2004; Pfeifer and Cornelißen, 2010; Rees and Sabia, 2010; Stevenson, 2010). However, the party culture surrounding popular sports presents the possibility of negative consequences for students. In three recent papers, researchers employing plausible specifications to retrieve causal evidences on the impact that high profile college sports have on the wider student body (Hernández-Julián and Rotthoff, 2014; Lindo et al., 2012, 2018). These papers document that football team success decreases academic performance and increases the prevalence of sexual assault among collegiate students.

The negative effects of greater sports success on student spectators and positive effects on athletes themselves present a troubling trade-off for provisioning and promoting school athletics. Given the concerns raised about popular sports on college campuses, worried parents and principals may wonder whether similar dynamics exist within high schools. Motivated by the literature considering the effects of athletic success on academic achievement and antisocial behaviour, we expand what is known by investigating how greater varsity football success affects 
high school students. ${ }^{1}$ In particular, we aim to explore the effect of athletic success on various broader aspects of students at school including university aspiration, academic performance, and antisocial behaviour.

Using school fixed effects models applied to a panel of more than 15,000 U.S. high schools merged with schools' annual varsity team football win-loss records, we estimate the effects of a team's success on the student body's average university aspiration, objective academic achievement, prevalence of antisocial behaviour. Specifically, we use school-level data from the Civil Rights Data Collection (CRDC) in the 2009-2017 academic years. We consider a set of measures for these school-wide academic outcomes including: a) university aspirations (SAT/ACT test taking, advanced placement (AP) course enrolment); b) academic performances (AP test and Algebra I pass rates, grade 12 retention); c) antisocial behaviours (chronic absenteeism, suspension, expulsion, sex-based bullying and harassment, referral to law enforcement and school-related arrest). One advantage of our school-level data is that we can generalize the effects of athletic success for across the whole public high school population in the U.S., rather than for a subgroup of the population (e.g. one school in (Hernández-Julián and Rotthoff, 2014; Lindo et al., 2012)). This likely improves the external validity of our study.

To our knowledge, the only study using CRDC data to examine the association between interscholastic sports and student outcomes is Veliz and Shakib (2014). Using an universal sample of high schools in the U.S, they are the first to propose that a school's sports participation rate is positively correlated with AP math, AP science, AP foreign language, and overall AP enrolment rates. However, the authors' analysis is limited to the 2009-10 school year and the study does not deal with the endogeneity between athletics participation rates and AP course

\footnotetext{
${ }^{1}$ Though there are sports rising in popularity such as basketball or soccer, football still reigns supreme in states with the most high school athletes. In the 2018-19 academic year, 11-man football players account for more than 22 percent of male athletes in the U.S. As reported in High School Athletics Participation Survey 2018-19 of National Federation of State High School Associations (NFHS), there are 1,006,013 boys that played football in 201819 - virtually double the number that participated in outdoor track and field $(605,354)$ or basketball $(540,769)$, and greater than baseball $(482,740)$ and soccer $(459,077)$ combined. https://www.nfhs.org/media/1020412/2018-19_ participation_survey.pdf
} 
enrolment rates. The correlation between interscholastic sports participation and AP course enrolment presented in Veliz and Shakib (2014) likely suffers many confounding factors. For example, students in high schools close to a big university with stellar athletic teams might be more motivated to participate in athletics and enrol in AP courses. Building on previous work of Lindo et al. (2012), we use the team's winning percentage in the same academic year as a measure of high school athletic success. We leverage the within-school variation in a varsity football team's winning percentage to identify the effects of athletic success on school-wide outcomes.

Contrary to the case of college campuses, our research finds no negative effects of team success on the high school student body; academic performance does not decline, antisocial behaviour does not rise. Our analysis yields three main findings. First, greater sports success increases the rate of male high school students taking the SAT/ACT and enrolling in AP coursework. On average, the estimates suggest that a one-standard-deviation increase in the winning percentage increases the rate of SAT/ACT test taking and enrolment in AP courses by 0.18 and 0.14 percentage-points respectively. We only find statistically significant effects of athletic success on the outcomes of male students but not for female students. Second, aspiration does not necessarily translate into actual achievement, and academic outcomes such as pass rates for AP and Algebra I tests remain largely the same, despite greater enrolment in AP courses. Finally, sports success does not appear to increase the antisocial behaviour for both male and female students. Most of the estimates for antisocial behaviours exhibit negative signs though generally not precisely estimated. The estimates suggest that a one-standard-deviation increase in a team's winning reduces by 0.08 percentage-points the suspension rate of male students.

As in the existing literature, we also consider the effects of athletic success on withinschool gender differences in the outcomes. These reflect the effects of athletic success on malefemale outcome gaps. Taking within-school differences by gender and estimating the relative effect of athletic success on student outcomes allow us to alleviate some sources of endogene- 
ity like measurement errors or little school-year heterogeneity that school fixed effects cannot always account for. Our estimates for the relative effects are quantitatively similar to separate estimates for boys but more precisely estimated. There are positive effects of athletic success on university aspirations, but no effects on academic performance. The estimates suggest that an increase by one standard deviation in a team's winnings increases on average the rate of boys taking the SAT/ACT test and enrolling in AP courses by 0.17 and 0.14 percentage-points respectively relative to girls. ${ }^{2}$ For antisocial behaviour, a one-standard-deviation increase in team's winning percentage reduces the rate of boys subjected to suspension and disciplined for sex-based bullying and harassment by 0.05 and 0.01 percentage-points respectively relative to girls. Further analysis generates evidence that all of the estimate magnitudes are persistent when we control for leading and lagged effects of athletic success. So our main results are not likely explained by the endogeneity of confounding trends. Besides, the positive effects of athletic success on university aspirations are not offset by declines in surrounding years.

Given the nature of school level data, we do not know explicitly whether the estimated effect of athletic success on higher-education aspiration is driven by athletes or non-athletes. However, we find a particular negative association between the effect size and school size. The size of the football team is largely constant regardless of school size. Larger impacts of sport success on smaller schools (with larger proportion of male football athletes) would suggest that our results are probably driven by student athletes. In reality, the predicted non-linear relationship between the treatment effect on school-level outcomes and student body size closely matches our estimates, suggesting that athletes are the salient sub-population. Our findings are consistent with the literature on the motivational effects of athletic participation on students. To the extent of such mechanisms in this literature, sports can help to accumulate human capital.

\footnotetext{
${ }^{2}$ The findings relate to the broad literature on gender gap in academic achievement (David and Melanie, 2013; Figlio et al., 2016; Hernández-Julián and Rotthoff, 2014; Holmlund and Sund, 2008; Lavy, 2008; Lindo et al., 2012). For instance, in this literature, boys are documented to benefit less from financial incentives and peer effects, but experience gender bias from teachers or schools more often than girls. This might explain why boys are falling behind girls in academic achievement.
} 
Teenagers perform better in high school (Barron et al., 2000; Cabane et al., 2016; Eide and Ronan, 2001; Felfe et al., 2016; Knaus et al., 2020; Lipscomb, 2007; Rees and Sabia, 2010; Schultz, 2017; Stevenson, 2010), are less truant (Cuffe et al., 2017), have better health (Cabane et al., 2016; Felfe et al., 2016; Lechner, 2009), improve social outcomes (Clarke and Ayres, 2014; Felfe et al., 2016; Knaus et al., 2020; Lechner, 2009), and experience better labour market outcomes (Barron et al., 2000; Eide and Ronan, 2001; Ewing, 2007; Lechner, 2009; Lechner and Downward, 2017; Lechner and Sari, 2015; Rooth, 2011; Stevenson, 2010) as a result of being an athlete. ${ }^{3}$ Since SAT/ACT test taking and AP courses should predict the demand for college enrolment, our paper contributes to the existing literature on the effects of athletic success and participation by documenting beneficial impacts on students' academic aspirations. Greater university participation may be an important channel through which high school sports leads to better long-term outcomes. ${ }^{4}$

The paper proceeds as follows: The next section summarizes the literature on the impacts of athletic success on collegiate students. Section 3.3 describes data used in our analysis. Section 3.4 provides the baseline identification strategy. Section 3.5 presents the estimated effects of athletic success and discusses further empirical considerations. Section 3.6 draws conclusions.

\footnotetext{
${ }^{3}$ Avoiding the main confounder from the self-selection into athletic participation, these studies claim the causal effects of being athletes. Some plausible specifications for identifying causality include the instrumental variable strategy (e.g. using the height of student, school and peer characteristics, or family background as an IV) (Barron et al., 2000; Eide and Ronan, 2001; Pfeifer and Cornelißen, 2010; Rees and Sabia, 2010); the natural experiment (Title IX regulations) (Stevenson, 2010); or the individual fixed-effects model (Cuffe et al., 2017; Lipscomb, 2007; Rees and Sabia, 2010).

${ }^{4}$ There are other potential mechanisms established in the literature to explain the effects of big-time sports. For example, athletics could have negative effects on academic outcomes of students by increasing the value of leisure time and decreasing academic effort (Clotfelter, 2019; Lindo et al., 2012; Metcalfe et al., 2019), but have positive effects on a school's reputation by an increase in the advertised effectiveness, and thus attract stronger students (Anderson, 2017; Mulholland et al., 2014; Pope and Pope, 2014).
} 


\subsection{Related Literature}

Of particular relevance to this study are three papers that investigate the effects of athletic success on college campuses. First, Lindo et al. (2012) and Hernández-Julián and Rotthoff (2014) show that academic performance among non-athletes declines in years with a more successful football team. In particular, using the administrative data of University of Oregon in 1999-2007 and leveraging the time-variant winning percentage of its football team to examine the variation in the academic performance (GPA), Lindo et al. (2012) suggest that an increase in football teams winning from 0 to 1 reduces GPAs of male students by 1.4 percent. The latent mechanism is shown to be that boys are more likely to exhibit behavioural issues in response to sports success than girls (e.g. drinking alcohol, partying, decreasing studying). Besides, the practice of strict grade curving may cover up damaging effects of athletic success on female students. However, Hernández-Julián and Rotthoff (2014) revisit Lindo et al. (2012) using undergraduate student-level data at Clemson University in 1982-2002, and find a contrary phenomenon that the academic performance of female students deteriorates more than males due to big-time sports. On average, an increase in teams winning from 0 to 1 decreases the grades of females by 1.0 percent. More concerning, Lindo et al. (2018) report greater incidence of rape involving college-age victims and assailants that coincides with Division 1 college football schedules. Using panel data from the 1991-2012 National Incident-Based Reporting System, Lindo et al. (2018) presents a reduced-form analysis on the effects of partying associated with football games on the incidence of rape. Their findings suggest a 28-percent increase in reports of rape victimization from college-aged (17-24) women on game days.

The literature on the impacts of sports on spectators generally documents that student fans experience more behavioural issues but engage in less studying around game day. For example, sports spectatorship often results in increases in alcohol consumption and partying (Glassman et al., 2007; Neal and Fromme, 2007), increases in arrests for alcohol-related offences and assaults (Rees and Schnepel, 2009), and increase in the level of interest in sports 
and decrease in academic endeavours (Clotfelter, 2019; Metcalfe et al., 2019). Despite strongly statistical evidences provided, these studies may observe intertemporal effects of sports events. It is possible that the effects of big time sports on academic and behavioural outcomes might evidence merely a substitution effect around the timing of sports games, e.g., the time spent on watching games takes away time for studying which is made up on subsequent days. Also, the intertemporal effect of game day on drinking or crime may reflect the concentration effect of partying.

Within the literature documenting the effects of athletics, there are also papers that find positive impacts of success on teams' institutions. The effects of athletic success on schools can be interpreted as positive advertising effects. For example, using a propensity score design applied to school-level data from several sources in 1986-2009, Anderson (2017) finds that the winning of teams in the Football Bowl Subdivision (FBS) increases donations, applications, academic reputation, and in-state enrolment. Pope and Pope (2014) use administrative data from the College Board's Test Takers Database in 1994-2001, and find that schools where basketball or football teams play in the final tournament get an increase of 6-8 percent in SAT scores received on average. Employing data from the U.S. News and World Report's annual guide to nominate America's Best Colleges in 1999-2010, Mulholland et al. (2014) find that FBS teams' success is associated with greater assessment scores by faculty and administrators from other peer institutions. 


\subsection{Data}

To investigate the response of students to athletic success, we use data from the Civil Rights Data Collection (CRDC), a mandatory biennial survey of public high schools in the U.S. ${ }^{5}$ We use data from the five latest waves spanning from 2009-10 to 2017-18 school years, ${ }^{6}$ because earlier years lack our key outcome variables, and because they do not neatly overlap with academic years. ${ }^{7}$ The data collected by school-year allows us to consider the response to big-time sports of high school students for an entire academic year. (Appendix Figure A3.1 describes the timeframe for the 2015-16 CRDC survey and high school football season.) The 2009-10 CRDC is a sample of approximately 7,000 school districts and over 72,000 schools, with more than 16,000 public high schools. The CRDC data between years 2011-12 and 2017-18 include more than 95,000 public schools with about 24,000 public high schools. This represents more than 99 percent of all school districts and public schools in the U.S. ${ }^{8}$ Since we employ the football team's winning percentage to measure athletic success, we restrict our sample to schools that offer interscholastic athletic programs. Although the interscholastic athletics involve the competition at any education level, such competition at the elementary and middle school are very rare with only roughly 0.5 percent of schools offering interscholastic athletics in the CRDC

\footnotetext{
${ }^{5}$ Data is issued by the U.S. Department of Education Office for Civil Rights (OCR). https://ocrdata.ed.gov/.

${ }^{6}$ The total duration of CRDC includes 8 waves of the survey year: 2000, 2004, 2006, 2009-10, 2011-12, 201314, 2015-16, and 2017-18. The first three waves of data, 2000-2006, lack information about outcomes regarding university aspiration, academic performance, and antisocial behaviour (e.g. the 2000-2006 CRDC do not contain the information about the number of students participating in SAT/ACT tests, students passing Algebra I, students retained in Grade 12, students subjected to suspension or discipline for engaging in bullying and harassment on the basis of sex).

${ }^{7}$ For example, in CRDC data 2015-16, schools report the number of students who enrol in AP courses at any time during the 2015-16 academic year; but the timeframe of CRDC data 2006 covers the calendar year, and thus it gives the cumulative number of students enrolling in AP courses in the entire year of 2006.

${ }^{8}$ Public high schools include long-term secure juvenile justice facilities, charter schools, alternative schools, and schools serving students with disabilities. In our analysis, the results are still robust when we drop alternative schools where high school sports are likely quite different in terms of participation, size, and scope.
} 
data. $^{9}$ We use a sample of public high schools offering grades 9-12 and interscholastic sports from CRDC. The final longitudinal sample consist of 72,883 school-year observations with more than 10,000 schools in the 2009-10 CRDC data and more than 15,000 schools in each biennial year from 2011-12 to 2017-18.

As outcomes, we take from the CRDC a set of measures for university aspiration, academic performance, and the prevalence of antisocial behaviour. First, to measure university aspirations, we use the SAT/ACT test participation rate and the AP course enrolment rate. ${ }^{10}$ The number of SAT/ACT participation rate is the number of students in grades 9-12 who take the SAT test, the ACT Test, or both, regardless of receiving valid scores on the tests divided by total enrolments. The AP course enrolment rate refers to the number of students in grades 9-12 who enrol in at least one AP course over the number of enrolments.

Second, to evaluate academic performances we use AP exam pass rate, and Algebra I pass rate and the retention rate of students in grade 12. The AP exam pass rate provides the number of students in grades 9-12 who achieve a qualifying score on an AP exam to enrol in the next level course at university divided by student enrolments. ${ }^{11}$ This information is only available for schools reporting greater than zero student participation in AP exams. The Algebra I exam pass rate indicates the number of students who pass Algebra I only in grades 9-12 over the number of enrolments. ${ }^{12}$ The grade 12 retention rate gives the cumulative number of students

\footnotetext{
${ }^{9}$ Inter-school athletic competition is often operated at the high school level. In particular, the National Federation of State High School Associations (NFHS) is the institution that oversees most high school sports activities. In the corresponding inter-college level, the National Collegiate Athletic Association (NCAA), the National Association of Intercollegiate Athletics (NAIA) and the National Junior College Athletic Association (NJCAA) govern almost all intercollegiate sports activities in the U.S.

${ }^{10}$ The denominator of outcome variables is the number of enrolments, an unduplicated count of students who enrol on a single date between September 27 and December 31 each year. The CRDC data have information about the number of enrolments by gender and ethnicity. We drop very few schools with missing data on enrolments. Appendix Table A3.1 provides more detailed definitions of variables used in our analysis.

${ }^{11}$ Students who earn AP exam scores of 3, 4, or 5, equivalent to a college course score of "middle C" or above, are considered to be qualified to receive college credit and/or placement into advanced courses. Exams are graded by external evaluators. Awarding of college credit is determined by each college or university.

${ }^{12}$ Students who pass Algebra I in middle school do not need to enrol in Algebra I in high school.
} 
who must repeat grade 12 because they do not accumulate enough credits to be promoted prior to the beginning of the following school year over total enrolments.

Third, for antisocial behaviours, we use the chronic absenteeism rate, suspension rate, expulsion rate, discipline for bullying on the basis of sex rate, and referral to law enforcement and arrest rate. The chronic absenteeism rate is the sum of excused and unexcused absences; it gives the number of students who are chronically absent 15 or more school days during the school year for any reason over student enrolments. ${ }^{13}$ In the CRDC, schools report the number of students receiving one or more in-school suspensions, only one out-of-school suspension, and more than one out-of-school suspension separately. For antisocial behaviours, we focus on the out-of-school suspension during which time students are not allowed to attend their normal school environment. The suspension rate gives the annual number of students without disabilities receiving one or more than one out-of-school suspensions over total enrolments. ${ }^{14}$ Next, we define an expelled student as a student without disabilities receiving an expulsion. ${ }^{15}$ The expulsion rate is the total number of students without disabilities receiving an expulsion divided by the total number of enrolments. The bullying on the basis of sex rate provides the number of students who are disciplined because of engaging in harassment or bullying on the basis of sex over total enrolments. Both male and female students can be victims of harassment or bullying on the basis of sex, and the harasser or bully and the victim can be of the same sex. Data includes alleged victims in grades 9-12 reported by a responsible school employee like a teacher

\footnotetext{
${ }^{13}$ In particular, a student is absent if he or she is not physically on school grounds nor participating in instruction or instruction-related activities at an approved off-grounds location for the school day.

${ }^{14}$ Students receiving an out-of-school suspension are temporarily removed from his or her regular school to home or behaviour centre for at least half a day but less than the remainder of the school year (schools may provide educational services like home instruction or tutoring). Students receiving in-school suspension remain in their schools under the supervision of school personnel.

${ }^{15}$ The local educational agency expels a student from his or her regular school for the remainder of the school year or longer. Students may receive home instruction or tutoring; or be transferred to an alternative school or regular school. In addition, our measures includes students expelled under zero tolerance policies (a policy imposed to those who commit serious offenses such as offenses involving guns, weapons, or violence).
} 
or school administrator. ${ }^{16}$ The referral to law enforcement and arrest rate is the cumulative sum of the number of students referred to a law enforcement agency or official, or a school-related arrest over the number of enrolments. ${ }^{17}$

We match the longitudinal data from CRDC to varsity football team win-loss records collected from MaxPreps by each school year. ${ }^{18}$ The varsity team, made up of students in grades 11 and 12, represents a school playing against other schools. ${ }^{19}$ Table 3.1 provides summary characteristics of data used in our analysis. On average, boys underperform in academics relative to girls, have lower university aspiration, more behavioural and disciplinary issues in our sample. Male SAT/ACT test participation and AP course enrolment rates are roughly 17.8 and 13.6 percent respectively, compared with 21.1 and 18.1 percent of female students. In terms of academic performance, the pass rates in AP and Algebra I of male students are 4.4 and 14.4 percent respectively, compared with 5.5 and 14.5 percent for females, while male retention rate in grade 12 is 1.1 percent versus 0.8 percent of females. Girls are more likely to be chronically absent; 19.8 percent of girls compared to 18.2 percent of boys. Boys are more prone to exhibit antisocial behaviours. The suspension, expulsion, sex-based bullying and harassment (it is henceforth called sex-based bullying in the tables), and referral and arrest rates of boys are 8.4, $0.6,0.4$, and 1.6 percent respectively, which are greater than the $4.9,0.3,0.1$, and 1.0 percent values for girls.

\footnotetext{
${ }^{16}$ CRDC defines the harassment or bullying on the basis of sex includes sexual harassment or bullying and gender-based harassment or bullying. Sexual harassment or bullying is unwelcome conduct of a sexual nature (e.g. verbal, nonverbal, or physical conduct of a sexual nature). Gender-based harassment or bullying is nonsexual intimidation or abusive behaviour (e.g. the harassment based on gender identity, gender expression, and nonconformity with gender stereotypes).

${ }^{17}$ Referral to law enforcement is an action by which a student is reported to any law enforcement agency or official for an incident that occurs on school grounds, during school-related events, or while taking school transportation. School-related arrest refers to an arrest of a student for any activity conducted on/off school grounds, or due to a referral by any school official.

${ }^{18}$ MaxPreps is a website specializing in American high school sports. https://www.maxpreps.com/national/ football.htm.

${ }^{19}$ Schools with high sport participation often separate football athletes into varsity, junior varsity, and freshman teams. Compared to varsity athletes, junior and freshman athletes are often less experienced and need time to develop their skills.
} 
To measure the concentration of low-income students within a school, we use the percentage of students eligible for free or reduced-price lunch (FRPL) under the National School Lunch Program. ${ }^{20}$ According to the U.S. Department of Education, high and mid-high poverty schools are those where more than half of the student body is eligible for FRPL. Both boys and girls from high poverty areas have lower academic aspiration, academic performance, and more reported antisocial behaviour than their counterparts from higher socioeconomic status areas, on average. (In Appendix Table A3.2, we summarize the measures of student academic aspiration, behaviour, and discipline by race and socioeconomic status.) Regarding racial heterogeneity, on average, Black and Hispanic students perform worse in academics and exhibit higher levels of behavioural and disciplinary problems at school.

\footnotetext{
${ }^{20}$ Free lunches are available to students in households with incomes at or below 130 percent of poverty, while reduced-price lunches are available to students in households with incomes from 130 to 185 percent of the federal poverty level. https://nces.ed.gov/fastfacts/display.asp?id=898.
} 
Table 3.1: Summary Statistics

\begin{tabular}{lccc}
\hline & All students & Male & Female \\
\hline Winning percentage & $0.480(0.260)$ & - & - \\
SAT/ACT test participation rate (\%) & $19.4(14.3)$ & $17.8(13.0)$ & $21.1(13.8)$ \\
AP course enrolment rate (\%) & $15.8(12.3)$ & $13.6(11.4)$ & $18.1(13.7)$ \\
AP pass rate (\%) & $5.0(6.9)$ & $4.4(6.4)$ & $5.5(7.5)$ \\
Algebra I pass rate (\%) & $14.9(10.0)$ & $14.4(8.6)$ & $14.5(8.6)$ \\
Grade 12 retention rate (\%) & $0.6(1.6)$ & $1.1(2.1)$ & $0.8(2.0)$ \\
Chronic absenteeism rate (\%) & $19.6(17.8)$ & $18.2(15.4)$ & $19.8(16.2)$ \\
Suspension rate (\%) & $6.5(8.5)$ & $8.4(9.6)$ & $4.9(7.2)$ \\
Expulsion rate (\%) & $0.4(1.9)$ & $0.6(2.4)$ & $0.3(1.5)$ \\
Sex-based bullying rate (\%) & $0.2(1.7)$ & $0.4(1.9)$ & $0.1(1.6)$ \\
Referral and arrest rate (\%) & $1.3(19.1)$ & $1.6(11.1)$ & $1.0(6.3)$ \\
Enrolments (1000s) & $0.919(0.749)$ & - & - \\
Male percentage & $0.512(0.044)$ & - & - \\
White percentage & $0.621(0.320)$ & - & - \\
Free/reduced lunch eligible percentage & $0.461(0.260)$ & - & - \\
Student to teacher ratio & $18.5(499.3)$ & - & - \\
Title I eligible school percentage & $0.627(0.483)$ & - & - \\
Special education school percentage & $0.008(0.090)$ & - & - \\
Magnet school percentage & $0.053(0.223)$ & - & - \\
Charter school percentage & $0.044(0.206)$ & - & - \\
Alternative school percentage & $0.006(0.077)$ & - & - \\
Observations & 72,883 & - & - \\
\hline
\end{tabular}

Notes: Table reports the summary characteristics of data in this study. The standard deviation is in parentheses. We collect the varsity football team's records from the website of MaxPreps. The number of students eligible to free and reduced lunch program is from Common Core of Data (CCD) of the National Center for Education Statistics (NCES). Others are from the CRDC data. The sample consists of U.S. public high schools from the 2009-10 academic year through 2017-18. The number of observations for AP course enrolment is 43,813 because there are many schools do not offer AP courses. The number of observations for AP pass is even lower of 37,731 since AP pass data are not available in the 2017 CRDC. The number of observations for chronic absenteeism is 46,040 as it is not available in the 2009 and 2011 CRDC. 


\subsection{Identification Strategy}

To retrieve the effect of athletic success on university aspiration, academic performance, and antisocial behaviour, we estimate the following reduced-form model using OLS:

$$
Y_{i t}=\alpha+\beta . \text { WinningPercentage } i t+X_{i t} \cdot \Gamma+\delta_{i}+\theta_{t}+\varepsilon_{i t}
$$

where $Y_{i t}$ represents one of the measures for university aspiration, academic performance, and antisocial behaviour in school $i$ in year $t$. WinningPercentage ${ }_{i t}$ is the ratio of wins to total games played by the varsity football team of school $i$ in the same year $t . \delta_{i}$ and $\theta_{t}$ are school and year fixed-effects. $X_{i t}$ is a vector of control variables for school $i$ in year $t$, including the percent of the student body that is male, white, eligible for free and reduced-lunch programs, the ratio of students to teachers, and indicators for different types of school: special education, magnet, charter, alternative school, and Title I eligible or not. ${ }^{21} \varepsilon_{i t}$ is the idiosyncratic error term. The estimated standard-errors account for clustering at the school level and are therefore robust to heteroskedasticity and within-school serial correlation. Using WinningPercentage $_{i t}$ as our measure of the athletic success that the student body is exposed to, the coefficient of interest $\beta$ indicates the causal effects of success on university aspiration, academic performance, and antisocial behaviour.

The fixed-effects identification strategy requires that the varsity football team's performance is not systematically correlated to unobservable school-specific factors that might explain for university aspiration, academic performance, and antisocial behaviour. In our specification, holding constant the time-invariant school heterogeneity, we leverage the within-school variation to estimate the causal effects of athletic success on school-wide academic outcomes. We focus on within-school variation rather than across-school variation in order to partial out some

\footnotetext{
${ }^{21}$ Title I is a federally funded education program. To be eligible for Title I funds, schools must have at least 40 percent of students qualify as low-income.
} 
unobservable school-specific factors that change little year-to-year and that may explain both athletic success and school-wide academic outcomes(e.g. school revenue from local property taxes). Figure 3.1 shows the distribution of the varsity football team's winning percentage after partialling out the school fixed-effects. ${ }^{22}$ We interpret the range and symmetry of the residuals as indicative that football team's winning percentage (conditional on school fixed-effects) provides a viable source of variation to identify the effect of athletic success on university aspiration, academic performance, and antisocial behaviour. ${ }^{23}$

Figure 3.1: The Distribution of Football Team's Winning Percentage after Partialling School-level Fixed-Effects

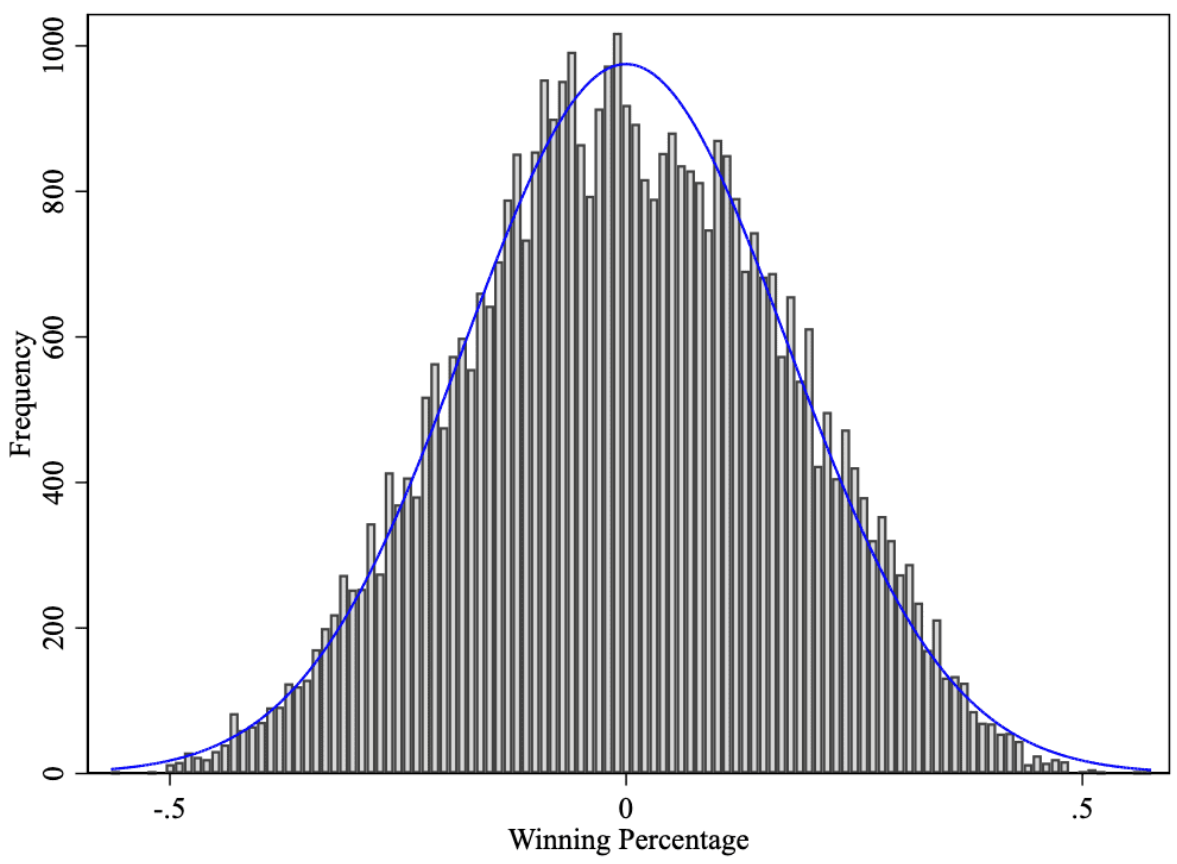

Notes: The blue line indicates the normal distribution.

\footnotetext{
${ }^{22}$ The original distribution of team's winning percentage is in Appendix Figure A3.2.

${ }^{23}$ Appendix Table A3.3 shows a multivariate regression of the football team's winning percentage on all school characteristics available, controlling for school-year fixed-effects.
} 


\subsection{Results and Discussion}

\subsubsection{Effects of Athletic Success on University Aspiration, Academic Performance, and Antisocial Behaviour}

Table 3.2 provides the OLS estimates of the effects of athletic success on university aspiration and academic performance from Equation 3.1. We find positive effects of athletic success on the SAT/ACT test participation and AP course enrolment of male students. In column 1 , the point estimate of the regression of male SAT/ACT test taking on the winning percentage is 0.685 and statistically significant at the 1 percent level. The coefficient represents about a four-percent increase over boys' average test taking rate, from Table 3.1. Winning percentage is a continuous variable from 0 to 1 and the standard deviation of winning percentage is 0.26 , so a one-standard-deviation increase in a varsity football team's winning percentage raises the SAT/ACT test taking rate of boys by 0.18 percentage-points. As the mean number of boys in a school in our sample is 471 , a football team going from winning a quarter of its games to three-quarters induces two additional boys to take the college entrance exams. Column 2 shows the point estimates of effect on AP course enrolment is 0.524 percentage-points (also approximately four percent of boys' average AP class enrolment rate) and statistically significant at the 5 percent level. On average, a one-standard-deviation increase in the football team's winning percentage raises the AP course enrolment rate of boys by 0.14 percentage-points. If a team goes from winning a quarter of games to three-quarters, it encourages one more boy to enrol in AP courses on average. The SAT/ACT test and AP courses are widely used for the admission process of tertiary institutions in the U.S. and therefore the findings strongly suggest that athletic success encourages some boys to aspire to higher education who otherwise would not.

Turning to the remaining columns, the estimated effects of athletic success on AP pass, Algebra I pass, and grade 12 retention rates of male students in Table 3.2 are not statistically 
significant at any conventional level. Academic performance does not appear to meaningfully improve alongside aspirations. While Lindo et al. (2012) and Hernández-Julián and Rotthoff (2014) estimating the effects of athletic success on GPAs face interpretative challenges due to the zero-sum nature of grading curves, it is unlikely that these effects are offset by teachers or gender heterogeneity in this study since our measures of academic performances are not curved at the school-level.

Table 3.2: Effects of Athletic Success on University Aspirations and Academic Performances

\begin{tabular}{lccccc}
\hline & $(1)$ & $(2)$ & $(3)$ & $(4)$ & $(5)$ \\
& $\begin{array}{c}\text { SAT/ACT } \\
\text { Taking }\end{array}$ & $\begin{array}{c}\text { AP } \\
\text { Enrolment }\end{array}$ & $\begin{array}{c}\text { AP Pass } \\
\text { Algebra I } \\
\text { Pass }\end{array}$ & $\begin{array}{c}\text { Grade 12 } \\
\text { Retention }\end{array}$ \\
\hline Boys & & & & & \\
Winning percentage & $0.685^{* * *}$ & $0.524^{* *}$ & 0.047 & -0.270 & -0.007 \\
& $(0.238)$ & $(0.226)$ & $(0.169)$ & $(0.170)$ & $(0.030)$ \\
Girls & & & & & \\
Winning percentage & 0.045 & -0.016 & 0.081 & -0.045 & 0.007 \\
& $(0.263)$ & $(0.273)$ & $(0.196)$ & $(0.169)$ & $(0.027)$ \\
& & & & & \\
Observations & 72,883 & 43,813 & 37,731 & 72,883 & 72,883 \\
\hline
\end{tabular}

Notes: Winning percentage is a continuous variable from 0 to 1 . The standard errors are clustered at the school level and are in parentheses. ${ }^{* * *} p<0.01, * * p<0.05, * p<0.10$.

In Table 3.3, we consider athletic success' effects on various forms of antisocial behaviour, including rates of chronic absenteeism, suspension, expulsion, sex-based bullying and harassment, and referral to law enforcement and school-related arrest. Column 2 of Table 3.3 suggests a negative effect of athletic success on suspension of male students, which implies a reduction of antisocial behaviour. The point estimate is 0.294 and statistically significant at the 10 percent level. A one-standard-deviation increase in the winning percentage reduces the suspension rate by 0.08 percentage-points on average. Importantly, null results in Tables 3.2 and 3.3 disconfirm a rise in antisocial behaviour and an academic decline found on college campuses 
when the team of a popular sport does well (Hernández-Julián and Rotthoff, 2014; Lindo et al., 2012, 2018).

Table 3.3: Effects of Athletic Success on Antisocial Behaviours

\begin{tabular}{lccccc}
\hline & $\begin{array}{c}(1) \\
\text { Chronic } \\
\text { Absenteeism }\end{array}$ & $\begin{array}{c}(2) \\
\text { Suspension }\end{array}$ & $\begin{array}{c}(3) \\
\text { Expulsion }\end{array}$ & $\begin{array}{c}(4) \\
\text { Sex-based } \\
\text { bullying }\end{array}$ & $\begin{array}{c}(5) \\
\text { Referral } \\
\text { \& Arrest }\end{array}$ \\
\hline Boys & & & & & \\
Winning percentage & 0.216 & $-0.294^{*}$ & -0.014 & -0.038 & 0.128 \\
& $(0.511)$ & $(0.154)$ & $(0.051)$ & $(0.049)$ & $(0.135)$ \\
Girls & & & & & \\
Winning percentage & 0.222 & -0.112 & -0.024 & -0.001 & 0.158 \\
& $(0.553)$ & $(0.107)$ & $(0.032)$ & $(0.045)$ & $(0.138)$ \\
Observations & 46,040 & 72,883 & 72,883 & 72,883 & 72,883 \\
\hline
\end{tabular}

Notes: Winning percentage is a continuous variable from 0 to 1 . The standard errors are clustered at the school level and are in parentheses. ${ }^{* * *} p<0.01,{ }^{* *} p<0.05, * p<0.10$.

None of the estimated effects of athletic success on female students are statistically significant at conventional levels. In terms of university aspiration, male students are more responsive to the big-time sports than female students. In Table 3.2, the point estimates of the regression of female SAT/ACT taking and AP enrolment on the winning percentage are near zero. There are non-negative effects of athletic success on academic performances of high school girls. The estimated effects on female students in Table 3.3 show no evidence that athletic success increases antisocial behaviour. 


\subsubsection{Are Effects of Success Driven by Athletes or Non-athletes?}

Our school-level data do not allow us to directly investigate whether a team's success motivates better outcomes among the wider student body or only the athletes themselves. However, we can assemble suggestive evidence that the benefits accrue primarily to the athletes by investigating the relationship between the effect size and school size. Under the hypothesis that only athletes are affected, we would expect the estimated impacts on our outcomes (measured in rates) to decrease at a known rate as a function of male enrolment, $N$, given that varsity teams are the same size, $N^{A}$, across schools. In particular, assume the effect of sports success on the participating varsity athletes is $\beta^{A}$, and 0 for all other boys. As a consequence, the pooled effect from Equation 3.1, $\beta$, will underestimate the effect on athletes, namely: $\beta=\beta^{A} \times \frac{N^{A}}{N}$. Using point estimates for outcomes in Table 3.2, we can backout the effect on athletes substituting in the coefficient estimates for $\beta ; 53$ for the varsity team size and median male enrolment of 411 for $N .{ }^{24}$ We base this on common knowledge that there are typically 53 players on a high school football team in the U.S. In the case of SAT/ACT test taking, we could infer that an increase from 0 to 1 in winning would result in a 5.3 percentage-points $\left(0.685 \times \frac{411}{53}\right)$ increase in test taking by football players. Likewise, the same increase in wins would imply a 4.1 percentage-points $\left(0.524 \times \frac{411}{53}\right)$ increase in AP class enrolment.

From the above equation, as enrolment increases, the magnitudes of the effects on the school average, $\beta$, decline in a non-linear fashion. We can augment regression Equation 3.1 to allow the effects of success to vary by school size, and compare this to the expected decline in our estimate given by the above equation. In particular, we interact winning percentage with a quadratic in the total size of the male student body. In Figure 3.2, we plot the estimated effect of team success on SAT/ACT taking and AP enrolment against male enrolment in black. The dashed area indicates the 95 percent confidence intervals. We overlay in red the theoretical drop in $\beta$ given the estimated effects on athletes implied by Table 3.2 with the assumption that

\footnotetext{
${ }^{24}$ Appendix Figure A3.3 presents the distribution of male enrolments.
} 
non-athletes are unaffected and an average varsity team size of 53. Figure 3.2 depicts negative associations between the school size and effect size of athletic success on SAT/ACT taking and AP enrolment. It is apparent from these graphs that the evolution of the estimated effects on school outcomes agree with predicted smaller effect in large schools under the assumption that student athletes are the entire compliant sub-population. Note that this agreement was not guaranteed; it is entirely possible for the empirical estimates of the quadratic model to reveal that large schools exhibit larger effects, perhaps because of greater social buzz associated with a team from a large school doing well. We interpret this exercise as suggestive evidence that our estimates reveal that athletic success predominantly affects participating athletes, with no impact on the wider student body.

Figure 3.2: The Association Between Effect and School Size
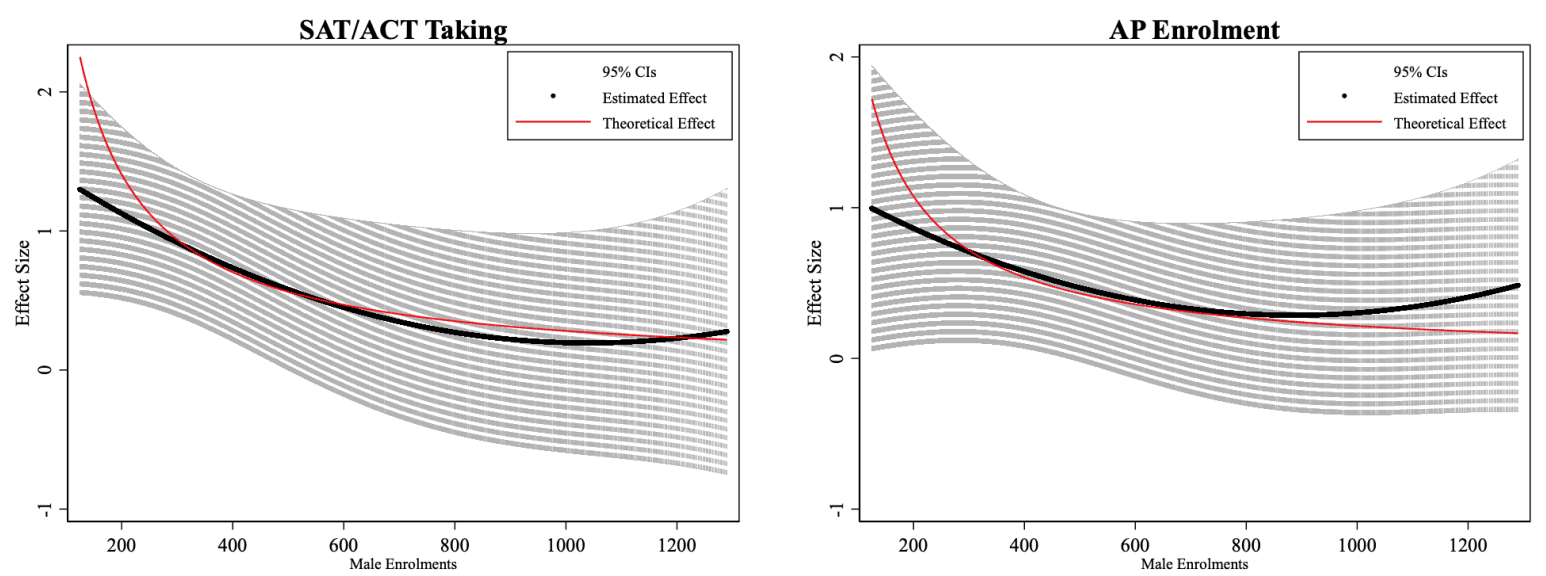

Notes: The red line represents the theoretical decline in $\beta$ given the average varsity team size of 53 and the median of male enrolments of 411. The black line indicates the estimated effect of team success on SAT/ACT taking and AP enrolment against male enrolment including the linear and quadratic school size trend, which is approximated by: $\widehat{\beta}=\widehat{\beta}_{1}+\widehat{\beta}_{2} . S i z e_{i t}+\widehat{\beta}_{3} . S i z e_{i t}^{2}$. The dashed area indicates the 95 percent confidence intervals of the estimates. In particular, we estimate the following model:

$$
\begin{gathered}
Y_{i t}=\alpha+\beta_{1} . \text { WinningPercentage }_{i t}+\beta_{2} .\left(\text { WinningPercentage }_{i t} \times \text { Size }_{i t}\right)+ \\
\beta_{3} .\left(\text { WinningPercentage }_{i t} \times \text { Size }_{i t}^{2}\right)+\beta_{4} . \text { Size }_{i t}+\beta_{5} . \text { Size }_{i t}^{2}+X_{i t} . \Gamma+\delta_{i}+\theta_{t}+\varepsilon_{i t}
\end{gathered}
$$

where $Y_{i t}$ represents outcomes for university aspirations that we find statistically significant at less than the 5 percent level of the effects of athletic success on, from estimating Equation 3.1 including: The SAT/ACT taking and AP enrolment of male students. Size $i t$ is the number of male enrolments of school $i$ in year $t$. 
In Figure 3.3, we stratify the sample by state and plot the point estimates (and their 95 percent confidence intervals) of the effect of team's winning percentage on SAT/ACT taking and AP enrolment. From right to left, we order the magnitudes of positive effects of athletic success increase. Interestingly, almost all states in red with the highest national ranking of high school football are above the horizontal reference line (the zero value). The pattern shows that positive effects of athletic success on SAT/ACT taking and AP enrolment are found in states with a reputation for highly ranked high school football. This supports the hypothesis that effects of success are likely driven by student athletes.

Figure 3.3: Effects of Athletic Success on the SAT/ACT Taking and AP Enrolment Rates of Male Students by State

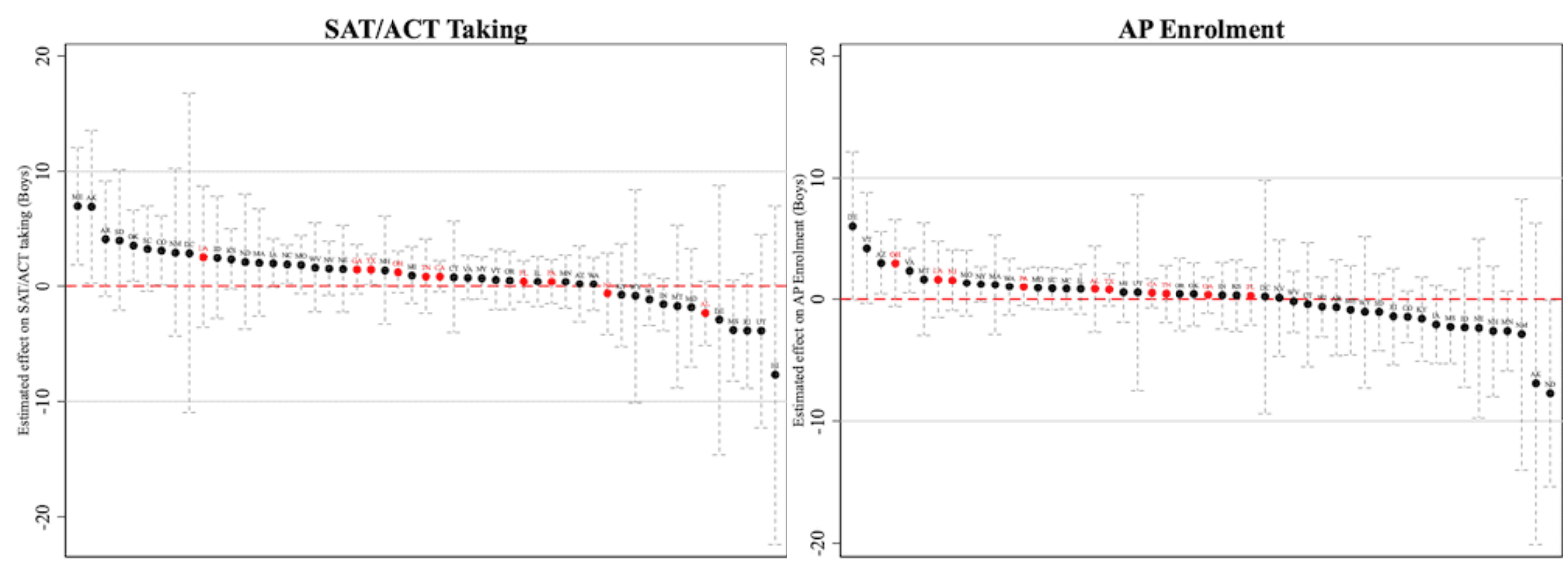

Notes: Figure shows the point estimates and their 95 percent confidence intervals from the regressions of SAT/ACT taking and AP enrolment of male students on the winning percentage by each state. High School Football America uses an algorithm to rank high school football states by the number of their teams in the Top 100. The red labels represent the ten states with highest ranking in high school football: Florida, California, Georgia, Texas, Ohio, Alabama, Pennsylvania, Louisiana, New Jersey, Tennessee. 


\subsubsection{Effects of Athletic Success on Boys Relative to Girls}

To explicitly speak to model the disproportionate response to athletic success by gender, we define the gender gap in outcomes, $\Delta Y_{i t}$, as the within-school boy-girl difference in rates. ${ }^{25}$ We estimate the following regression by OLS:

$$
\Delta Y_{i t}=\alpha+\theta . \text { WinningPercentage } i t+X_{i t} \cdot \Gamma+\delta_{i}+\theta_{t}+\varepsilon_{i t}
$$

The coefficient $\theta$ represents the effects of athletic success on university aspiration, academic performance, and antisocial behaviour of boys versus girls. The primary motivation for us to do this exercise is that estimating the effects of athletic success on boys relative to girls can address bias caused by measurement errors like data misreporting. Moreover, taking the difference between male and female outcomes and estimating the effects of athletic success on males relative to females allow us to alleviate the concern that school fixed effects cannot account for the comovement of a school's sport success and its academic outcomes. For example, schools with more funding can hire quality principals who find the time and capacity to inspire athletics and manage learning better. The boy-girl difference context can alleviate such concern that schools could become better at both education and sports.

The within-school gender differences strategy leads to precise estimates with small standard errors in Tables 3.4 and 3.5. In Table 3.4, the estimates suggest that an increase of one standard-deviation in teams winning results in a 0.17 percentage-points increase in SAT/ACT taking and 0.14 percentage-points increase in AP enrolment of boys relative to girls. Both of the estimate magnitudes of relative effects are nearly the same as those effects on boys in Table 3.2. We interpret this as a positive effect on higher-education aspirations of boys relative to girls,

\footnotetext{
${ }^{25}$ For example, the within-school gender difference in SAT/ACT test taking is defined in percentage-point terms as:

$$
\text { SAT/ACT taking gap rate }=\left(\frac{\text { SAT/ACT taking by men }}{\text { Total male enrolments }}\right)-\left(\frac{\text { SAT/ACT taking by women }}{\text { Total female enrolments }}\right)
$$
}


since the SAT/ACT tests only serve as a means of college entry, and the primary tangible benefit of enrolling in an AP course is to obtain college credits.

Table 3.4: Relative Effects of Athletic Success on University Aspirations and Academic Performances

\begin{tabular}{lccccc}
\hline & $(1)$ & $(2)$ & $(3)$ & $(4)$ & $(5)$ \\
& $\begin{array}{c}\text { SAT/ACT } \\
\text { Taking }\end{array}$ & $\begin{array}{c}\text { AP } \\
\text { Enrolment }\end{array}$ & AP Pass & $\begin{array}{c}\text { Algebra I } \\
\text { Pass }\end{array}$ & $\begin{array}{c}\text { Grade 12 } \\
\text { Retention }\end{array}$ \\
\hline Boy-Girl Differences & & & & & \\
Winning percentage & $0.640^{* * *}$ & $0.543^{* * *}$ & -0.024 & -0.187 & -0.014 \\
& $(0.129)$ & $(0.141)$ & $(0.080)$ & $(0.122)$ & $(0.021)$ \\
Observations & 72,883 & 43,813 & 37,731 & 72,883 & 72,883 \\
\hline
\end{tabular}

Notes: Winning percentage is a continuous variable from 0 to 1 . The standard errors are clustered at the school level and are in parentheses. $* * * p<0.01, * * p<0.05, * p<0.10$.

The results in Table 3.5 do not provide strong statistical evidences on effects of athletic success on antisocial behaviour. The within-school gender difference estimates can avoid the endogeneity bias from measurement error though. The suspension and sex-based bullying and harassment rates of male students reduce by 0.05 and 0.01 percentage-points respectively relative to females. Both of the estimates are statistically significant at the 10 percent level.

Table 3.5: Relative Effects of Athletic Success on Antisocial Behaviours

\begin{tabular}{lccccc}
\hline & $\begin{array}{c}(1) \\
\text { Chronic } \\
\text { Absenteeism }\end{array}$ & $\begin{array}{c}(2) \\
\text { Suspension }\end{array}$ & $\begin{array}{c}(3) \\
\text { Expulsion }\end{array}$ & $\begin{array}{c}(4) \\
\text { Sex-based } \\
\text { bullying }\end{array}$ & $\begin{array}{c}(5) \\
\text { Referral } \\
\text { \& Arrest }\end{array}$ \\
\hline Boy-Girl Differences & & & & & \\
Winning percentage & -0.005 & $-0.183^{*}$ & 0.010 & $-0.038^{*}$ & -0.030 \\
& $(0.224)$ & $(0.096)$ & $(0.032)$ & $(0.021)$ & $(0.044)$ \\
Observations & 46,040 & 72,883 & 72,883 & 72,883 & 72,883 \\
\hline
\end{tabular}

Notes: Winning percentage is a continuous variable from 0 to 1 . The standard errors are clustered at the school level and are in parentheses. ${ }^{* * *} p<0.01,{ }^{* *} p<0.05, * p<0.10$. 


\subsubsection{Robustness Checks}

We examine the persistence in the estimated effects of athletic success by including positive and negative lags for the winning percentage of football teams into Equation 3.2. Table 3.6 gives the estimated coefficients of a set of variables representing the athletic success of the school in previous years (Year (t-3), Year (t-2), and Year(t-1)), the same school year (Year $(\mathrm{t})$ ), and the following school year (Year $(\mathrm{t}+1)$ ). If the effects primarily accrue to participating senior athletes, one should not observe much effect of athletic success in other school years on school-wide outcomes this year. Since a majority of senior athletes in varsity teams graduate at the end of the year, the athletic success next year would not affect the outcomes of this year. (The descriptive timeline of football seasons and CRDC data collecting in Appendix Figure A3.1 supports our argument that athletic success during previous years should not affect schoolwide academic outcomes in present years.) In Table 3.6, we find no effect of team's winning percentage in surrounding years on the SAT/ACT taking and AP enrolment of male students. Besides, the magnitudes of the effects of a team's winning percentage in the year of success appear insensitive to the inclusion of lags, compared to estimates in Table 3.4. This implies that estimated effects of athletic success are not likely a result of leading or lagged effects, or confounding trends. Intuitively, if freshman students with high academic aspirations are more likely to enrol in the year of big-time sports, the SAT/ACT taking and AP enrolment rates then increase two years later. We do not observe any effect of athletic success in previous years, so not is likely that endogeneity from positive serial correlation biases the estimate. As before, academic performance does not respond to athletic success in the year of success, or anywhere over the five-year period. Table 3.6 also shows no offsetting detrimental effects on antisocial behaviour in the previous and following school years. The evidence lends reassuring support to the validity of our identification strategy. 


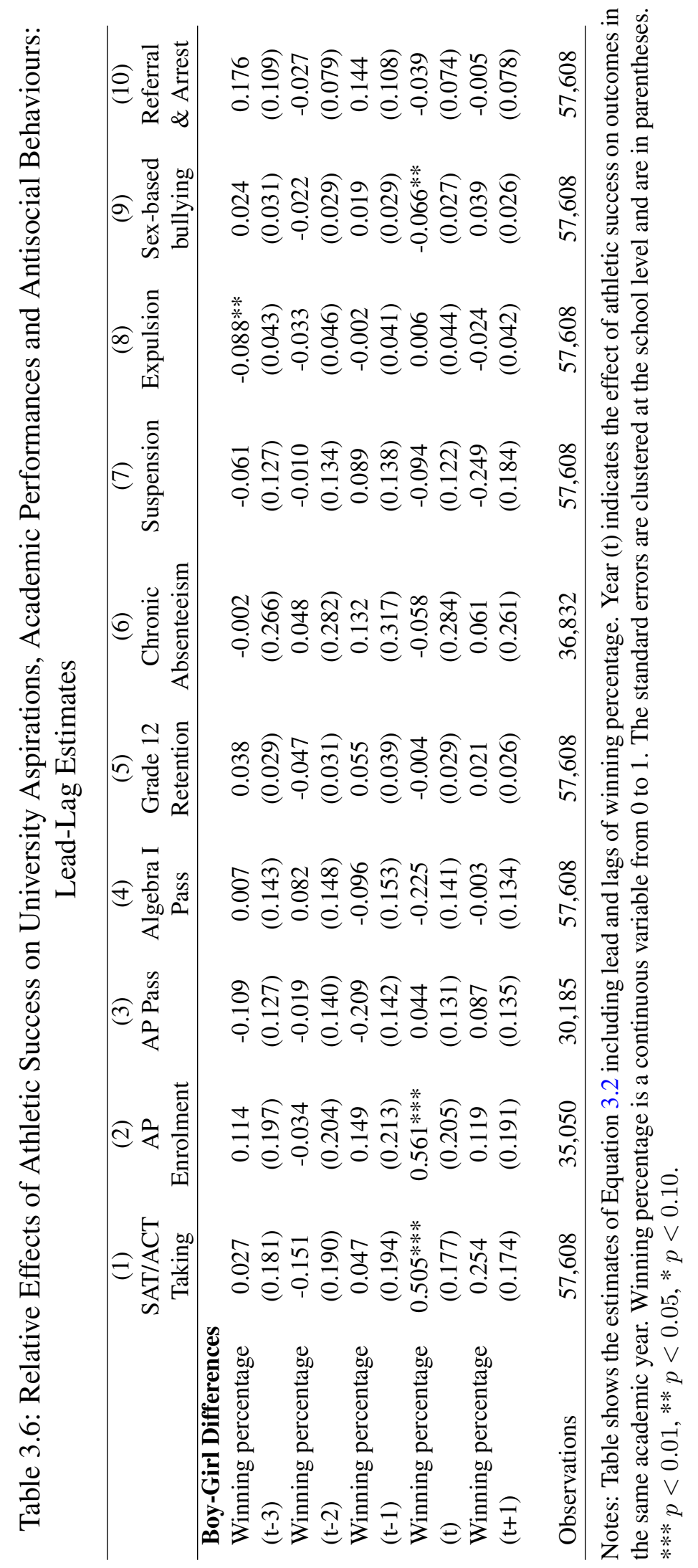


How much winning should be defined as athletic success? In our sample, the median of the football team's winning percentage is 50 percent. This is a reassuring sign that selection into the sample is not a function of winning percentage. However, estimating the average effects of athletic success may obscure heterogeneity in the effects at different points in the distribution of winning percentage. For example, there may be very little effect when a team's winning increases from 25 percent of games to 50 percent, but a huge effect of going from 50 to 75 percent. Unlike the collegiate and professional football level, a high school football game is where two teams from the same state compete against each other. In each state-year, we dichotomize the winning percentage into binary indicators denoting whether a football team is greater than the 75 th percentile of winning, greater than the 50th percentile to less than or equal to the 75 th percentile, greater than the 25 th percentile to less than or equal to the 50th percentile (less than or equal to the 25 th percentile is the omitted group). To detect the heterogeneity and possible non-linearities in the effects of athletic success on school-wide academic outcomes, we estimate the following model:

$$
\begin{gathered}
\Delta Y_{i t}=\alpha+\beta_{1} \cdot \mathbb{1}[25-50 \text { th WinningPercentile }]_{i t}+\beta_{2} \cdot \mathbb{1}[50-75 \text { th Winning } \\
\text { Percentile }]_{i t}+\beta_{3} \cdot \mathbb{1}[75-100 \text { th WinningPercentile }]_{i t}+X_{i t} \cdot \Gamma+\delta_{i}+\theta_{t}+\varepsilon_{i t}
\end{gathered}
$$

In Table 3.7, the estimates suggest that schools with football teams that above the 25th percentile of winning in that state-year experience an increase in the SAT/ACT taking and AP enrolment compared to first quartile. On average, the highest win percentage teams (winning percentage in the fourth quartile) increase SAT/ACT taking and AP enrolment by 0.49 and 036-percentagepoints compared most-losing teams (winning percentage in the first quartile). Together, the estimates point to a negative effect of being a lower performing team, and a positive effect of being a high performance team, and not much difference between teams in the middle quartiles. Much the same as the estimates using winning percentage as a continuous variable, the effects of athletic success on antisocial behaviour are not strongly statistically significant in Table 3.7. 
The chronic absenteeism rate reduces by 0.11 percentage-points with football teams in the fourth quartile and sex-based bullying and harassment rate decreases by 0.03 percentage-points with teams in the third quartile. Note that in Table 3.7, the point estimates from any column are not jointly statistically different across quartile of winning. 


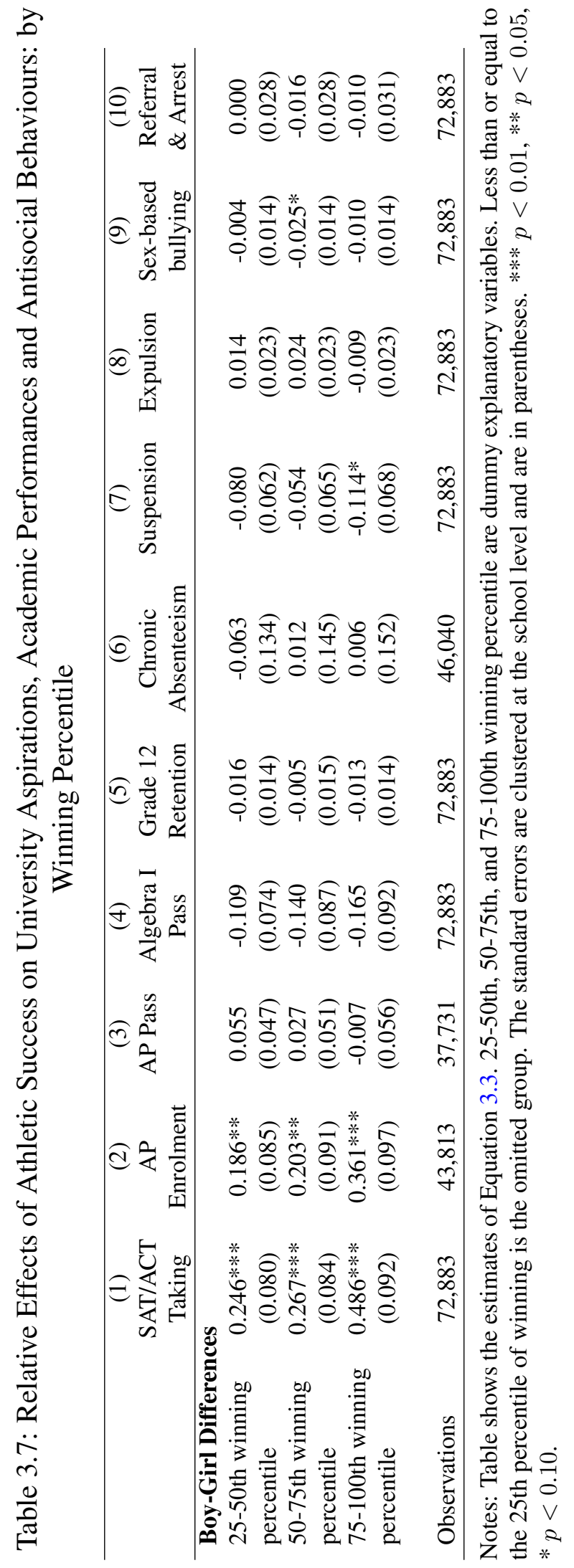




\subsubsection{Heterogenous Effects of Athletic Success}

The relevant literature documents a greater effect of athletic success on academic outcomes among socioeconomically disadvantaged, low-ability, and minority students (Lindo et al., 2012; Hernández-Julián and Rotthoff, 2014; Metcalfe et al., 2019; Pope and Pope, 2014). Theoretically, the existence of heterogeneity in the effects could stem from various sources. For example, financially disadvantaged students may be enabled by an athletic scholarship to attend higher education and therefore are more responsive to success. At the same time, students on the margin of attending college from high SES schools may have more access to AP classes, and thus, are the only ones able to respond to success through increased AP course uptake. In Table 3.8, we stratify the estimates of the effects of athletic success by socioeconomic status. The estimates show marginally greater impacts of athletic success on SAT/ACT taking and AP enrolment in high and mid-high poverty high schools. 


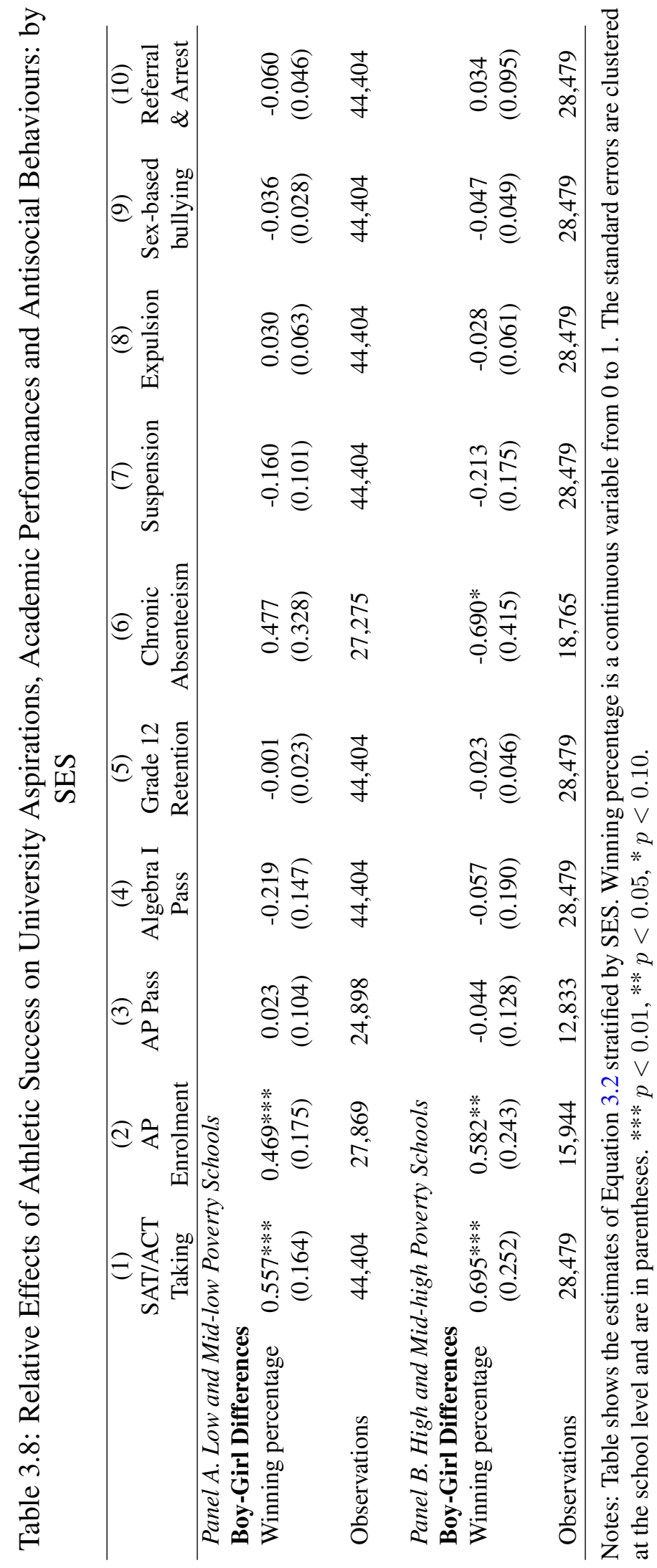


In Table 3.9, we separately estimate the effect of athletic success for Black and Hispanic students, and non-Black/Hispanic students. ${ }^{26}$ Among these different groups of students, Blacks and Hispanics are more responsive to athletic success by taking SAT/ACT tests. The estimated effect of athletic success on the SAT/ACT taking rate of Blacks and Hispanics in column 1 of Table 3.9 are quantitatively greater to the effect on non-Black/Hispanic students and the main estimates of all students in Table 3.4. The point estimates are statistically significant at below the 10 percent level. It is especially notable to observe a stronger impact of athletic success on the university aspiration of Black and Hispanic students given that they are less likely to enrol in college than Asian or White students on average. ${ }^{27}$ The lack of impacts of athletic success on AP enrolment for Blacks and Hispanics which might be explained by schools with more minority students failing to offer AP courses. The standard errors indicate lower precision estimates. In general, the results from socioeconomic and racial heterogeneity analysis are consistent with the main estimates in prior tables. There are no negative impacts of athletic success on academic performance and antisocial behaviour across any group of students.

\footnotetext{
${ }^{26}$ Data is disaggregated into five race/ethnicity categories in the 2009 CRDC (Hispanic, White, Black/AfricanAmerican, Asian/Pacific Islander, and American Indian/Alaska Native), and seven race/ethnicity categories (Hispanic/Latino, White, Black/African-American, Asian, Native Hawaiian/Other Pacific Islander, American Indian/Alaska Native, and Two or More Races) in the 2011-2017 CRDC.

${ }^{27}$ In 2016, the average college enrolment rates for Blacks and Hispanics are 36 and 39 percent, versus 42 and 58 percent for Whites and Asians respectively. https://nces.ed.gov/pubs2019/2019038.pdf.
} 


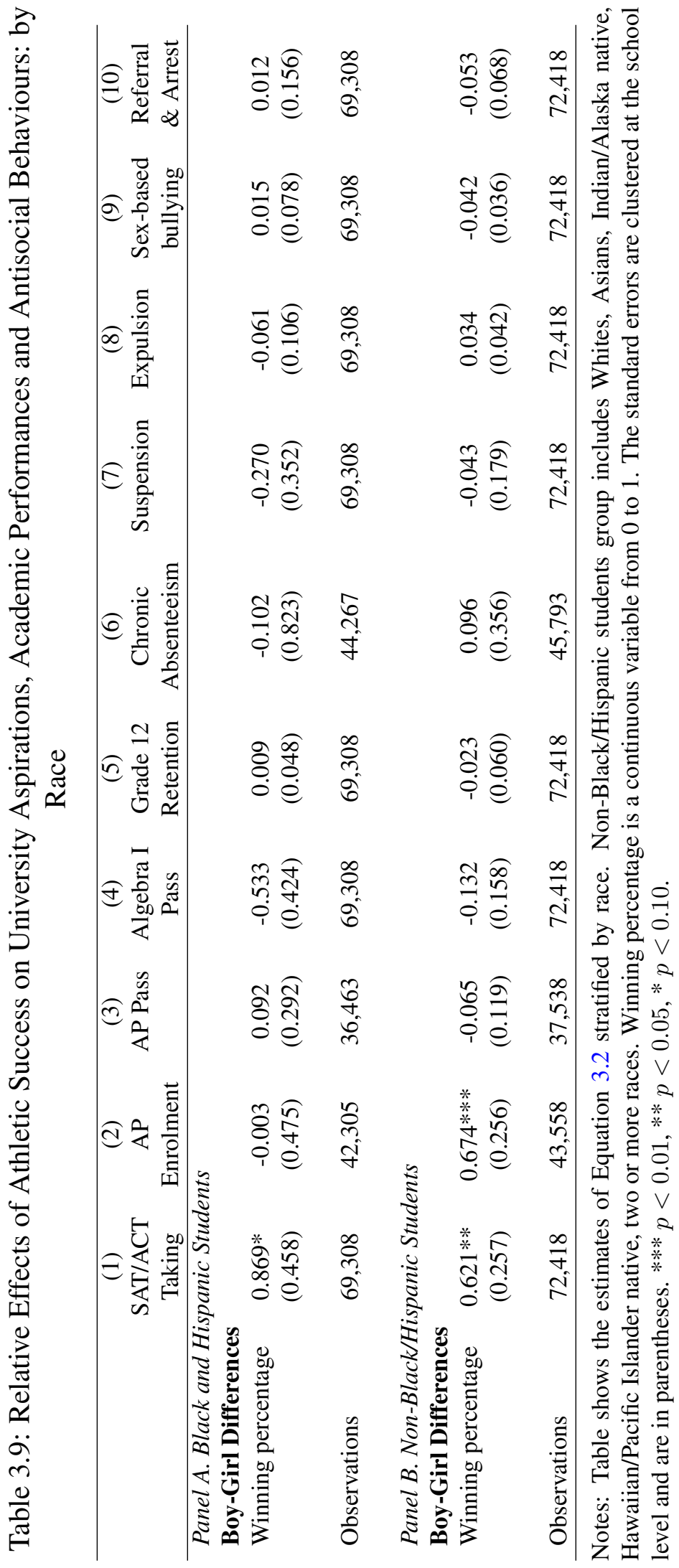




\subsection{Conclusions}

In this paper, we leverage within-school variation to estimate the causal effects of athletic success on university aspiration, academic performance, and anti-social behaviour using a panel of public high schools in the U.S. from the 2009-10 to 2017-18 academic years. We find no adverse impacts on academic performance and antisocial behaviour. The findings are particularly noteworthy given documented negative impacts of sports on college campuses in the existing literature. The lack of worrying effects of sports on academics or antisocial behaviors should reassure parents, who may wonder if the negative effects documented on college campuses extend to high schools. Indeed, high school athletics may bring beneficial impacts to some students in terms of university aspirations. We show that greater athletic success increases SAT/ACT taking and AP enrolment. These findings agree with policy-makers and principals who support more fundraising plans to promote athletic programs.

In this study, we are limited in our ability to test possible mechanisms for effects of athletic success given the school-level data (e.g. CRDC does not report the SAT/ACT taking or AP enrolment by athletes and non-athletes separately). Our analysis suggests that the effects of a team's success are most likely driven by athletes, which is consistent with the literature documenting beneficial impacts because of participating in sports. Sports participation is an investment in human capital with possible long term benefits, and may build character and improve social skills for students. Besides the drawbacks to using aggregated data, there are advantages. A representative sample of schools gives us greater confidence in the external validity of this study. Lindo et al. (2012) find a deterioration in academic performance of male students at Oregon likely because of the party culture that goes along with big-time sports, while Hernández-Julián and Rotthoff (2014) do not find a decline in academic performance of male students at Clemson because they do not change their academic and social life regardless of the football team's performance. Besides controlling for some plausible factors explaining the 
effects of success such as the gender, racial, and socioeconomic disparity in enrolment, we can rule out unobservable factors like the party and sports viewership cultures at particular schools.

Our estimates show that only male students are responsive to team success. Consequently, a better understanding of the relationship between sports success and the gender gap in education is needed. It may be that data from a wider variety of sports could reveal that female athletes respond much the same as male athletes to sports success. According to the National Women's Law Center, nearly 30 percent of 16,000 U.S. public high schools have a large gender equity gap in sports despite Title IX. ${ }^{28}$ It remains possible that gender gaps are not larger, in part, because girls do not partake in the benefits of athletics in proportion to their representation in the student body.

\footnotetext{
${ }^{28}$ The term "large gender equity gap" refers to a gap of 10 percentage-points or higher between the percentage of spots on teams allocated to girls and the percentage of female students. For example, if at School A, girls are 45 percent of all students but only get 33 percent of all the spots on teams, then School A has a gender equity gap of 12 percentage-points. https://nwlc.org/blog/girls-sports-and-equality-state-state-ranking-title-ix/.
} 


\section{Appendix}

Figure A3.1: The Timeline of 2015-16 CRDC and Football Season

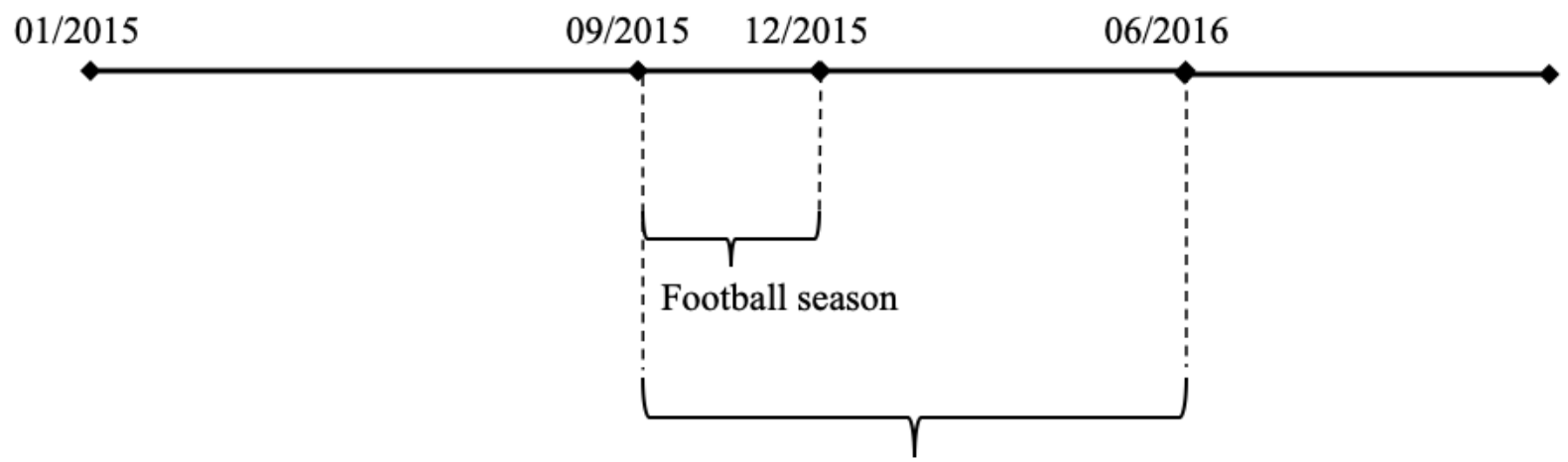

CRDC 2015-2016 data collection

Notes: The dashed lines indicate the time period of CRDC 2015-16 data collection and the regular season of high school football in the U.S. The regular season typically consists of ten games where each team play against team from same class. The first game of the season is usually in early September. At the end of the regular season, schools are ranked by their record and split up into brackets by district and classification. The top teams in each district make the elimination playoffs. Teams winning the district championship title get to play the seeds in the inter-district round and can advance the next round for area, regional, sub-state championships if they keep winning. To nominate the state and national champions sometimes the post-season round is held in late-November and December. The timeframe of CRDC 2015-16 supports our specification to explain the variation in the academic and behavioural outcomes by team's performance in the same school year. 
Figure A3.2: The Distribution of Football Team's Winning Percentage

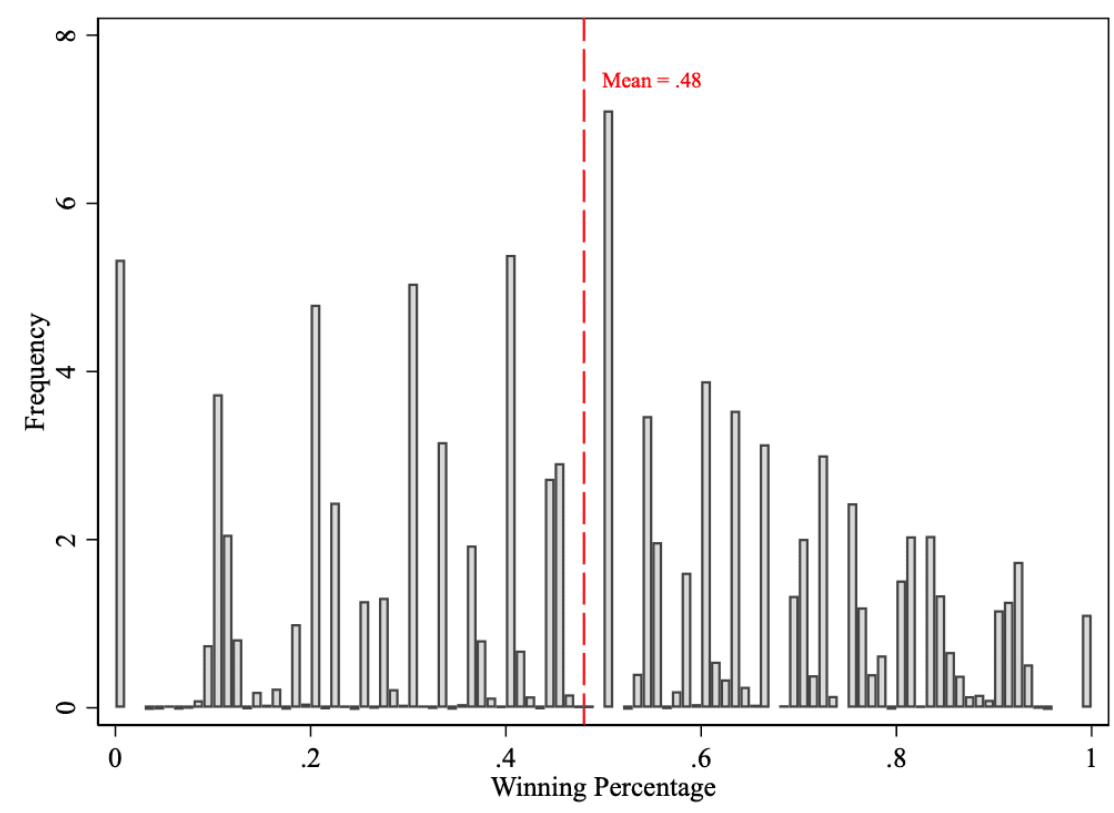

Notes: The red line indicates the mean of winning percentage.

Figure A3.3: The Distribution of Male Enrolments

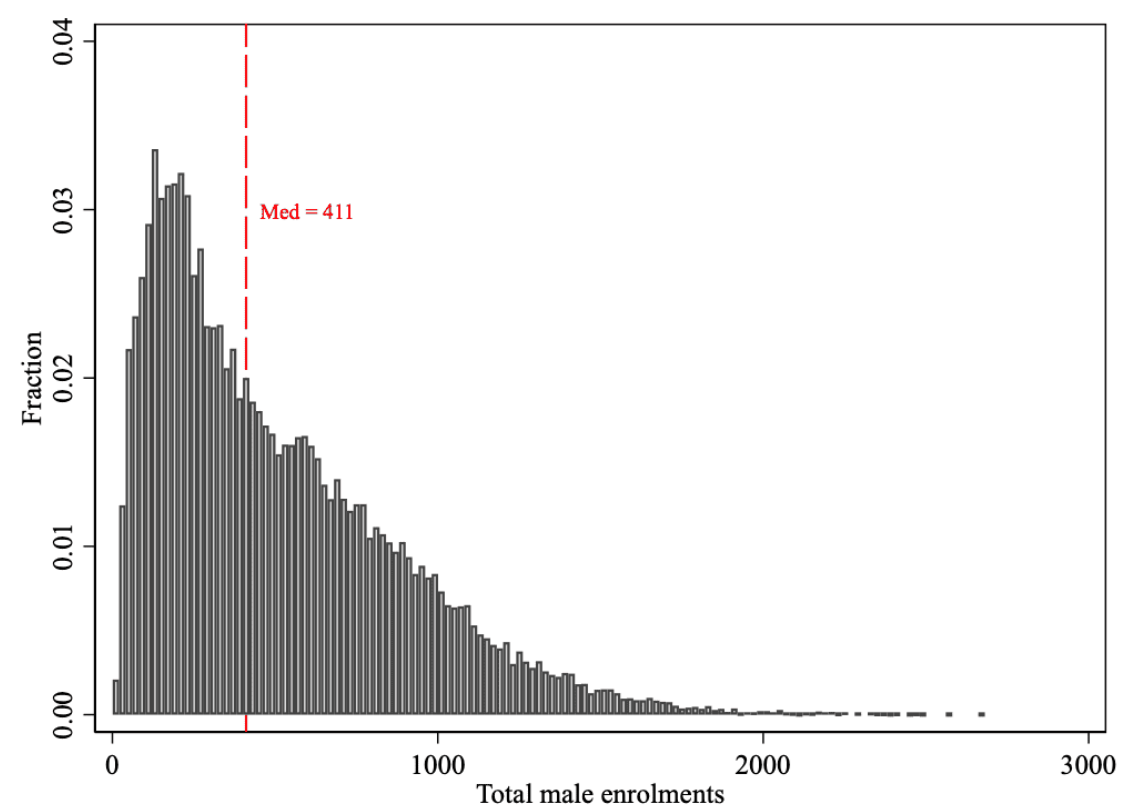

Notes: The red line indicates the median of male enrolments. 
Figure A3.4: Effects of Athletic Success on Male SAT/ACT Taking and AP Enrolment by Winning Percentile


Notes: Figure plots the estimated coefficients and their 95 percent confidence intervals from the following model:

$$
Y_{i t}=\alpha+\beta_{j} \sum_{j=1}^{9} \mathbb{1}\left[p_{i j t}\right]+X_{i t} . \Gamma+\delta_{i}+\theta_{t}+\varepsilon_{i t}
$$

where $Y_{i t}$ represents outcomes for university aspiration that we find statistically significant at less than the 5 percent level of the effects of athletic success on, from estimating Equation 3.1 including: The SAT/ACT taking and AP enrolment of male students. $p_{i j t}$ is a set of dummies for school $i$ in year $t$ that indicate each of nine categories of winning percentile, $j$, including: Greater than the 10th percentile and less than or equal to the 20th percentile, greater than the 20th percentile and less than or equal to the 30th percentile, etc. (Less than or equal to the 10th percentile is the omitted group). From left to right, the magnitudes of positive effects of winning on SAT/ACT taking and AP enrolment increase compared to the omitted group. 
Table A3.1: Variable Definition

\begin{tabular}{l} 
Variables \\
\hline Athletic Success \\
Winning percentage \\
University Aspiration \\
SAT/ACT taking rate \\
AP course enrolment rate \\
\\
Academic Performance \\
AP pass rate
\end{tabular}

Description

The ratio of wins to total games played by high school varsity football team

The total number of male or female students taking SAT/ACT test divided by the total number of male or female enrolments

The total number of male or female students enrolling in at least one AP course divided by the total number of male or female enrolments

The total number of male or female students passing at least one AP course divided by the total number of male or female enrolments

Algebra I pass rate

Grade 12 retention rate

The total number of male or female students retained in grade 12 divided by the total number of male or female enrolments

\section{Antisocial Behaviour}

Chronic absenteeism rate

The total number of chronic absenteeism of male or female students (students missing at least 15 days of school in a year) divided by the total number of male or female enrolments

Suspension rate

The total number of male or female students receiving $1+$ outof-school suspension divided by the total number of male or female enrolments

Expulsion rate

The total number of male or female students without disabilities receiving an expulsion with educational services, without educational services and under zero tolerance policies divided by the total number of male or female enrolments 
Sex-based bullying rate

Referral and arrest rate

\section{School Characteristics}

Enrolments (1000s)

Male percentage

White percentage

Free/reduced lunch eligible percentage

Student to teacher ratio

Title I eligible school

Special education school

Magnet school

Charter school

Alternative school
The total number of male or female students disciplined due to engaging in harassment or bullying on the basis of sex divided by the total number of male or female enrolments

The total number of male or female students without disabilities referred to a law enforcement agency or official and received a school-related arrest divided by the total number of male or female enrolments

Total number of student enrolments

The total number of male enrolments divided by the total enrolments

The total number of white student enrolments divided by the total enrolments

The total number of students eligible to free and reduced lunch program divided by the total enrolments

Total number of student enrolments divided by total full-time classroom teachers

1 if Title I eligible school, 0 otherwise

1 if special education school, 0 otherwise

1 if magnet school, 0 otherwise

1 if charter school, 0 otherwise

1 if alternative school, 0 otherwise 


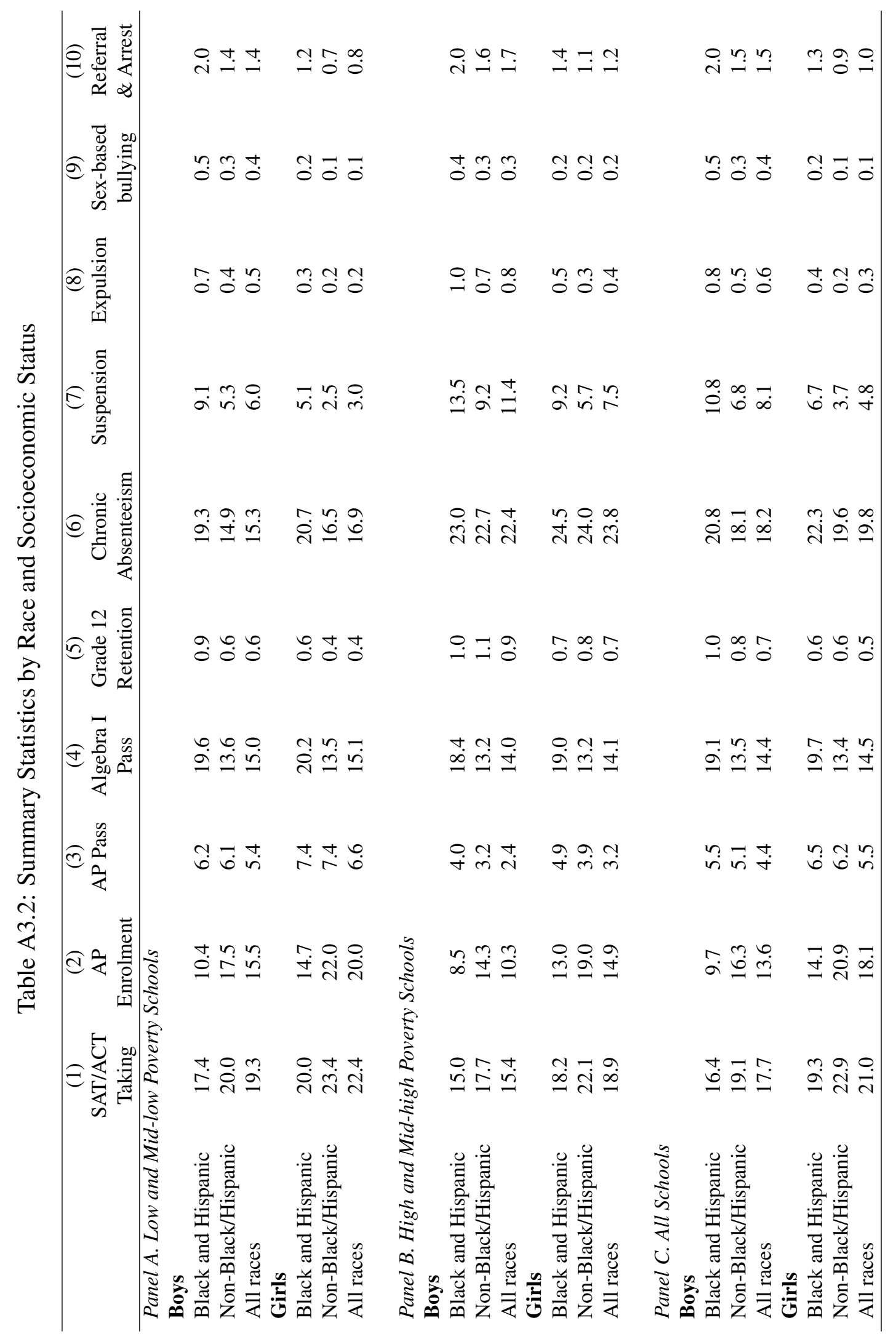


Table A3.3: The Association Between Team' Winning and School Characteristics

\begin{tabular}{lc}
\hline & Winning percentage \\
\hline Male percentage & $0.374 * * *$ \\
White percentage & $(0.051)$ \\
& 0.028 \\
Free and reduced lunch eligible percentage & $(0.039)$ \\
& -0.033 \\
Student to teacher ratio (logarithm) & $(0.016)$ \\
& -0.015 \\
Title I eligible school percentage & $(0.013)$ \\
& -0.002 \\
Special education school percentage & $(0.005)$ \\
& 0.012 \\
Magnet school percentage & $(0.014)$ \\
Charter school percentage & -0.001 \\
& $(0.009)$ \\
Alternative school percentage & -0.012 \\
& $(0.022)$ \\
R-squared & -0.043 \\
Observations & $(0.035)$ \\
School FE & \\
Year FE & 0.477 \\
\hline
\end{tabular}

Notes: Table presents a multivariate regression of the football team's winning percentage on all school characteristics available. Winning percentage is a continuous variable from 0 to 1 . Except the percentage of male students, none of these school characteristics are associated to the winning percentage. The winning percentage is positively associated to the percentage of male students. An increase in the percentage of male students implies a larger pool of potential football players and therefore easier to recruit competent ones. If the increase in the percentage of male students is driven by a drop in female enrolment and thus there is a decrease in total enrolment, the football team could play in a less competitive athletic division. In each state, there is at least one sanctioning association that operates sports competition for high schools. Each association divides member schools into two to eight size classifications (1A, 2A, 3A, 4A, 5A, 6A, $7 \mathrm{~A}, 8 \mathrm{~A}$ ) based on the number of enrolments. Schools are assured to compete against other schools in the school's same size classification, which can change if its enrolment increases or decreases over the years. Both scenarios may lead to a football team's improved performance. However, the variation in percentage of male students is arguably random by each academic year and might not account for the school-wide academic outcomes in the short run. Hence, the endogeneity is less an issue even if we do not control for the percentage of male students in the main specification. The standard errors are clustered at the school level and are in parentheses. ${ }^{* * *} p<0.01,{ }^{* *} p<0.05, * p<0.10$. 


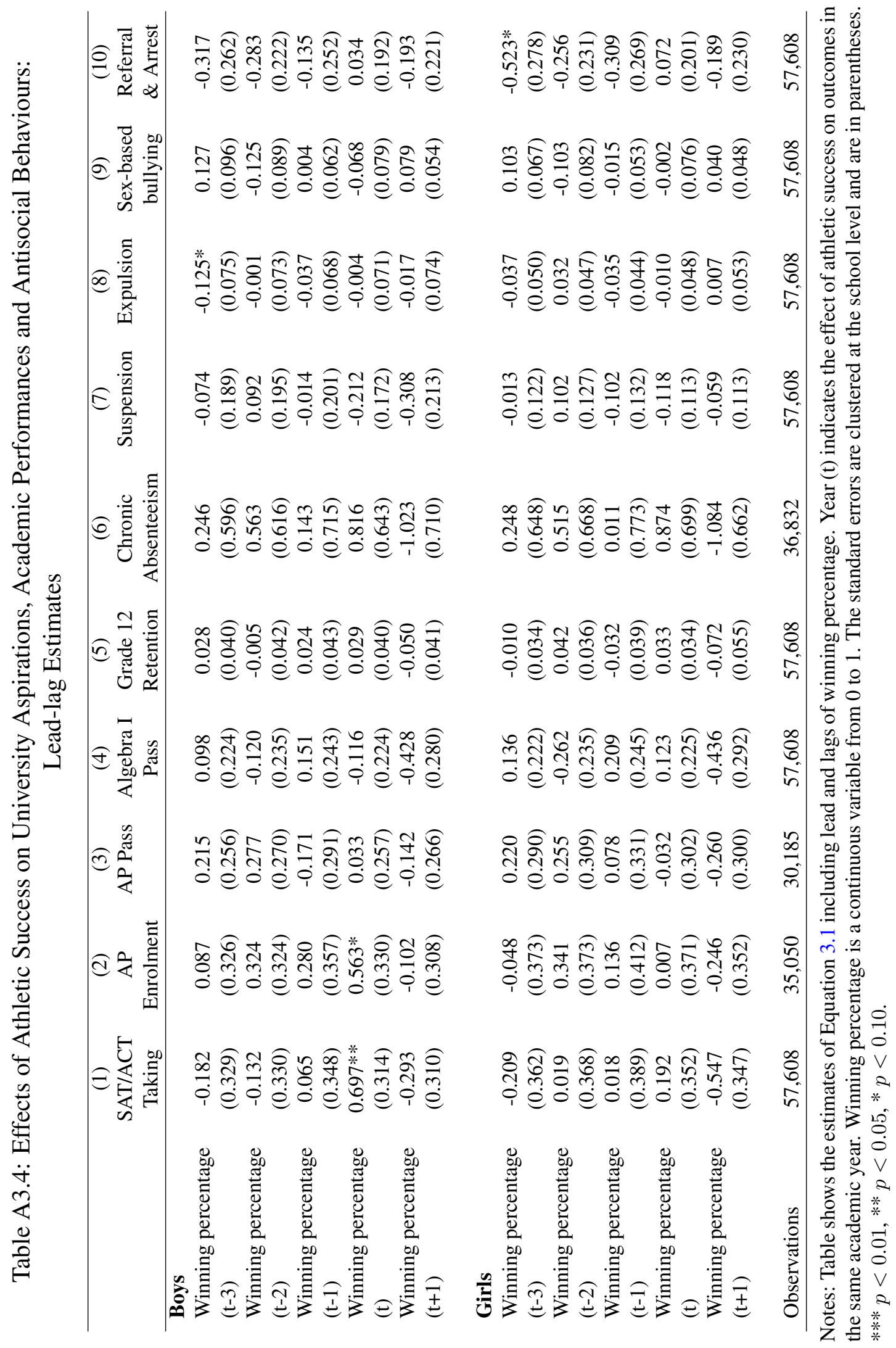




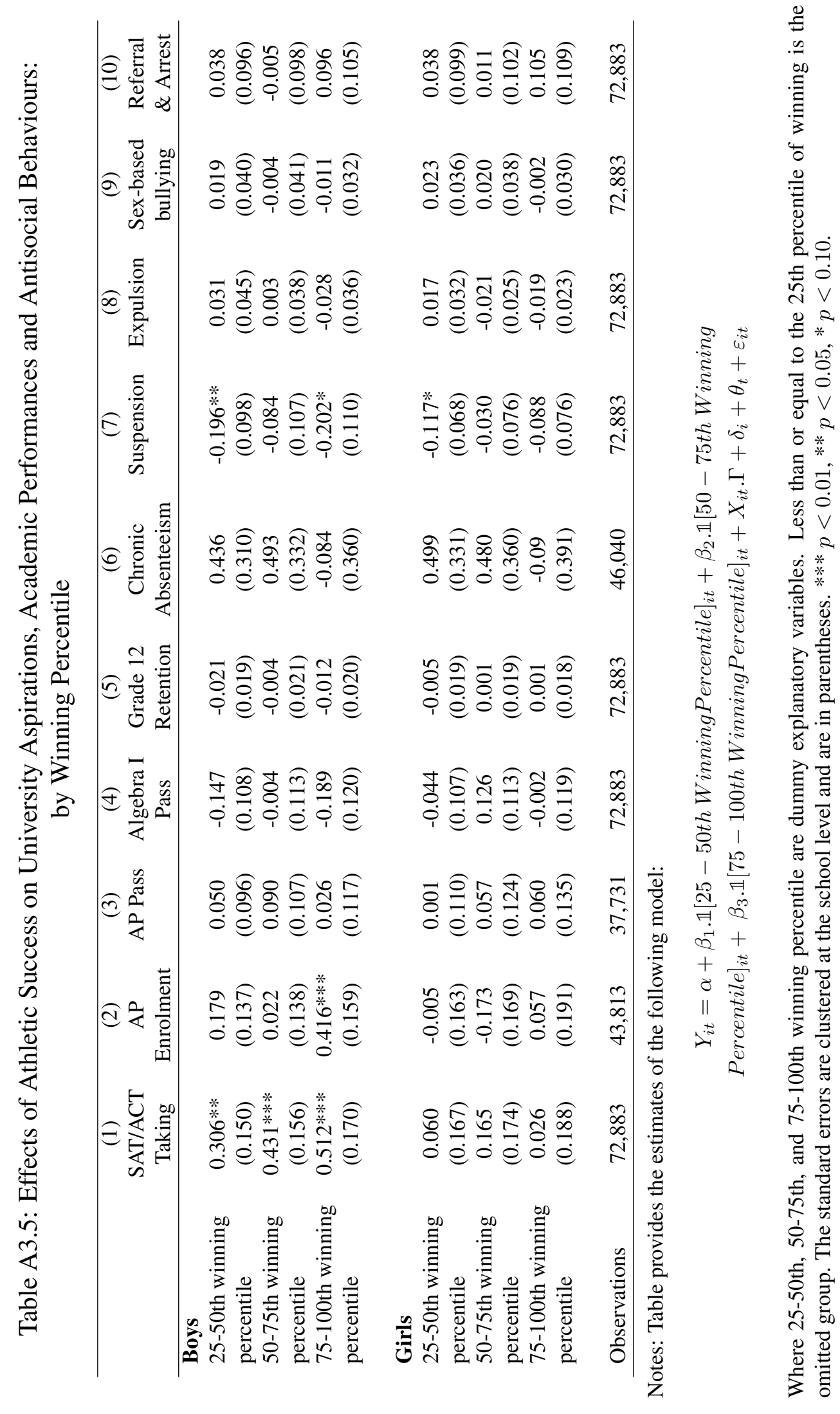




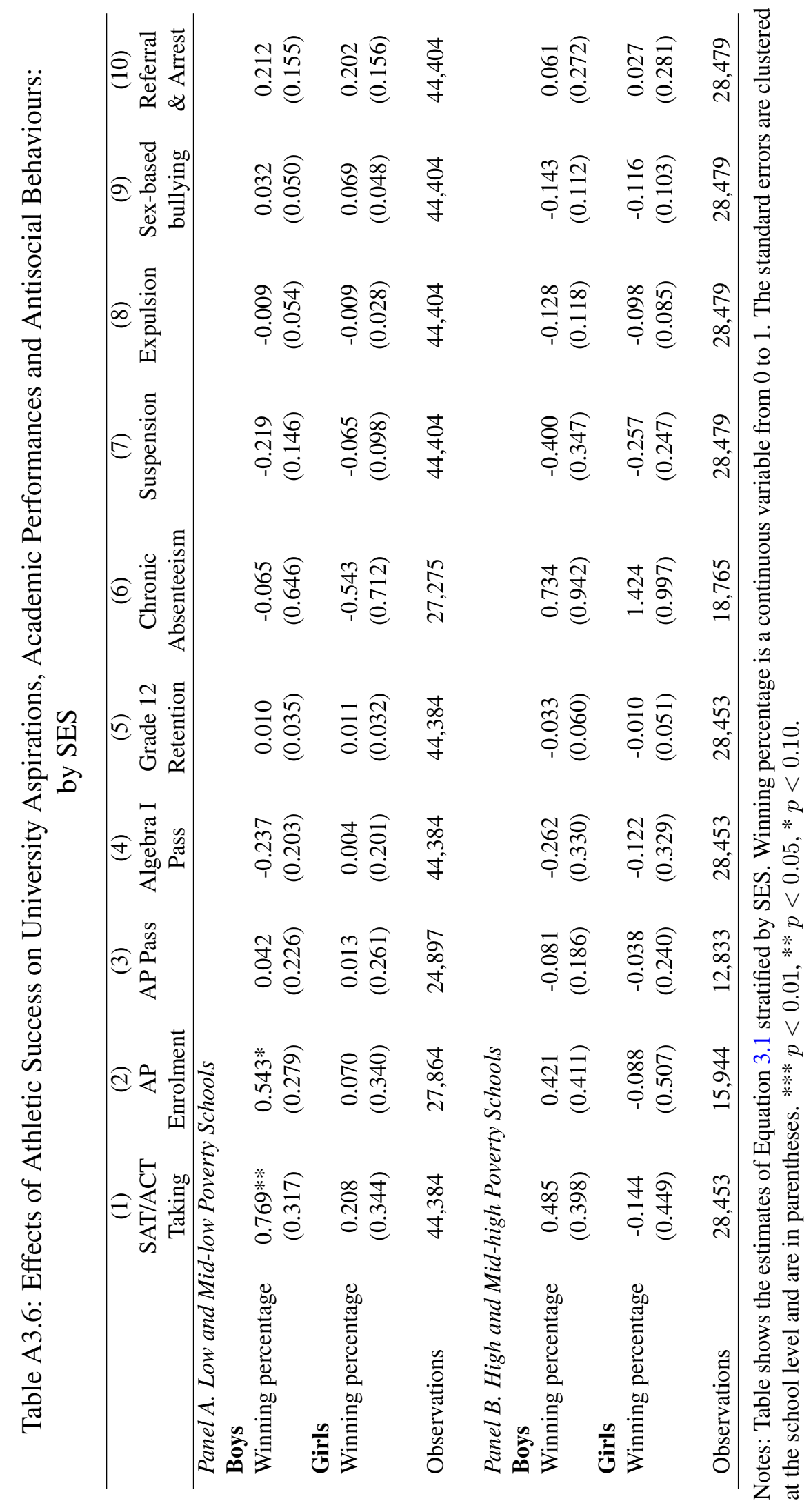




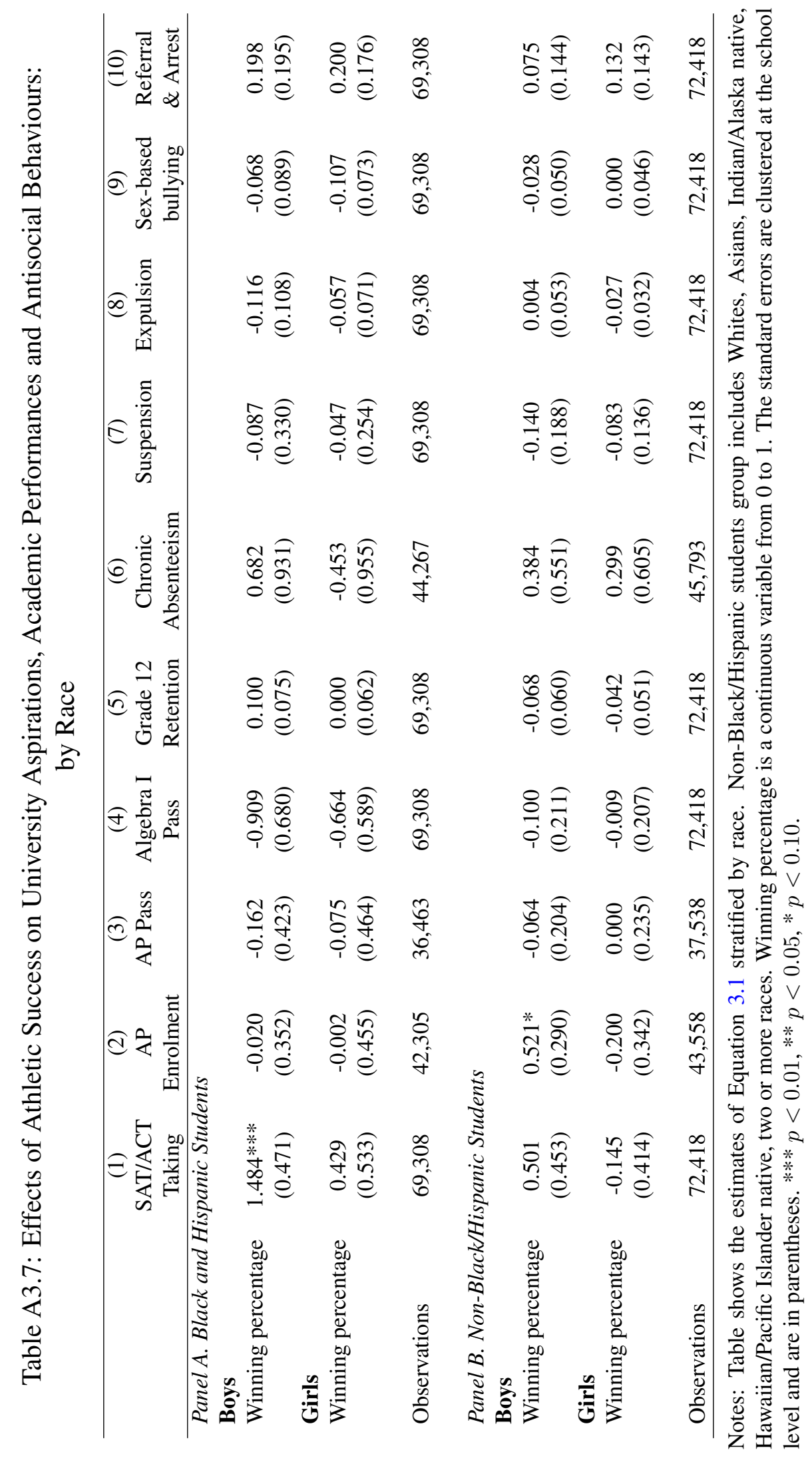




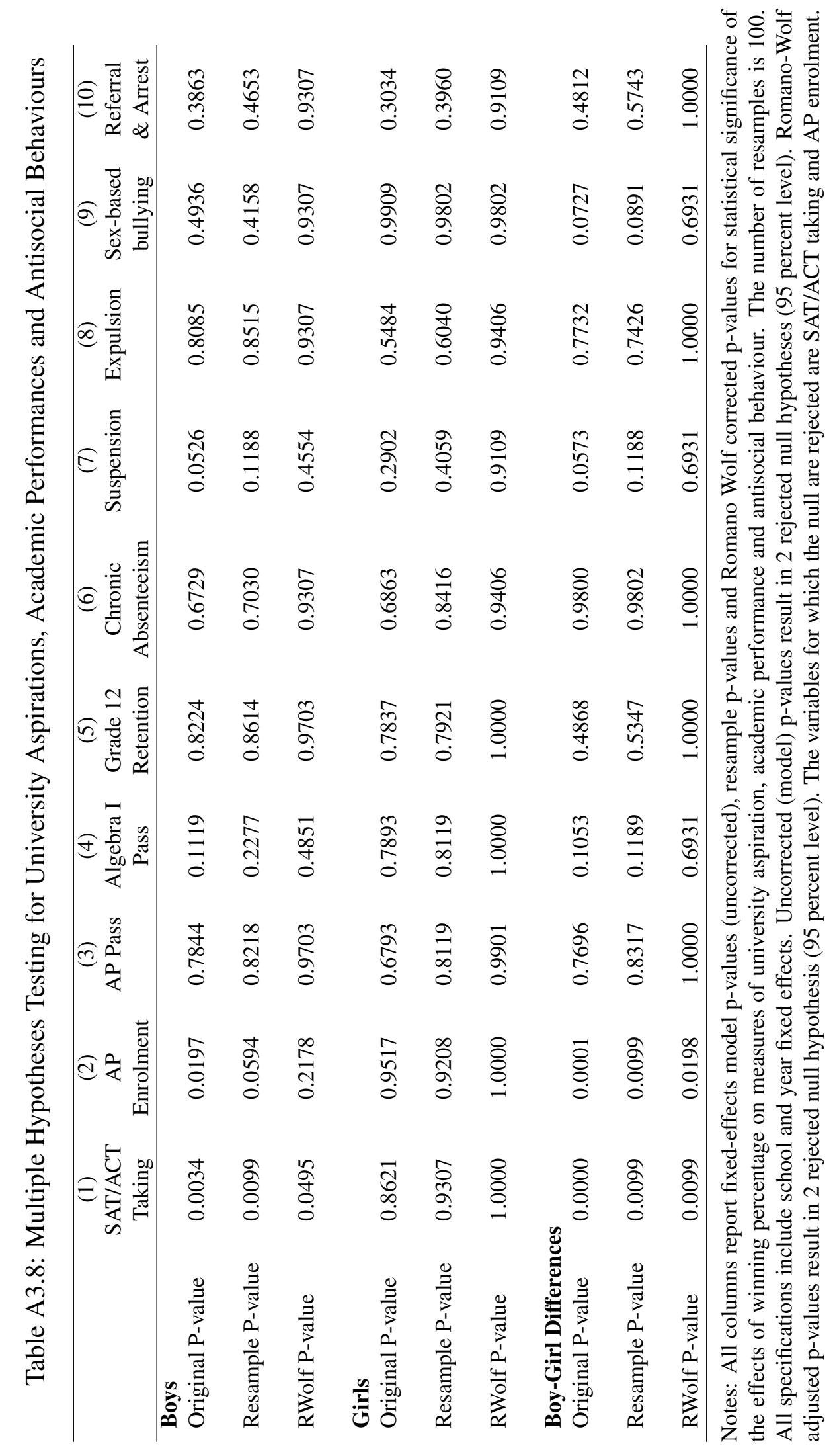


Table A3.9: The Importance of Selection on Unobservables

\begin{tabular}{lcccc}
\hline & \multicolumn{2}{c}{ SAT/ACT Taking } & \multicolumn{2}{c}{ AP Enrolment } \\
\cline { 2 - 5 } & No Controls & With Controls & No Controls & With Controls \\
\hline Boys & & & & \\
Winning Percentage & $0.711^{* * *}$ & $0.685^{* * *}$ & $0.429^{*}$ & $0.524^{* *}$ \\
& -0.233 & -0.238 & -0.226 & -0.226 \\
& & & & \\
R-squared & 0.011 & 0.03 & 0.015 & 0.05 \\
Delta & & -5.223 & & 2.449 \\
Girls & & & & \\
Winning Percentage & 0.064 & 0.045 & -0.117 & -0.016 \\
& -0.26 & -0.263 & -0.276 & -0.273 \\
R-squared & & & & \\
Delta & 0.011 & 0.027 & 0.02 & 0.061 \\
\hline
\end{tabular}

Notes: Table shows the examination on the importance of selection on unobservables. A general concern is our estimated effects of athletic success on university aspirations are driven by selection on schools that are better in both educational and physical activities because of unobserved characteristics. Comparing the models with and without covariates, we calculate Delta which is the ratio of the impacts of unobservables to the impacts of observables. Column 1 and 3 report estimates from a regression of SAT/ACT taking and AP enrolment rates on the winning percentage without further controls. Column 2 and 4 add controls as in main estimates of Equation 3.1. All of estiamtes include school and year fixed-effects. Delta represents the degree of selection on unobserved covariates relative to the degree of selection on observables to account for the estimated effects. To calculate Delta, we follow the recommendation in syntax written by Oster (2019), and set Rmax to 0.7 in the execution. Oster (2019) propose that the effects are robust if the absolute value of delta is greater than 1 . In our results, the absolute values of Delta are indeed greater than 1 . This confirms that our estimated effects on university aspirations are unlikely biased due to unobservables and supports a causal interpretation on the effects of athletic success on student outcomes. The standard errors are clustered at the school level and are in parentheses. $* * * p<0.01, * * p<0.05, * p<0.10$. 


\section{CHAPTER 4. THE ECONOMIC IMPACTS OF A PANDEMIC OUTBREAK. WHAT HAPPENED AFTER SARS IN 2003?}

\subsection{Introduction}

The current COVID-19 pandemic has a catastrophic economic impact across the world, but despite a rapidly growing literature, the likely overall impacts of this pandemic are still largely unknown (Altig et al., 2020; Baker et al., 2020; Beach et al., 2020; Hailu, 2020). The existing research for COVID-19 basically evaluates the effects in the first year, 2020. The main motivation of this study is to gain instructive insight into the overall impacts of the COVID-19 pandemic that are still largely unknown as the pandemic continues into 2021, and the economic impacts will most likely exist into 2022 and longer. We aim to learn from previous pandemic outbreaks. Such information may also have significant policy implications because a government's decisions over timing and extent of reopening depend critically on the likely future path of the pandemic-economic curve.

The SARS epidemic in 2003 is an interesting case, given the similarities between the two coronaviruses themselves, and the ways in which the affected economies reacted. It therefore may be instructive to revisit the economic impacts of the 2003 outbreak of SARS. Of particular relevance to this paper are some previous studies analysing the impacts of SARS on the affected Asian economies (Lee and McKibbin, 2004; Chou et al., 2004; Siu and Wong, 2004). For instance, in a widely cited paper, Lee and McKibbin (2004) estimate that SARS had caused $2.63,1.05,0.49$, and 0.47 percentage-points decline in annual GDP for the most heavily affected 
countries of Hong Kong, China, Taiwan, and Singapore, respectively. Based on a computable general equilibrium model for Asia-Pacific, they examine the direct and indirect economic impacts of SARS rather than focusing only on the affected industries such as healthcare, tourism, or retail service sector as previous studies have done (Chou et al., 2004; Siu and Wong, 2004).

In this paper, we examine post-pandemic data, rather than rely on semi-real-time structural modelling as is done by Lee and McKibbin (2004). Our study introduces three novelties in re-examining the economic impacts of SARS. First, we apply a modern econometric method, Synthetic Control (Abadie and Gardeazabal, 2003; Abadie et al., 2010). This allows us to rigorously estimate the counterfactual growth trajectory for the affected units without the epidemic. Second, we employ both conventional macroeconomic data from National Bureau of Statistics of China and night-time light data from the Defense Meteorological Program Operational LineScan System (DMSP-OLS) in 1993-2013 that were not available in the immediate aftermath of the epidemic when most previous research was done. Last, we focus particularly on China and examine the economic impact of SARS on Beijing, Guangdong, Hebei, and Shanxi since these were the provincial-level divisions that were affected the most. ${ }^{1}$ We do not examine the impacts of SARS on economic activity at the national level, despite strongly descriptive evidences on a short-term negative effect of the epidemic on GDP per capita in Q2, 2003 in the heavily affected countries. The adverse economic impacts of SARS lasted only during the immediate epidemic quarter given its relatively limited spread to other countries and the affected countries' abilities to stop its spread very quickly. Another rationale for not examining the economic impacts of SARS across countries is the emergence of China as a dominant trading partner for East Asian countries, after China had joined the World Trade Organization (WTO) in 2001. For example, Hong Kong, Singapore, Taiwan were all heavily reliant on China's trade and were (and still are) to some extent entrepôt economies. Leveraging the within-country analysis allows us to get rid

\footnotetext{
${ }^{1}$ Strictly speaking, Guangdong, Hebei, and Shanxi are provinces, while Beijing is a municipality. But all are one administrative step below the central government (a province-level administrative division). To simplify, we call all province-level subdivisions (provinces, autonomous regions, municipalities) "provinces".
} 
of simultaneous big events, which happen at the country level and pose a challenge to extract the pure economic impact of SARS.

We find evidences on negative effects of the SARS pandemic on economic growth. The evidences imply adverse effects of a pandemic outbreak persist somewhat in the long run. On average, the results suggest that 2003 SARS outbreak leads to 20-percent decline in night-time lights (NTL) per capita in Beijing. The findings are not entirely consistent with the widely held optimistic view of a V-shaped recovery after the SARS pandemic, as we show that SARS did lead to statistically observable declines in economic activity in the most heavily-affected provincial economy. It seems that national economies have indeed bounced back quickly, but more local affected areas have taken longer to recover.

Our study contributes to the literature that examines the impacts of disease outbreaks. Most past research efforts have been directed at understanding the economic impact of noninfectious (or non-epidemic) diseases, and health more broadly (Baldwin and Weisbrod, 1974; Gillies et al., 1996; Weisbrod et al., 1974). ${ }^{2}$ To better understand the potential economic impacts of COVID-19, one could draw on recent studies investigating the economic impacts of the 1918-19 pandemic flu (Almond, 2006; Barro et al., 2020; Beach et al., 2018; Boberg-Fazlic et al., 2017; Guimbeau et al., 2020; Helgertz and Bengtsson, 2019; Karlsson et al., 2014; Noy et al., 2020). ${ }^{3}$ Starting from Almond (2006), several papers have investigated the long-term impact of exposure to an epidemic on in-utero human development by focusing specifically on the 1918-19 influenza pandemic (Beach et al., 2018; Boberg-Fazlic et al., 2017; Guimbeau

\footnotetext{
${ }^{2}$ Indeed, several past studies have looked at the economic impacts of previous epidemics. For example, HIV/AIDS (Barnett et al., 2000; Dixon et al., 2002; Kabajulizi and Ncube, 2017), avian influenza H5N1 (Bloom et al., 2005), and dengue (Castañeda-Orjuela et al., 2012). The one epidemic that has received more research attention is HIV/AIDS, especially within the context of African development, but also in high-prevalence countries or regions elsewhere. Dixon et al. (2002) find that the spread of AIDS led to reductions of labour supply, productivity, exports and overall economic development in Africa in the 1990s. More recently, Kabajulizi and Ncube (2017) evaluate the transition of the management of AIDS into a chronic condition requiring investment in continuing treatment, and investigate the impact of these fiscal costs on Uganda's economic development. In addition to past research on the economics of HIV/AIDS, the literature on other epidemics is quite limited.

${ }^{3}$ There is also a growing literature identifying the economic impacts of the 2014 Ebola epidemic in West Africa (Campante et al., 2020; Kostova et al., 2019; Maffioli, 2021).
} 
et al., 2020). Karlsson et al. (2014) focus on Sweden's experience with the 1918-19 influenza to describe in more detail the impact of the pandemic on poverty and other macroeconomic outcomes, while Noy et al. (2020) do the same for Japan's experience with the 1918-19 event. ${ }^{4}$ Others attempt to estimate the economic impact of epidemics by looking at a panel of countrylevel macroeconomic data together with a historical record of past epidemics. For example, Jordà et al. (2020) use the rates of return on assets with data going back to the fourteenth century to study medium and long run impacts of pandemics. They find that the macroeconomic after-effects of pandemics can persist for decades. Barro et al. (2020) use cross-country comparisons in the aftermath of the 1918-19 influenza to identify declines in GDP and consumption of 6 and 8 percent, respectively. Overall, these recent papers suggest that the adverse economic impacts of pandemics may persist for a long period of time. ${ }^{5}$

The paper proceeds as follows: Section 4.2 summarizes the background to the economic impacts of 2003 SARS. Section 4.3 presents the data and methodology. Section 4.4 discusses the results. Section 4.5 concludes with some directions for future research.

\subsection{Background on Economic Impacts of 2003 SARS}

The most significant presence of SARS was registered in four Asian economies: China, Hong Kong, Singapore, and Taiwan. Once the pandemic became known, the number of international visitors fell precipitously in these economies. Brahmbhatt and Dutta (2008) estimate that the GDP loss amounted to US \$13 billion. By all descriptive accounts, these losses did not affect any of these national economies for more than two quarters and even the most heavily affected countries were already growing rapidly by Q3 2003. The observed affects were distributed unequally across sectors; disproportionately affecting tourism, leisure, and transport,

\footnotetext{
${ }^{4}$ For a review of the myriad literatures that have looked at non-economic impacts of the 1918-19 pandemic, see Beach et al. (2020).

${ }^{5}$ While the literature on the economic impacts of COVID-19 has been extensive already, we do not survey this literature here. For a literature review, see Brodeur et al. (2020).
} 
especially airlines. In Hong Kong, international visitor arrivals dropped by 65 percent on the previous year's figure during April 2003 (APEC, 2004). Airlines, and specifically the city's carrier-Cathay Pacific_-cancelled over 45 percent of their scheduled flights during the epidemic's peak, and their monthly passenger rate fell by 80 percent (Noy and Shields, 2019). Notably, cross-border trade, and especially the Hong Kong-China movement of goods, continued without significant disruption. Even the stock market reaction was comparatively mild, with the Hong Kong Seng Index dropping by 1.78 percent between March 12 and April 30.

The main channel of impact during the SARS epidemic was the behavioural change of millions of individuals (Noy and Shields, 2019). Indeed, public opinion surveys at the height of the epidemic reveal that 23 percent of respondents in Hong Kong, for example, thought that they were either very or somewhat likely to become infected with SARS, which was dramatically incommensurate with the eventual infection rate of only 0.0026 percent (Leung et al., 2004). Similar exaggerated perceptions were recorded in Taiwan where 74 percent of survey respondents rated the likelihood of death following SARS contraction as 4-or-5 on a 5-point scale (Liu et al., 2005), while the actual case-fatality rate was 10 percent (still much higher than SARSCOV-2). Disproportionate risk assessments were even found in places hardly affected by the epidemic, such as the U.S. where 16 percent of survey respondents felt that they or their family were 'somewhat' or 'very likely' to get infected with SARS in the next 12 months (Brahmbhatt and Dutta, 2008).

The economic consequences of an epidemic can usually be delineated into direct and indirect impacts. Direct impacts include lost income and output due to death and symptomatic illness as well as increased healthcare costs, whereas indirect costs arise, specifically in this case, from aggregate behavioural changes driven by the public's perception of the epidemic outbreak or by government directives. ${ }^{6}$ Because there was relatively limited mortality and morbidity associated with SARS, its economic analysis differs from some other notable epidemics. Typically,

\footnotetext{
${ }^{6}$ Yet, the difference between the two is often very hard to disentangle (Katafuchi et al., 2020).
} 
economic losses in such epidemics as HIV/AIDS in the 1980s and 1990s or the influenza of 1918-19 were first, and maybe foremost, measured via the cost of illness and death and the loss of income associated with that mortality and morbidity. This cannot be the basis for an evaluation of the economic impacts of SARS as such an approach will severely underestimate its costs.

\subsection{Data and Methodology}

\subsubsection{Data}

We use two data sources to measure economic growth in China. The first source is the official statistics, provided by National Bureau of Statistics of China. Quarterly GDP of China's provinces are not available for long enough to run the synthetic control algorithm. Hence, we use annual GDP series from the National Bureau of Statistics of China. Data for covariates includes investment in fixed assets and household spending. We obtain data from 1993, the first year in which data is available, to 2013. The second one is constructed from night-light remote sensing data in 1993-2013 by aggregating data from the Defense Meteorological Program Operational Line-Scan System (DMSP-OLS) of US National Oceanic and Atmospheric Administration (NOAA). ${ }^{7}$ The sensor in the DMSP-OLS data is not sensitive enough for bright light, so in densely populated urban areas it always registers the highest reading possible throughout the city. Hence, the data can only be used aggregated to the provincial level. Night-time light data has previously been considered as a useful proxy for regional economic activity (Chen and Nordhaus, 2011; Henderson et al., 2012) and have been specifically preferred in the Chinese context (Clark et al., 2020). The SARS epidemic emerged in Guangdong in November 2002. The pre-intervention period is before the year of $2003\left(T_{0}=2002\right)$. Though the epidemic spread

\footnotetext{
${ }^{7}$ We use Version 4 DMSP-OLS Night-time Lights Time Series. The satellite night-light data is available in annual frequency from 1992 to 2013. Visible Infrared Imaging Radiometer Suite (VIIRS), a newer night-light data, is available at higher resolution and frequency and can be fruitfully used for city-level analysis. Yet, the data is only available after 2012.
} 
to 26 provinces, there were more than 2,500 and 1,500 cases reported in Beijing and Guangdong, respectively; this is significantly more than all the other provinces combined. The number of cases of SARS was highest in Beijing and Guangdong, followed by Shanxi and Hebei. ${ }^{8}$ We set Beijing, Guangdong, Hebei, Shanxi as treated units. Table 4.1 presents the series of 30 provincial-level administrative regions including 4 treated and 26 control units. ${ }^{9}$

Table 4.1: List of the Treated and Control Provinces of China

\begin{tabular}{l|llll}
\hline Treated Group & Control Group & & & \\
\hline Beijing & Anhui & Henan & Inner Mongolia & Tianjin \\
Guangdong & Fujian & Hubei & Ningxia & Xinjiang \\
Hebei & Gansu & Hunan & Qinghai & Tibet \\
Shanxi & Guangxi & Jiangsu & Shaanxi & Yunnan \\
& Guizhou & Jiangxi & Shandong & Zhejiang \\
& Hainan & Jilin & Shanghai & \\
& Heilongjiang & Liaoning & Sichuan & \\
\hline
\end{tabular}

Notes: Data from National Bureau of Statistics of China Tables includes 31 first-level administrative divisions. We drop Chongqing as missing data on population. Municipalities include: Beijing, Shanghai, Tianjin. Autonomous regions include: Guangxi, Inner Mongolia, Ningxia, Xinjiang, Tibet. Others are provinces.

\subsubsection{Methodology}

We use the synthetic control methodology (SCM), first developed in Abadie and Gardeazabal (2003), to identify the impact of SARS. The SCM has previously been used in estimating the impact of extreme sudden-onset shocks in many settings (Cavallo et al., 2013; Noy et al., 2015). The approach involves the calculation of a synthetic counterfactual, i.e., observation of the SARS-affected region without the epidemic, by weighting the average of all units in the donor pool that have not been directly or were marginally affected by the "treatment" of the SARS 2003 epidemic. Following Abadie et al. (2010), let $Y_{i t}$ be the GDP/NTL per capita for

\footnotetext{
${ }^{8}$ Given that Beijing is a municipality that is much smaller in size than other provinces and the economy are interconnected across provinces, the impact on the economy of Beijing can have spill-over effects to neighbouring provinces: Shanxi and Hebei.

${ }^{9}$ We also drop Chongqing as the population data, one of the predictors, is missing before 1997.
} 
province $i$ at year $t$. We set $i=I$ for the treated province, where $1 \leq i \leq N$. Then $Y_{I t}$ is the outcome for provinces exposed to the epidemic at time $t$.

As the SARS epidemic outbreak mostly started in Q1, 2003 (with the very first patients diagnosed in November 2002), we set $\left(T_{0}=2002\right)$, where $1 \leq T_{0} \leq T$. Our sample includes 21 time periods, in which there are 10 pre- and 11 post-intervention periods. The economic impact of SARS can be observed by the GDP/NTL per capita for province $i$ at year $t$, where $t \geq T_{0}+1$. The assumption is that the epidemic had no effect on the outcome before the event, i.e., $Y_{\text {It }}=Y_{i t}$, where $1 \leq i \leq N$ and $t \leq T_{0} .^{10}$

To calculate p-value, we implement the approach to get a distribution of "in-place" placebo effects proposed by Galiani and Quistorff (2017). This non-parametric statistical significance test does not impose any distributional assumption on the errors (placebo effects are as large as the estimates for treated unit). Let $\widehat{\alpha}_{i t}$ be the estimated effect for a particular posttreatment period of province $i$ at year $t$, where $1 \leq i \leq N$ and $t \geq T_{0}+1$. The distribution of placebos for the treated unit is $\widehat{\alpha}_{I t}^{P L}=\left\{\widehat{\alpha}_{i t}: i \neq I\right\}$. We then compute the two-sided p-value as: $p-$ value $=\operatorname{Pr}\left(\left|\widehat{\alpha}_{I t}^{P L}\right| \geq\left|\widehat{\alpha}_{I t}\right|\right)=\frac{\sum_{i \neq I} \mathbb{1}\left[\left|\widehat{\alpha}_{i t}^{P L}\right| \geq\left|\widehat{\alpha}_{I t}\right|\right]}{N^{P L}}$.

\subsection{Results and Discussion}

In the synthetic control analysis for GDP per capita in Beijing, Guangdong, Hebei, and Shanxi, the predictors include household spending and investment per capita. The goodness of fit over the pre-intervention period and the balance for all predictors indicate a plausible pool of control units. (Though, in Appendix Figure A4.1, even for the pre-intervention period, the synthetic is not able to replicate the trend of Beijing. The placebo tests in Appendix Figure A4.2 indicate there is little evidence that annual per capita income in Beijing and Guangdong was affected by the epidemic.) The lack of clear results in the analysis for GDP per capita may be attributed to measurement errors in macroeconomic data. Indeed Clark et al. (2020) questions

\footnotetext{
${ }^{10}$ See further details in Abadie et al. (2010).
} 
the quality of China's official regional GDP statistics. Using the night-time lights to compute the optimal weights for a battery of economic activities, Clark et al. (2020) argue that China's actual GDP growth may be higher than in official reports. Given the absence of satisfactory macroeconomic data, we use the night-time light data as an alternative proxy for economic activity.

In Figure 4.1, we identify the economic impacts by examining changes in night light around the SARS period in 2003. We run the synthetic control algorithm with the average per-province annual normalized night-light data in Beijing, Guangdong, Hebei, Shanxi. The predictors include: the population density, household spending, investment per capita, and the lag (-1) of GDP per capita. The results, in Figure 4.1, do suggest a noticeable decline in economic activity during the SARS period in the two affected areas that are most associated with SARS, Beijing and Guangdong. As described earlier, the actual provincial per capita GDP data, which might be perceived as less reliable, does not corroborate that. The normalized NTL per capita declines by 0.033 and 0.004 points (20 and 30 percent) in Beijing and Guangdong, respectively, against the counterfactual rapid growth that the synthetic model predicts. We also ran the synthetic control algorithm for Shanxi and Hebei, two neighbouring provinces that were also affected by the epidemic. Shanxi and Hebei also show a drop in night lights, though one that is significantly small. 
Figure 4.1: Synthetic Analysis for Annual NTL Per Capita:

Beijing, Guangdong, Hebei, Shanxi
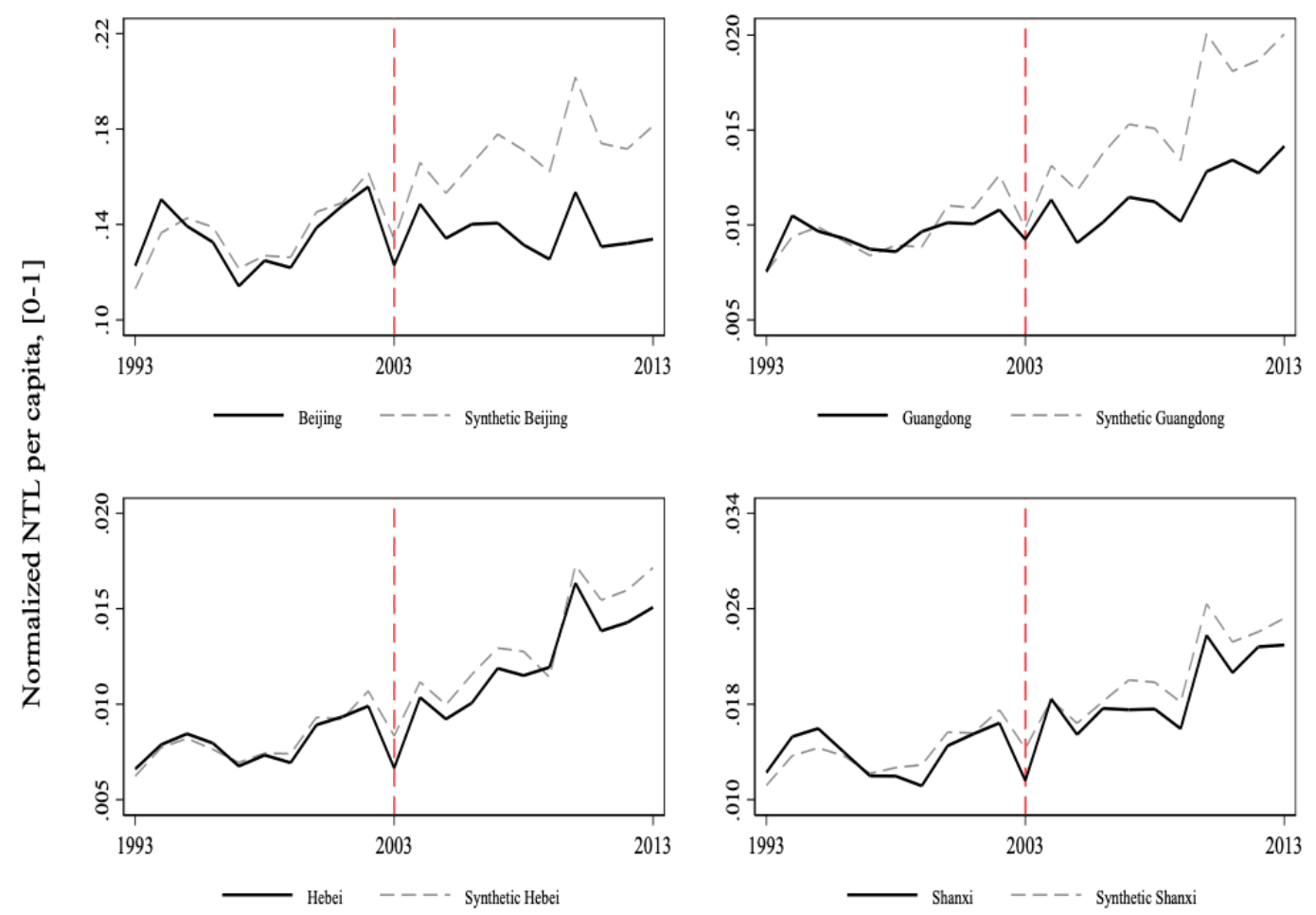

Notes: The red dash line indicates the SARS outbreak. The graphs compare the annual normalized NTL per capita in a treated province with the synthetic counterfactual (of the same province without SARS). The overall period includes 21 quarters. The pre-intervention period is 1993 to 2002, and post-intervention period is 2003 to 2013 . 
Figure 4.2 provides the placebo effects for all other provinces. The validity of our results will be in doubt should we find many placebos (SARS-unaffected) provinces with similarly negative effects. But the results in Figure 4.2 seem to confirm our findings of a negative impact of SARS on Guangdong and Beijing. In table 4.2, we present the point estimates of effect on NTL and the two-sided p-value for each post-treatment period. Only the point estimates for Beijing are statistically different from the placebo in all post-treatment periods. This provides further support for our finding of a negative impact of the epidemic in the most heavily affected Chinese province.

Figure 4.2: Placebo Tests of Synthetic Analysis for Annual NTL Per Capita: Beijing, Guangdong, Hebei, Shanxi
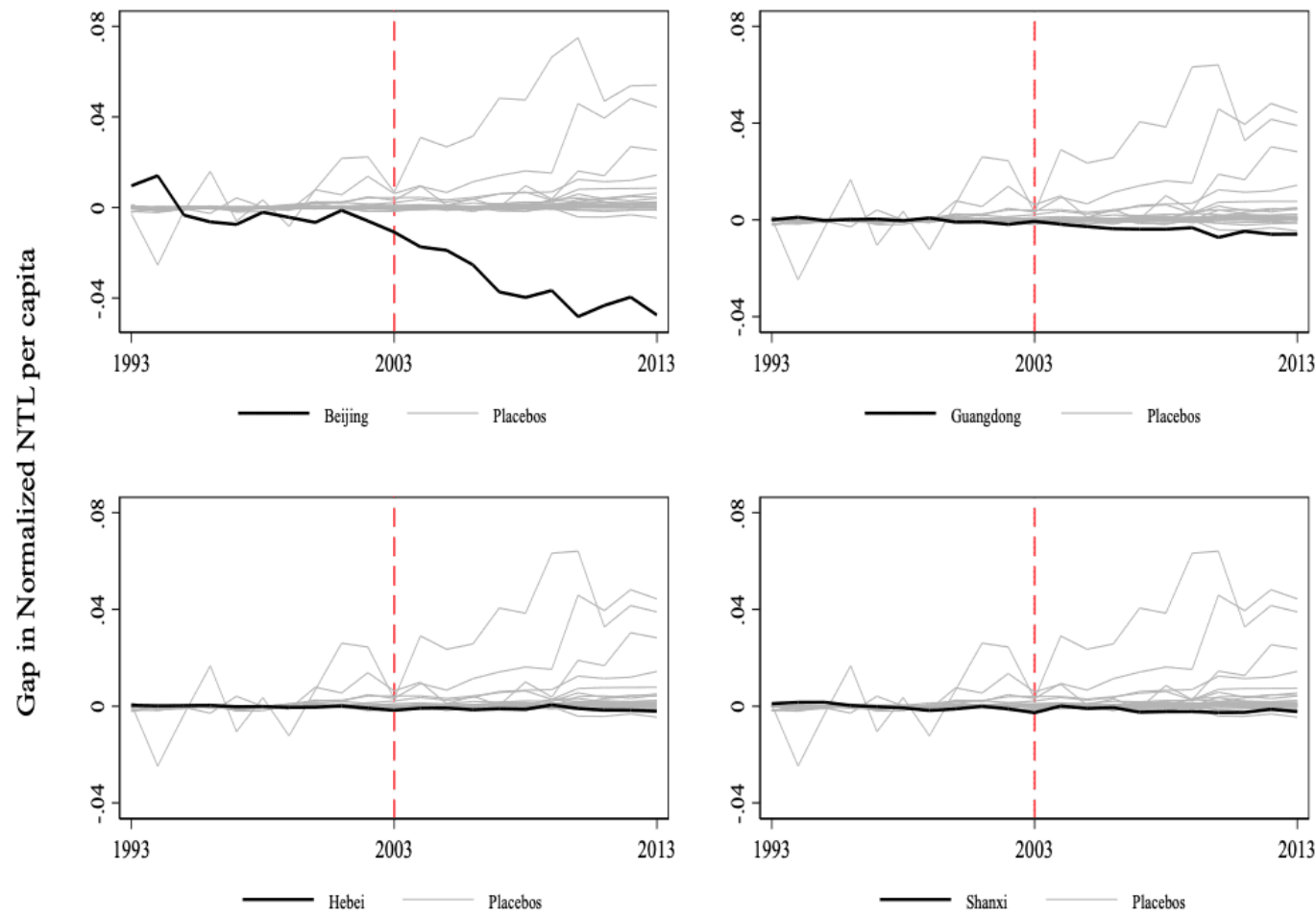

Notes: The red dash line indicates the SARS outbreak. The graphs show the difference between annual normalized NTL per capita of a treated province and its synthetic counterfactual, the dark line. The grey lines are the difference of annual normalized NTL per capita of each province in the donor pool and its counterfactual. The synthetic control of each province is a weighted average of all other province excluding the treated province: Beijing, Guangdong, Hebei, Shanxi. 
Table 4.2: Synthetic Control Estimates for the Effects of SARS on Normalized Annual NTL per capita: Beijing, Guangdong, Hebei, Shanxi

\begin{tabular}{|c|c|c|c|c|}
\hline & $\begin{array}{c}(1) \\
\text { Beijing }\end{array}$ & $\begin{array}{c}\text { (2) } \\
\text { Guangdong }\end{array}$ & $\begin{array}{c}(3) \\
\text { Hebei }\end{array}$ & $\begin{array}{c}\text { (4) } \\
\text { Shanxi }\end{array}$ \\
\hline Overall Effect & $\begin{array}{c}-0.033 * * \\
(0.029)\end{array}$ & $\begin{array}{l}-0.004 \\
(0.196)\end{array}$ & $\begin{array}{c}-0.001 \\
(0.436)\end{array}$ & $\begin{array}{l}-0.002 \\
(0.342)\end{array}$ \\
\hline 2003 & $\begin{array}{c}-0.011 * * * \\
(0.000)\end{array}$ & $\begin{array}{l}-0.001 \\
(0.360)\end{array}$ & $\begin{array}{l}-0.002 \\
(0.240)\end{array}$ & $\begin{array}{l}-0.003 \\
(0.160)\end{array}$ \\
\hline 2004 & $\begin{array}{c}-0.017 * * \\
(0.040)\end{array}$ & $\begin{array}{l}-0.002 \\
(0.200)\end{array}$ & $\begin{array}{l}-0.001 \\
(0.400)\end{array}$ & $\begin{array}{c}0.000 \\
(0.720)\end{array}$ \\
\hline 2005 & $\begin{array}{c}-0.019 * * \\
(0.040)\end{array}$ & $\begin{array}{l}-0.003 \\
(0.120)\end{array}$ & $\begin{array}{c}-0.001 \\
(0.320)\end{array}$ & $\begin{array}{c}-0.001 \\
(0.240)\end{array}$ \\
\hline 2006 & $\begin{array}{c}-0.025^{* *} \\
(0.040)\end{array}$ & $\begin{array}{l}-0.004 \\
(0.200)\end{array}$ & $\begin{array}{c}-0.001 \\
(0.320)\end{array}$ & $\begin{array}{c}-0.001 \\
(0.320)\end{array}$ \\
\hline 2007 & $\begin{array}{c}-0.037 * * \\
(0.040)\end{array}$ & $\begin{array}{l}-0.004 \\
(0.160)\end{array}$ & $\begin{array}{c}-0.001 \\
(0.400)\end{array}$ & $\begin{array}{c}-0.003 \\
(0.160)\end{array}$ \\
\hline 2008 & $\begin{array}{c}-0.040 * * * \\
(0.000)\end{array}$ & $\begin{array}{l}-0.004 \\
(0.200)\end{array}$ & $\begin{array}{c}-0.001 \\
(0.400)\end{array}$ & $\begin{array}{c}-0.002 \\
(0.200)\end{array}$ \\
\hline 2009 & $\begin{array}{c}-0.037 * * \\
(0.040)\end{array}$ & $\begin{array}{l}-0.003 \\
(0.160)\end{array}$ & $\begin{array}{c}0.001 \\
(0.480)\end{array}$ & $\begin{array}{l}-0.002 \\
(0.280)\end{array}$ \\
\hline 2010 & $\begin{array}{c}-0.048 * * \\
(0.040)\end{array}$ & $\begin{array}{l}-0.007 \\
(0.160)\end{array}$ & $\begin{array}{l}-0.001 \\
(0.760)\end{array}$ & $\begin{array}{l}-0.003 \\
(0.360)\end{array}$ \\
\hline 2011 & $\begin{array}{c}-0.043 * * * \\
(0.000)\end{array}$ & $\begin{array}{l}-0.005 \\
(0.200)\end{array}$ & $\begin{array}{c}-0.001 \\
(0.520)\end{array}$ & $\begin{array}{c}-0.003 \\
(0.360)\end{array}$ \\
\hline 2012 & $\begin{array}{c}-0.040 * \\
(0.080)\end{array}$ & $\begin{array}{l}-0.006 \\
(0.200)\end{array}$ & $\begin{array}{l}-0.002 \\
(0.520)\end{array}$ & $\begin{array}{c}-0.001 \\
(0.600)\end{array}$ \\
\hline 2013 & $\begin{array}{c}-0.047 * * * \\
(0.000)\end{array}$ & $\begin{array}{l}-0.006 \\
(0.200)\end{array}$ & $\begin{array}{l}-0.002 \\
(0.440)\end{array}$ & $\begin{array}{l}-0.002 \\
(0.360)\end{array}$ \\
\hline
\end{tabular}

Notes: P-values are in parentheses. $* * * p<0.01, * * p<0.05, * p<0.10$. 


\subsection{Conclusions}

We quantify the effect of the 2003 SARS epidemic on the economic growth in Chinese provincial-level administrative regions by measuring economic growth with GDP and night-time lights. In this study, we use the synthetic control methods, to create pre- and post-intervention comparisons between observed and counterfactual outcomes. Using night-light data, we find observed evidences of a persistent negative effect of SARS in Beijing and Guangdong, the two most heavily affected Chinese provinces. Only the estimated effect of SARS on NTL per capita of Beijing is strongly statistically significant. While we observe a negative effect in Beijing, there are potential spill-over effects on other provinces. The SCM may thus provide a lower bound of the effect. For a traditional SCM, the critical assumption is that the synthetic algorithm can replicate the trajectories of the treated units in the pre-intervention period. There is a growing literature that develops methods to improve the ability or accuracy of the SCM algorithm to replicate accurately pre-intervention given the multiple possibilities for how to do so (Ben-Michael et al., 2018; Robbins et al., 2017), or alternatively relax the assumptions required for the original SCM (Doudchenko and Imbens, 2016; Powell, 2018). However, these methodologies may penalize extrapolation from the convex hull since the treated units may be outside the convex hull of control units. For that insight, the original SCM is still likely a plausible methodology to identify the economic impact of pandemic outbreak.

A broad picture is that the national economies prove to be quite resilient to the 2003 SARS pandemic, a temporary but large shock. Our results suggest that, while country-level macroeconomic impact assessment will be useful for the central government to identify overall impacts, such macro-analysis may mask some local-level impacts if localities were affected differently. In these cases, it is imperative to conduct disaggregated local/national assessments of impacts of a pandemic in addition to any macroeconomic analysis. More detailed microeconomic data will shed more light on the possible mechanisms behind any observed decline as well as its duration. Such an analysis is part of our future research agenda. 


\section{Appendix}

Figure A4.1: Synthetic Analysis for Annual GDP Per Capita: Beijing, Guangdong, Hebei, Shanxi
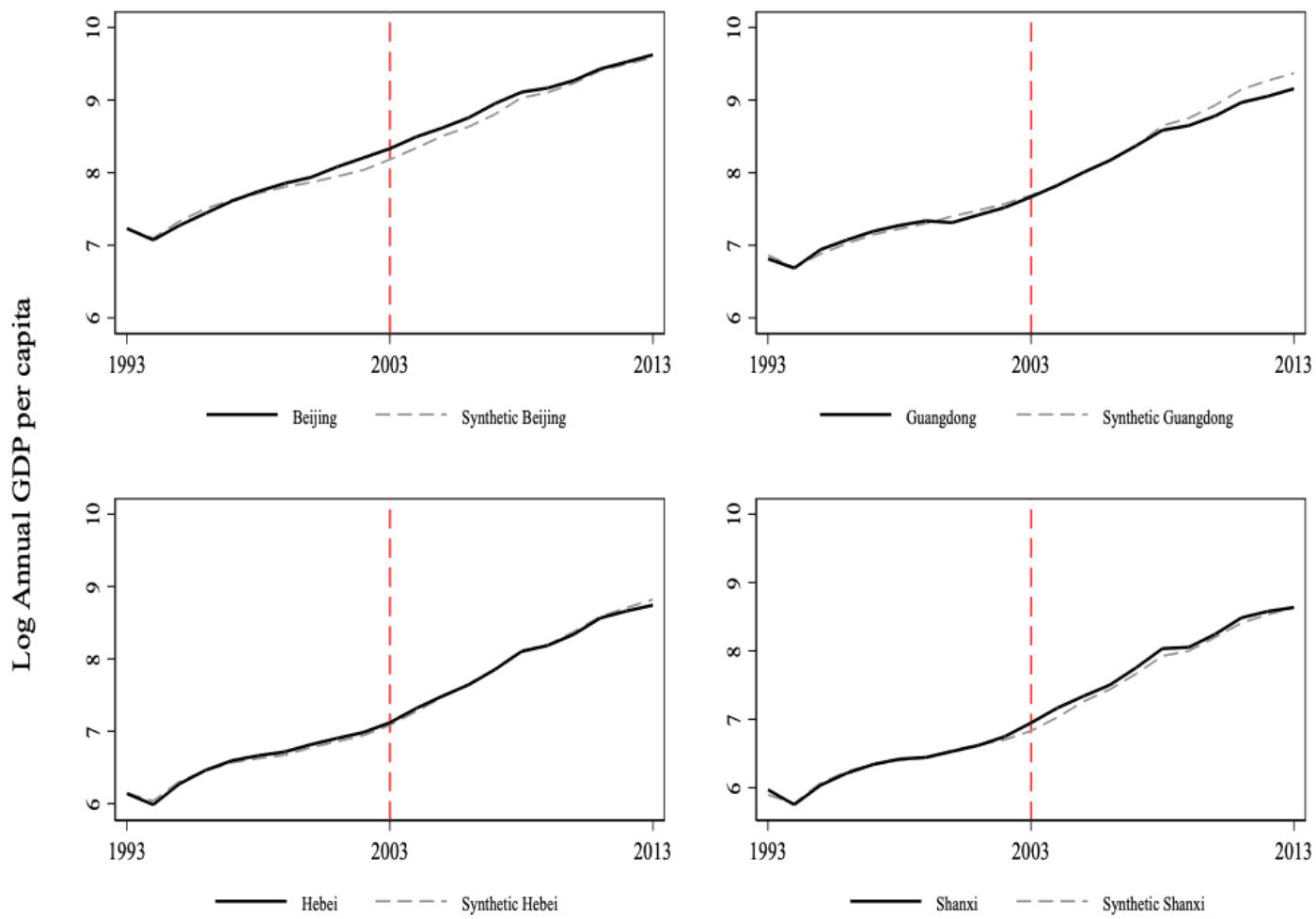

Notes: The red dash line indicates the SARS outbreak. The graphs compare the logarithm of annual GDP per capita in a treated province with the synthetic counterfactual (of the same province without SARS). The overall period includes 21 quarters. The pre-intervention period is 1993 to 2002, and post-intervention period is 2003 to 2013 
Figure A4.2: Placebo Tests of Synthetic Analysis for Annual GDP Per Capita:

Beijing, Guangdong, Hebei, Shanxi
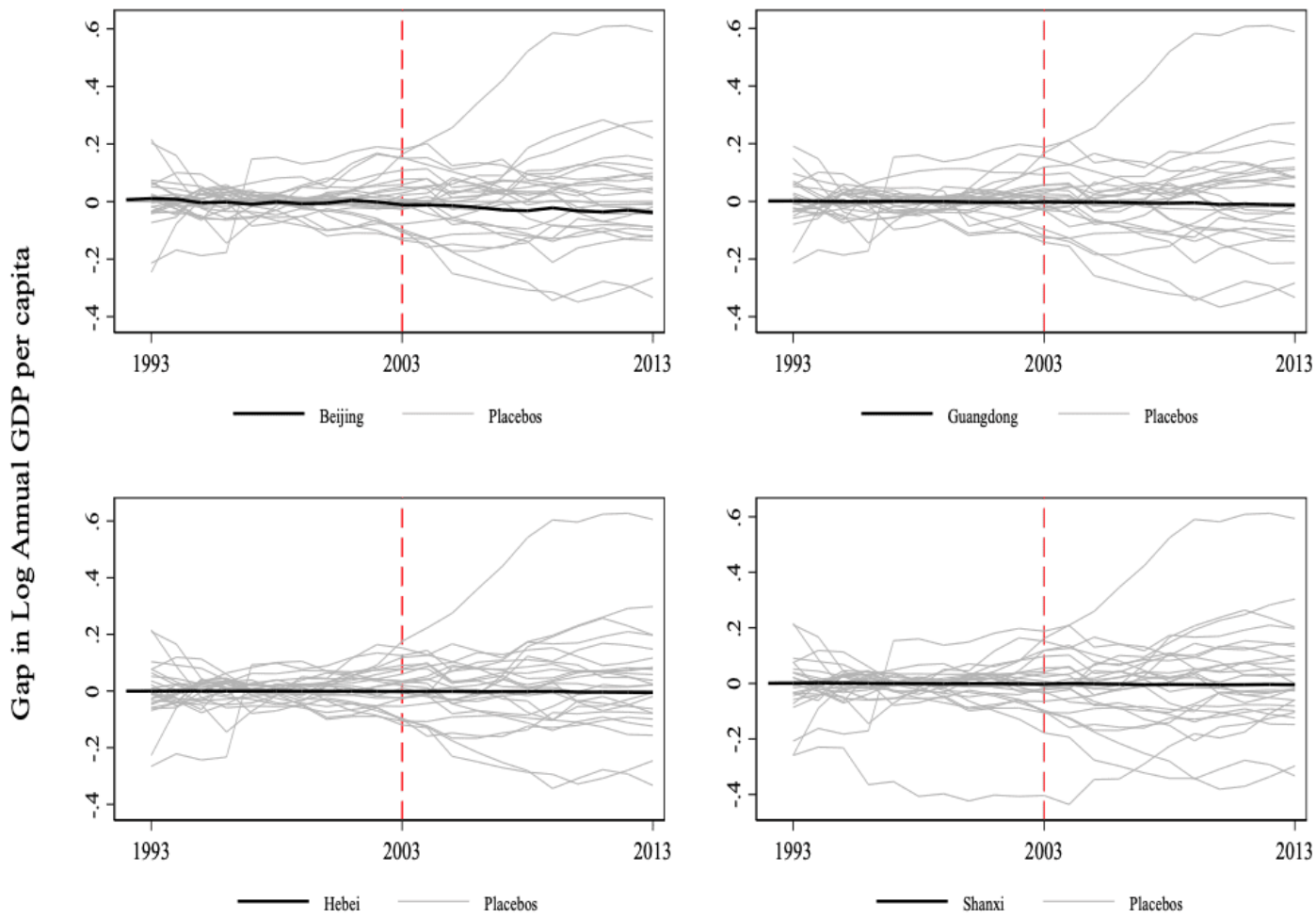

Notes: The red dash line indicates the SARS outbreak. The graphs show the difference between the logarithm of annual GDP per capita of a treated province and its synthetic counterfactual, the dark line. The grey lines are the difference of the logarithm of annual GDP per capita of each province in the donor pool and its counterfactual. The synthetic control of each province is a weighted average of all other province excluding the treated province: Beijing, Guangdong, Hebei, Shanxi. 
Figure A4.3: The Distribution of the 2003 SARS cases in China

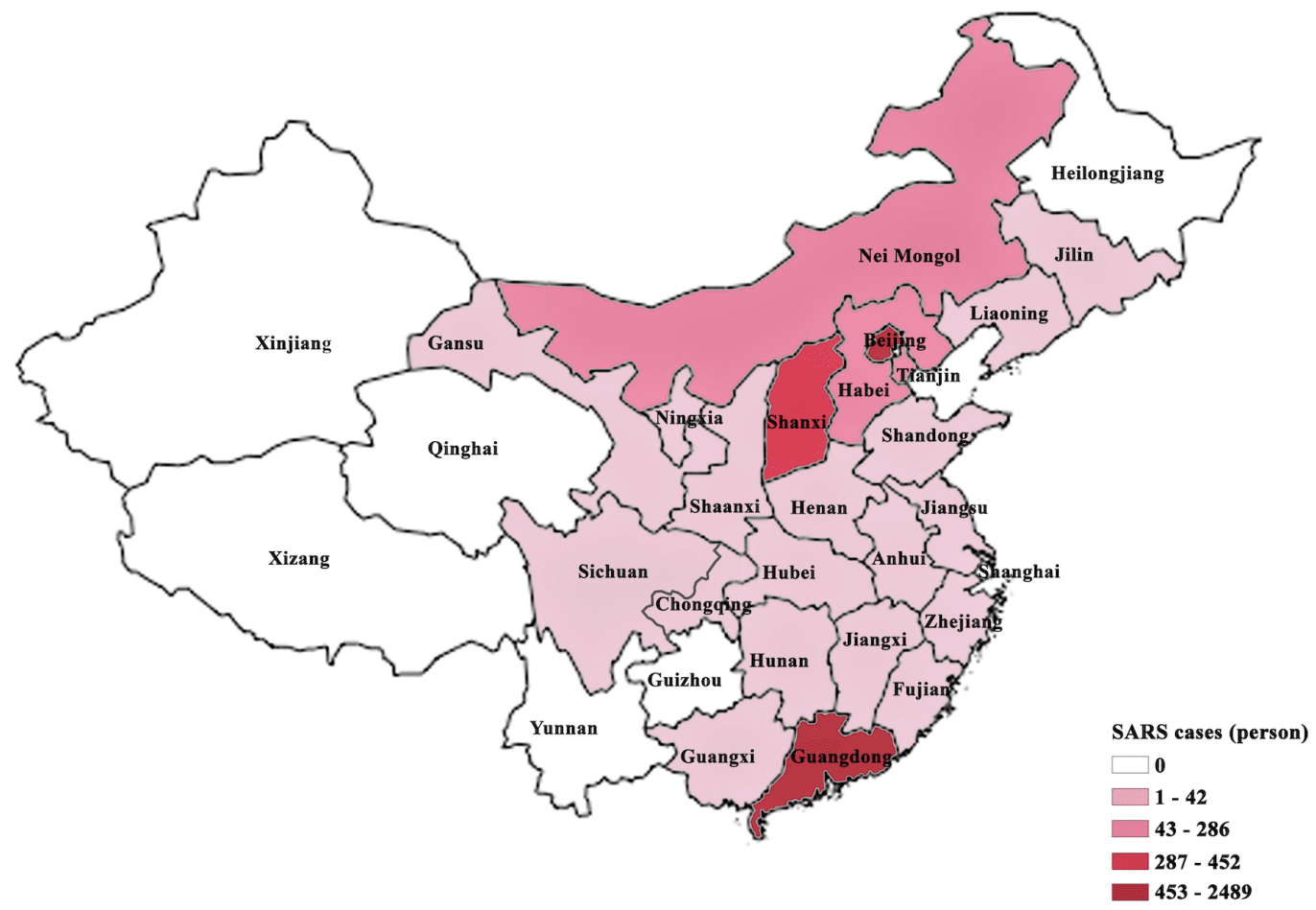

Notes: Figure shows the distribution of 2003 SARS cases in China by first-level administrative divisions. Source: Xu et al. (2014) 
Table A4.2: Synthetic Control Estimates for the Effects of SARS on Log Annual GDP per capita: Beijing, Guangdong, Hebei, Shanxi

\begin{tabular}{|c|c|c|c|c|}
\hline & $\begin{array}{c}(1) \\
\text { Beijing }\end{array}$ & $\begin{array}{c}(2) \\
\text { Guangdong }\end{array}$ & $\begin{array}{c}(3) \\
\text { Hebei }\end{array}$ & $\begin{array}{c}\text { (4) } \\
\text { Shanxi }\end{array}$ \\
\hline Overall Effect & $\begin{array}{c}0.087 \\
(0.564)\end{array}$ & $\begin{array}{l}-0.085 \\
(0.606)\end{array}$ & $\begin{array}{c}-0.011 \\
(0.848)\end{array}$ & $\begin{array}{c}0.074 \\
(0.606)\end{array}$ \\
\hline 2003 & $\begin{array}{c}0.149 \\
(0.125)\end{array}$ & $\begin{array}{l}-0.023 \\
(0.750)\end{array}$ & $\begin{array}{c}0.034 \\
(0.667)\end{array}$ & $\begin{array}{c}0.117 \\
(0.250)\end{array}$ \\
\hline 2004 & $\begin{array}{c}0.153 \\
(0.125)\end{array}$ & $\begin{array}{c}0.007 \\
(0.917)\end{array}$ & $\begin{array}{c}0.043 \\
(0.667)\end{array}$ & $\begin{array}{c}0.138 \\
(0.167)\end{array}$ \\
\hline 2005 & $\begin{array}{c}0.112 \\
(0.375)\end{array}$ & $\begin{array}{l}-0.010 \\
(0.958)\end{array}$ & $\begin{array}{c}0.013 \\
(0.917)\end{array}$ & $\begin{array}{c}0.078 \\
(0.542)\end{array}$ \\
\hline 2006 & $\begin{array}{c}0.124 \\
(0.375)\end{array}$ & $\begin{array}{c}0.006 \\
(0.958)\end{array}$ & $\begin{array}{c}-0.011 \\
(0.917)\end{array}$ & $\begin{array}{c}0.065 \\
(0.625)\end{array}$ \\
\hline 2007 & $\begin{array}{c}0.147 \\
(0.250)\end{array}$ & $\begin{array}{c}0.004 \\
(0.958)\end{array}$ & $\begin{array}{c}-0.003 \\
(0.958)\end{array}$ & $\begin{array}{c}0.090 \\
(0.542)\end{array}$ \\
\hline 2008 & $\begin{array}{c}0.076 \\
(0.667)\end{array}$ & $\begin{array}{c}-0.062 \\
(0.708)\end{array}$ & $\begin{array}{c}-0.016 \\
(0.917)\end{array}$ & $\begin{array}{c}0.109 \\
(0.542)\end{array}$ \\
\hline 2009 & $\begin{array}{c}0.062 \\
(0.750)\end{array}$ & $\begin{array}{l}-0.102 \\
(0.458)\end{array}$ & $\begin{array}{c}-0.005 \\
(1.000)\end{array}$ & $\begin{array}{c}0.053 \\
(0.750)\end{array}$ \\
\hline 2010 & $\begin{array}{c}0.037 \\
(0.833)\end{array}$ & $\begin{array}{l}-0.147 \\
(0.292)\end{array}$ & $\begin{array}{c}-0.037 \\
(0.833)\end{array}$ & $\begin{array}{c}0.044 \\
(0.792)\end{array}$ \\
\hline 2011 & $\begin{array}{c}0.022 \\
(0.917)\end{array}$ & $\begin{array}{c}-0.178 \\
(0.250)\end{array}$ & $\begin{array}{c}-0.019 \\
(0.917)\end{array}$ & $\begin{array}{c}0.076 \\
(0.583)\end{array}$ \\
\hline 2012 & $\begin{array}{c}0.029 \\
(0.917)\end{array}$ & $\begin{array}{c}-0.216 \\
(0.208)\end{array}$ & $\begin{array}{c}-0.046 \\
(0.875)\end{array}$ & $\begin{array}{c}0.048 \\
(0.875)\end{array}$ \\
\hline 2013 & $\begin{array}{c}0.041 \\
(0.875)\end{array}$ & $\begin{array}{c}-0.213 \\
(0.208)\end{array}$ & $\begin{array}{c}-0.078 \\
(0.667)\end{array}$ & $\begin{array}{l}-0.001 \\
(1.000)\end{array}$ \\
\hline
\end{tabular}

Notes: P-values are in parentheses. $* * * p<0.01,{ }^{* *} p<0.05,{ }^{*} p<0.10$. 
Table A4.4: Predictors of Synthetic Analysis for Beijing, Guangdong, Hebei, Shanxi

\begin{tabular}{lcccc}
\hline & \multicolumn{2}{c}{$(1)$} & \multicolumn{2}{c}{$(2)$} \\
& Log Annual GDP per capita & Normalized NTL per capita \\
\hline & Beijing & Synthetic & Beijing & Synthetic \\
\cline { 2 - 5 } Household spending & 823.232 & 814.648 & 823.232 & 687.717 \\
Investment per capita & 1008.266 & 1008.135 & 1008.266 & 766.78 \\
Population density & & & 762.46 & 1106.989 \\
Log GDP per capita (t-1) & & & 7.583 & 7.392 \\
\hline & Guangdong & Synthetic & Guangdong & Synthetic \\
\cline { 2 - 5 } Household spending & 553.627 & 533.942 & 553.627 & 431.955 \\
Investment per capita & 438.319 & 495.559 & 438.319 & 420.909 \\
Population density & & & 411.489 & 400.554 \\
Log GDP per capita (t-1) & & & 7.117 & 6.946 \\
\hline & Hebei & Synthetic & Hebei & Synthetic \\
\cline { 2 - 5 } Household spending & 258.593 & 282.922 & 258.593 & 280.597 \\
Investment per capita & 259.586 & 259.097 & 259.586 & 244.81 \\
Population density & & & 345.406 & 381.182 \\
Log GDP per capita (t-1) & & & 6.505 & 6.49 \\
\hline & Shanxi & Synthetic & Shanxi & Synthetic \\
\cline { 2 - 5 } Household spending & 227.511 & 233.423 & 227.511 & 269.111 \\
Investment per capita & 175.321 & 192.225 & 175.321 & 175.902 \\
Population density & & & 200.453 & 201.781 \\
Log GDP per capita (t-1) & & & 6.259 & 6.257 \\
\hline
\end{tabular}




\section{CHAPTER 5. CONCLUSION}

Paying close attention to challenges in the nature of data and evaluation, these three studies attempt to contribute to the literature widely categorized in labour economics by providing some causal inferences. Some policy implications can be made along the way.

After the introduction, in the second chapter, I extend the literature that identifying the causal effects of childbirth on female labour supply by documenting cross- and within-country associations between the motherhood employment penalty and gender wage gap. The finding agrees with the view that the response of a mother's labour supply to childbirth is potentially driven by gender equality in the labour market. Further research is still needed to gain more insight into exogenous movements in the deep parameters causing the gender wage gap and shifting the response of mother's labour supply to childbirth. Governments in developed and developing countries commit to put women's rights and gender equality on the agenda, and according to the Global Gender Gap Report 2016, ${ }^{1}$ if the gender pay gap continues to narrow at the current pace, it is projected to close in more than half a century on average around the globe. To improve the effectiveness of gender equality programming, governments in developed countries may need to amend current laws and and governments in developing countries may need to enact more polices.

In the third chapter, I investigate the impacts of high school football success on university aspiration, academic performance, and antisocial behaviour. The aim of this chapter is to reconsider what is documented in the literature about the negative impacts of athletic success on college campuses. Overall, the findings of this chapter highlight the non-negative effects of ath-

\footnotetext{
${ }^{1}$ To measure the global gender gap and evaluate the progress over time, The World Economic Forum (WEF) produce the Global Gender Gap Report annually since 2006. http://www3.weforum.org/docs/GGGR16/WEF_Global_Gender_Gap_Report_2016.pdf.
} 
letic success on high school campuses and agree with the research emphasizing the role of athletics. High school athletics do not threaten academic performance and antisocial behaviour, they actually bring beneficial impacts on university aspiration. The non-negative effects of athletic success on academic performances and positive effects on university aspirations soothe worried parents, who may be concerned if extracurricular activities worsen high school academic performances. Since high schools are unique settings to offer athletic programs, principals and policy makers might strive to implement more programs to help boost fundraising given that the budget for high school athletics is quite tight. ${ }^{2}$ There is anecdotal evidence that the growth of athletic programs at school causes boys to lag far behind girls in academics. In contrast, using a gap rate for within-school boy-girl differences in outcomes, we find that athletic success contributes to reducing the gender gap in SAT/ACT taking and AP enrolment. We would emphasize that our conclusion from these findings - that sports only benefit boys in term of aspiration-is not that policies for gender equality like Title IX are unwarranted. If anything, we identify that the effects of football success on aspiration are driven by male athletes. We leave the very important question of how female students respond to athletic success to future work. It is possible that data from a wider range of sports could show that female athletes respond to success in a similar way to male athletes. More policies on gender equality are also worth pursuing, seeing that the gender inequality in school athletics is still wide, though Title IX has been in effect for decades.

The final chapter revisits the economic impacts of SARS 2003 to understand the economic consequences of a pandemic and what is happening with the COVID-19 pandemic. I focus on heterogenous impact at lower administrative levels by using disaggregated data from China. I observe a long-term diminution of 20 percent in per-capita night-time lights in Beijing, the most affected Chinese region. These finding suggest that the benign picture that emerges from the country level has to be re-considered-while national economies have indeed bounced

\footnotetext{
${ }^{2}$ According to National Federation of State High School Associations, the budget for activity programs comprises of less than 3 percent of a total school's budget on average. https://www.nfhs.org/articles/the-case-for-high-school-activities.
} 
back quickly, more local economies have taken longer to recover. The explanation for this is most assistance and stimulation policy responses to the SARS pandemic are at national level, but the pandemic disproportionately affected local areas (similar to what is happening with COVID19). From a policy perspective, the lesson we can draw is that recovery programs tailored specifically for different local areas would be more effective. 


\section{BIBLIOGRAPHY}

Aaronson, D., Dehejia, R., Jordan, A., Pop-Eleches, C., Samii, C., and Schulze, K. (2017). The effect of fertility on mothers' labor supply over the last two centuries. Report, National Bureau of Economic Research.

Abadie, A., Diamond, A., and Hainmueller, J. (2010). Synthetic control methods for comparative case studies: Estimating the effect of california's tobacco control program. Journal of the American statistical Association, 105(490):493-505.

Abadie, A. and Gardeazabal, J. (2003). The economic costs of conflict: A case study of the basque country. American economic review, 93(1):113-132.

Addati, L., Cattaneo, U., Esquivel, V., and Valarino, I. (2018). Care work and care jobs for the future of decent work. Op. cit.

Agüero, J. M. and Marks, M. S. (2011). Motherhood and female labor supply in the developing world evidence from infertility shocks. Journal of Human Resources, 46(4):800-826.

Ajefu, J. B. (2019). Does having children affect women's entrepreneurship decision? evidence from nigeria. Review of Economics of the Household, 17(3):843-860.

Almond, D. (2006). Is the 1918 influenza pandemic over? long-term effects of in utero influenza exposure in the post-1940 us population. Journal of political Economy, 114(4):672-712.

Altig, D., Baker, S., Barrero, J. M., Bloom, N., Bunn, P., Chen, S., Davis, S. J., Leather, J., Meyer, B., and Mihaylov, E. (2020). Economic uncertainty before and during the covid-19 pandemic. Journal of Public Economics, 191:104274.

Anderson, D. J., Binder, M., and Krause, K. (2003). The motherhood wage penalty revisited: Experience, heterogeneity, work effort, and work-schedule flexibility. ILR Review, 56(2):273294.

Anderson, M. L. (2017). The benefits of college athletic success: An application of the propensity score design. Review of Economics and Statistics, 99(1):119-134.

Angrist, J., Lavy, V., and Schlosser, A. (2010). Multiple experiments for the causal link between the quantity and quality of children. Journal of Labor Economics, 28(4):773-824. 
Angrist, J. D. and Evans, W. N. (1998). Children and their parents' labor supply: Evidence from exogenous variation in family size. American Economic Review, 88(3):450-477.

APEC, A.-P. E. C. (2004). Commentaries analyses-the economic impact of sars on the apec region. Asia-Pacific Biotech News, 8(01):33-38.

Autor, D. (2010). The polarization of job opportunities in the us labor market: Implications for employment and earnings. Center for American Progress and The Hamilton Project, 6:11-19.

Autor, D. H. (2014). Skills, education, and the rise of earnings inequality among the "other 99 percent". Science, 344(6186):843-851.

Bailey, M. J. (2006). More power to the pill: the impact of contraceptive freedom on women's life cycle labor supply. The Quarterly Journal of Economics, 121(1):289-320.

Baker, S. R., Bloom, N., Davis, S. J., and Terry, S. J. (2020). Covid-induced economic uncertainty. Report 0898-2937, National Bureau of Economic Research.

Baldwin, R. E. and Weisbrod, B. A. (1974). Disease and labor productivity. Economic Development and Cultural Change, 22(3):414-435.

Baranowska-Rataj, A. and Matysiak, A. (2016). The causal effects of the number of children on female employment-do european institutional and gender conditions matter? Journal of Labor Research, 37(3):343-367.

Barnett, T., Whiteside, A., Khodakevich, L., Kruglov, Y., and Steshenko, V. (2000). The hiv/aids epidemic in ukraine: its potential social and economic impact. Social science medicine, 51(9):1387-1403.

Barro, R. J., Ursúa, J. F., and Weng, J. (2020). The coronavirus and the great influenza pandemic: Lessons from the "spanish flu" for the coronavirus's potential effects on mortality and economic activity. Report 0898-2937, National Bureau of Economic Research.

Barron, J. M., Ewing, B. T., and Waddell, G. R. (2000). The effects of high school athletic participation on education and labor market outcomes. Review of Economics and Statistics, 82(3):409-421.

Beach, B., Clay, K., and Saavedra, M. H. (2020). The 1918 influenza pandemic and its lessons for covid-19. National Bureau of Economic Research Working Paper Series, (w27673).

Beach, B., Ferrie, J. P., and Saavedra, M. H. (2018). Fetal shock or selection? the 1918 influenza pandemic and human capital development. Report, National Bureau of Economic Research. 
Ben-Michael, E., Feller, A., and Rothstein, J. (2018). The augmented synthetic control method. arXiv preprint arXiv:1811.04170.

Bentancor, A. and Clarke, D. (2017). Assessing plan b: The effect of the morning after pill on children and women. The Economic Journal, 127(607):2525-2552.

Bhalotra, S. and Clarke, D. (2019). Twin birth and maternal condition. Review of Economics and Statistics, 101(5):853-864.

Bisbee, J., Dehejia, R., Pop-Eleches, C., and Samii, C. (2017). Local instruments, global extrapolation: External validity of the labor supply-fertility local average treatment effect. Journal of Labor Economics, 35(S1):S99-S147.

Blau, F. D. and Kahn, L. M. (2013). Female labor supply: Why is the united states falling behind? American Economic Review, 103(3):251-56.

Blau, F. D. and Kahn, L. M. (2017). The gender wage gap: Extent, trends, and explanations. Journal of economic literature, 55(3):789-865.

Bloom, D. E., Canning, D., Fink, G., and Finlay, J. E. (2009). Fertility, female labor force participation, and the demographic dividend. Journal of Economic growth, 14(2):79-101.

Bloom, E., De Wit, V., and Carangal-San Jose, M. J. (2005). Potential economic impact of an avian flu pandemic on asia.

Blundell, R. and MaCurdy, T. (1999). Labor supply: A review of alternative approaches. Handbook of labor economics, 3:1559-1695.

Boberg-Fazlic, N., Ivets, M., Karlsson, M., and Nilsson, T. (2017). Disease and fertility: Evidence from the 1918 influenza pandemic in sweden.

Brahmbhatt, M. and Dutta, A. (2008). On SARS type economic effects during infectious disease outbreaks. The World Bank.

Brodeur, A., Gray, D. M., Islam, A., and Bhuiyan, S. (2020). A literature review of the economics of covid-19.

Bronars, S. G. and Grogger, J. (1994). The economic consequences of unwed motherhood: Using twin births as a natural experiment. The American Economic Review, pages 11411156.

Cabane, C., Hille, A., and Lechner, M. (2016). Mozart or pele? the effects of adolescents' participation in music and sports. Labour Economics, 41:90-103. 
Campante, F. R., Depetris-Chauvin, E., and Durante, R. (2020). The virus of fear: The political impact of ebola in the us. Report 0898-2937, National Bureau of Economic Research.

Castañeda-Orjuela, C., Díaz, H., Alvis-Guzman, N., Olarte, A., Rodriguez, H., Camargo, G., and De la Hoz-Restrepo, F. (2012). Burden of disease and economic impact of dengue and severe dengue in colombia, 2011. Value in health regional issues, 1(2):123-128.

Cavallo, E., Galiani, S., Noy, I., and Pantano, J. (2013). Catastrophic natural disasters and economic growth. Review of Economics and Statistics, 95(5):1549-1561.

Chen, X. and Nordhaus, W. D. (2011). Using luminosity data as a proxy for economic statistics. Proceedings of the National Academy of Sciences, 108(21):8589-8594.

Chevalier, A. and Viitanen, T. K. (2003). The long-run labour market consequences of teenage motherhood in britain. Journal of population economics, 16(2):323-343.

Chou, J., Kuo, N.-F., and Peng, S.-L. (2004). Potential impacts of the sars outbreak on taiwan's economy. Asian Economic Papers, 3(1):84-99.

Clark, H., Pinkovskiy, M., and Sala-i Martin, X. (2020). China's gdp growth may be understated. China Economic Review, 62(C).

Clarke, P. and Ayres, I. (2014). The chastain effect: Using title ix to measure the causal effect of participating in high school sports on adult women's social lives. The Journal of SocioEconomics, 48:62-71.

Clotfelter, C. T. (2019). Big-time sports in American universities. Cambridge University Press.

Cools, S., Markussen, S., and Strøm, M. (2017). Children and careers: How family size affects parents' labor market outcomes in the long run. Demography, 54(5):1773-1793.

Cristia, J. P. (2008). The effect of a first child on female labor supply evidence from women seeking fertility services. Journal of Human Resources, 43(3):487-510.

Cruces, G. and Galiani, S. (2007). Fertility and female labor supply in latin america: New causal evidence. Labour Economics, 14(3):565-573.

Cuffe, H. E., Waddell, G. R., and Bignell, W. (2017). Can school sports reduce racial gaps in truancy and achievement? Economic Inquiry, 55(4):1966-1985.

Cáceres-Delpiano, J. (2012). Can we still learn something from the relationship between fertility and mother's employment? evidence from developing countries. Demography, 49(1):151174. 
David, A. and Melanie, W. (2013). Wayward sons: The emerging gender gap in labor markets and education. Third Way Report.

Dehejia, R., Pop-Eleches, C., and Samii, C. (2019). From local to global: External validity in a fertility natural experiment. Journal of Business Economic Statistics, pages 1-27.

Dixon, S., McDonald, S., and Roberts, J. (2002). The impact of hiv and aids on africa's economic development. Bmj, 324(7331):232-234.

Doudchenko, N. and Imbens, G. W. (2016). Balancing, regression, difference-in-differences and synthetic control methods: A synthesis. Report, National Bureau of Economic Research.

Edlund, L. and Machado, C. (2015). How the other half lived: Marriage and emancipation in the age of the pill. European Economic Review, 80:295-309.

Eide, E. R. and Ronan, N. (2001). Is participation in high school athletics an investment or a consumption good?: Evidence from high school and beyond. Economics of Education Review, 20(5):431-442.

Ewing, B. T. (2007). The labor market effects of high school athletic participation: Evidence from wage and fringe benefit differentials. Journal of Sports Economics, 8(3):255-265.

Felfe, C., Lechner, M., and Steinmayr, A. (2016). Sports and child development. PloS one, 11(5):e0151729.

Figlio, D., Karbownik, K., Roth, J., and Wasserman, M. (2016). School quality and the gender gap in educational achievement. American Economic Review, 106(5):289-95.

Fontaine, I. (2017). The causal effect of family size on mother's labor supply: evidence from reunion island and mainland france.

Galiani, S. and Quistorff, B. (2017). The synth_runner package: Utilities to automate synthetic control estimation using synth. The Stata Journal, 17(4):834-849.

Gangl, M. and Ziefle, A. (2009). Motherhood, labor force behavior, and women's careers: An empirical assessment of the wage penalty for motherhood in britain, germany, and the united states. Demography, 46(2):341-369.

Gascoigne, C., Parry, E., and Buchanan, D. (2015). Extreme work, gendered work? how extreme jobs and the discourse of 'personal choice' perpetuate gender inequality. Organization, 22(4):457-475.

Gillies, P., Tolley, K., and Wolstenholme, J. (1996). Is aids a disease of poverty? AIDS care, $8(3): 351-364$. 
Ginja, R., Jans, J., and Karimi, A. (2020). Parental leave benefits, household labor supply, and children's long-run outcomes. Journal of Labor Economics, 38(1):261-320.

Glassman, T., Werch, C. E., Jobli, E., and Bian, H. (2007). Alcohol-related fan behavior on college football game day. Journal of American College Health, 56(3):255-260.

Goldin, C. (2014). A grand gender convergence: Its last chapter. American Economic Review, 104(4):1091-1119.

Goldin, C. and Mitchell, J. (2017). The new life cycle of women's employment: Disappearing humps, sagging middles, expanding tops. Journal of Economic Perspectives, 31(1):161-82.

González, L. (2013). The effect of a universal child benefit on conceptions, abortions, and early maternal labor supply. American Economic Journal: Economic Policy, 5(3):160-88.

Grimshaw, D. and Rubery, J. (2015). The motherhood pay gap. Geneva: International Labour Organization, 57(1):1-69.

Guimbeau, A., Menon, N., and Musacchio, A. (2020). The brazilian bombshell? the long-term impact of the 1918 influenza pandemic the south american way. Report 0898-2937, National Bureau of Economic Research.

Guo, R., Li, H., Yi, J., and Zhang, J. (2018). Fertility, household structure, and parental labor supply: Evidence from china. Journal of Comparative Economics, 46(1):145-156.

Hailu, G. (2020). Economic thoughts on covid-19 for canadian food processors. Canadian Journal of Agricultural Economics/Revue canadienne d'agroeconomie, 68(2):163-169.

He, X. and Zhu, R. (2016). Fertility and female labour force participation: Causal evidence from urban c hina. The Manchester School, 84(5):664-674.

Helgertz, J. and Bengtsson, T. (2019). The long-lasting influenza: the impact of fetal stress during the 1918 influenza pandemic on socioeconomic attainment and health in sweden, 1968-2012. Demography, 56(4):1389-1425.

Henderson, J. V., Storeygard, A., and Weil, D. N. (2012). Measuring economic growth from outer space. American economic review, 102(2):994-1028.

Hernández-Julián, R. and Rotthoff, K. W. (2014). The impact of college football on academic achievement. Economics of Education review, 43:141-147.

Holmlund, H. and Sund, K. (2008). Is the gender gap in school performance affected by the sex of the teacher? Labour Economics, 15(1):37-53. 
Jacobsen, J. P., Pearce III, J. W., and Rosenbloom, J. L. (1999). The effects of childbearing on married women's labor supply and earnings: using twin births as a natural experiment. Journal of Human Resources, pages 449-474.

Jordà, , Singh, S. R., and Taylor, A. M. (2020). Longer-run economic consequences of pandemics. Report 0898-2937, National Bureau of economic research.

Kabajulizi, J. and Ncube, M. (2017). Financing hiv/aids responses in africa: Impact evidence from uganda. Journal of Policy Modeling, 39(5):843-860.

Karlsson, M., Nilsson, T., and Pichler, S. (2014). The impact of the 1918 spanish flu epidemic on economic performance in sweden: An investigation into the consequences of an extraordinary mortality shock. Journal of health economics, 36:1-19.

Katafuchi, Y., Kurita, K., and Managi, S. (2020). Self-restraint behavior under covid-19 through stigma: Theory and evidence based on mobility data.

Kleven, H. and Landais, C. (2017). Gender inequality and economic development: fertility, education and norms. Economica, 84(334):180-209.

Kleven, H., Landais, C., and Søgaard, J. E. (2019). Children and gender inequality: Evidence from denmark. American Economic Journal: Applied Economics, 11(4):181-209.

Knaus, M. C., Lechner, M., and Reimers, A. K. (2020). For better or worse?-the effects of physical education on child development. Labour Economics, 67:101904.

Kostova, D., Cassell, C. H., Redd, J. T., Williams, D. E., Singh, T., Martel, L. D., and Bunnell, R. E. (2019). Long-distance effects of epidemics: Assessing the link between the 2014 west africa ebola outbreak and us exports and employment. Health economics, 28(11):1248-1261.

Lavy, V. (2008). Do gender stereotypes reduce girls' or boys' human capital outcomes? evidence from a natural experiment. Journal of public Economics, 92(10-11):2083-2105.

Lechner, M. (2009). Long-run labour market and health effects of individual sports activities. Journal of health economics, 28(4):839-854.

Lechner, M. and Downward, P. (2017). Heterogeneous sports participation and labour market outcomes in england. Applied Economics, 49(4):335-348.

Lechner, M. and Sari, N. (2015). Labor market effects of sports and exercise: Evidence from canadian panel data. Labour Economics, 35:1-15.

Lee, J.-W. and McKibbin, W. J. (2004). Globalization and disease: The case of sars. Asian Economic Papers, 3(1):113-131. 
Leung, G. M., Quah, S., Ho, L.-M., Ho, S.-Y., Hedley, A. J., Lee, H.-P., and Lam, T.-H. (2004). A tale of two cities: community psychobehavioral surveillance and related impact on outbreak control in hong kong and singapore during the severe acute respiratory syndrome epidemic. Infection control and hospital epidemiology, 25(12):1033-1041.

Lindo, J. M., Siminski, P., and Swensen, I. D. (2018). College party culture and sexual assault. American Economic Journal: Applied Economics, 10(1):236-65.

Lindo, J. M., Swensen, I. D., and Waddell, G. R. (2012). Are big-time sports a threat to student achievement? American Economic Journal: Applied Economics, 4(4):254-74.

Lipscomb, S. (2007). Secondary school extracurricular involvement and academic achievement: A fixed effects approach. Economics of Education Review, 26(4):463-472.

Liu, J., Hammitt, J. K., Wang, J., and Tsou, M. (2005). Valuation of the risk of sars in taiwan. Health Economics, 14(1):83-91.

Lundberg, S. and Rose, E. (2000). Parenthood and the earnings of married men and women. Labour Economics, 7(6):689-710.

Lundborg, P., Plug, E., and Rasmussen, A. W. (2017). Can women have children and a career? iv evidence from ivf treatments. American Economic Review, 107(6):1611-37.

Maffioli, E. M. (2021). The political economy of health epidemics: evidence from the ebola outbreak. Journal of Development Economics, 151:102651.

Marianne, B. (2011). New perspectives on gender, volume 4, pages 1543-1590. Elsevier.

Metcalfe, R., Burgess, S., and Proud, S. (2019). Students' effort and educational achievement: Using the timing of the world cup to vary the value of leisure. Journal of Public Economics, 172:111-126.

Mishel, L., Schmitt, J., and Shierholz, H. (2013). Assessing the job polarization explanation of growing wage inequality. Economic Policy Institute. Working Paper.

Morrissey, T. W. (2017). Child care and parent labor force participation: a review of the research literature. Review of Economics of the Household, 15(1):1-24.

Mulholland, S. E., Tomic, A. S., and Sholander, S. N. (2014). The faculty flutie factor: Does football performance affect a university's us news and world report peer assessment score? Economics of Education Review, 43:79-90.

Neal, D. J. and Fromme, K. (2007). Hook'em horns and heavy drinking: Alcohol use and collegiate sports. Addictive behaviors, 32(11):2681-2693. 
Noy, I., Okubo, T., and Strobl, E. (2020). The japanese textile sector and the influenza pandemic of 1918-1920. Report, CESifo.

Noy, I., Okuyama, Y., and Sawada, Y. (2015). The long-run socio-economic consequences of a large disaster: The 1995 earthquake in kobe. PloS one, 10(10):e0138714.

Noy, I. and Shields, S. (2019). The 2003 severe acute respiratory syndrome epidemic: A retroactive examination of economic costs. Asian Development Bank Economics Working Paper Series, (591).

Olivetti, C. and Petrongolo, B. (2016). The evolution of gender gaps in industrialized countries. Annual review of Economics, 8:405-434.

Oreffice, S. (2007). Did the legalization of abortion increase women's household bargaining power? evidence from labor supply. Review of Economics of the Household, 5(2):181-207.

Oster, E. (2019). Unobservable selection and coefficient stability: Theory and evidence. Journal of Business \& Economic Statistics, 37(2):187-204.

Persico, N., Postlewaite, A., and Silverman, D. (2004). The effect of adolescent experience on labor market outcomes: The case of height. Journal of Political Economy, 112(5):1019-1053.

Pfeifer, C. and Cornelißen, T. (2010). The impact of participation in sports on educational attainment—new evidence from germany. Economics of Education Review, 29(1):94-103.

Pope, D. G. and Pope, J. C. (2014). Understanding college application decisions: Why college sports success matters. Journal of Sports Economics, 15(2):107-131.

Powell, D. (2018). Imperfect synthetic controls: did the massachusetts health care reform save lives? Available at SSRN 3192710.

Raley, S., Bianchi, S. M., and Wang, W. (2012). When do fathers care? mothers' economic contribution and fathers' involvement in child care. American Journal of Sociology, 117(5):142259.

Rees, D. I. and Sabia, J. J. (2010). Sports participation and academic performance: Evidence from the national longitudinal study of adolescent health. Economics of Education Review, 29(5):751-759.

Rees, D. I. and Schnepel, K. T. (2009). College football games and crime. Journal of Sports Economics, 10(1):68-87. 
Robbins, M. W., Saunders, J., and Kilmer, B. (2017). A framework for synthetic control methods with high-dimensional, micro-level data: evaluating a neighborhood-specific crime intervention. Journal of the American Statistical Association, 112(517):109-126.

Rooth, D.-O. (2011). Work out or out of work - the labor market return to physical fitness and leisure sports activities. Labour Economics, 18(3):399-409.

Sandner, M. (2019). Effects of early childhood intervention on fertility and maternal employment: Evidence from a randomized controlled trial. Journal of health economics, 63:159-181.

Schultz, K. (2017). Do high school athletes get better grades during the off-season? Journal of Sports Economics, 18(2):182-208.

Schultz, T. P. (2009). How does family planning promote development? evidence from a social experiment in matlab, bangladesh, 1977-1996. Yale University, Economic Growth Center, New Haven, Conn.

Siu, A. and Wong, Y. R. (2004). Economic impact of sars: the case of hong kong. Asian Economic Papers, 3(1):62-83.

Stevenson, B. (2010). Beyond the classroom: Using title ix to measure the return to high school sports. The Review of Economics and Statistics, 92(2):284-301.

Veliz, P. and Shakib, S. (2014). Gender, academics, and interscholastic sports participation at the school level: a gender-specific analysis of the relationship between interscholastic sports participation and ap enrollment. Sociological focus, 47(2):101-120.

Vere, J. P. (2011). Fertility and parents' labour supply: new evidence from us census data: Winner of the oep prize for best paper on women and work. Oxford Economic Papers, 63(2):211231.

Wang, H. (2014). Fertility and female labor force participation: Evidence from the one-child policy in china. In 2014 Annual Meeting, July, pages 27-29.

Weisbrod, B. A., Andreano, R. L., Baldwin, R. E., Epstein, E. H., Kelley, A. C., and Helminiak, T. W. (1974). Disease and economic development: The impact of parasitic diseases in st. lucia. International journal of social economics.

Xu, C., Wang, J., Wang, L., and Cao, C. (2014). Spatial pattern of severe acute respiratory syndrome in-out flow in 2003 in mainland china. BMC infectious diseases, 14(1):1-10.

Zhang, J. (2017). A dilemma of fertility and female labor supply: Identification using taiwanese twins. China Economic Review, 43:47-63. 